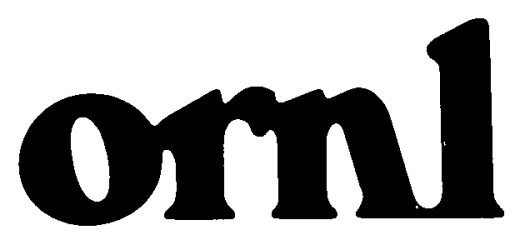

OAK RIDGE NATIONAL LABORATORY

LOCKHEED MATIR/7

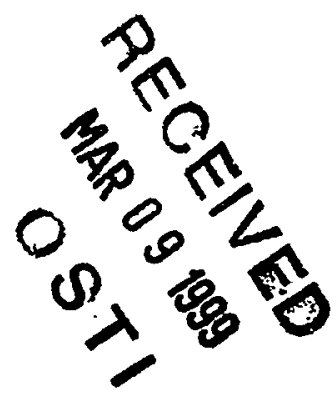

ORNL/M-6589

\title{
Metals and Ceramics Division History 1946-1996
}




\section{DISCLAIMER}

This report was prepared as an account of work sponsored by an agency of the United States Government. Neither the United States Government nor any agency thereof, nor any of their employees, make any warranty, express or implied, or assumes any legal liability or responsibility for the accuracy, completeness, or usefulness of any information, apparatus, product, or process disclosed, or represents that its use would not infringe privately owned rights. Reference herein to any specific commercial product, process, or service by trade name, trademark, manufacturer, or otherwise does not necessarily constitute or imply its endorsement, recommendation, or favoring by the United States Government or any agency thereof. The views and opinions of authors expressed herein do not necessarily state or reflect those of the United States Government or any agency thereof. 


\section{DISCLAIMER}

Portions of this document may be illegible in electronic image products. Images are produced from the best available original document. 


\section{contributors}

The story of the Metals and Ceramics Division is the story of its people and the work they did, as well as the projects that resided in the Division or that the Division contributed to. Many people wrote and rewrote reams of paper trying to pull this document together, and those who wrote various sections (whether used or not) are listed below.

Those who are not listed are the rest of you; you rummaged around in your memories to provide facts and anecdotes, typed documents for others, proofread drafts, and so on. And mainly, you did the outstanding work that gave this Division a story to tell. Thanks to all of you for 50 interesting and productive years.

September 30, 1997

Douglas F. Craig, Director

Metals and Ceramics Division

Oak Ridge National Laboratory

Thanks to each of these writers and editors:
G. M. Adamson
S.A. David
P. H. Miller
C.A. Baldwin
J. R. DiStefano
R. K. Nanstad
R.J. Beaver
R. J. Gray
S. Peterson
E. E. Bloom
M. J. Kania
P. L Rittenhouse
E. S. Bomar
P. R. Kasten
J.D. Sease
R.A. Bradley
E.A. Kenik
G. M. Slaughter
D.A. Canonico
R.W. Knight
C.J.Sparks
J.V. Cathcart
W.D. Manly
K. Spence
R. E. Clausing
L.K. Mansur
P.A.Teague
J.H. Coobs
H. E. McCoy
V.J.Tennery
R. H. Cooper
C. J. McHargue
J. R.Weir, Jr.
J. E. Cunningham 


\section{table of contents}

introduction .................................................................................................................................................. I

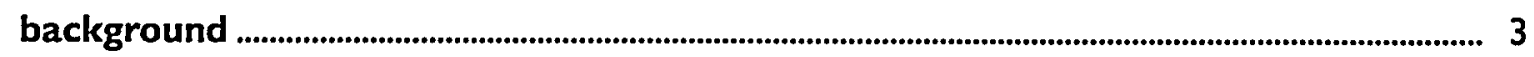

radiation materials science in m\&c .................................................................................................................. 4

metallographic services ...................................................................................................................................... 12

fundamental and applied research...................................................................................................................... 19

the roofs over our heads ........................................................................................................................................... 30

1946-1960: reactor material years ........................................................................................................... 37

ornl graphite reactor ............................................................................................................................................... 38

materials testing and tank-type reactors......................................................................................................... 42

aircraft nuclear propulsion-aircraft reactor test.............................................................................................. 48

homogeneous reactor project................................................................................................................................

1 950-1 1975: reactor project years ...........................................................................................................5

army package power reactor ............................................................................................................................... 58

geneva conference display reactor .................................................................................................................60

thorium metallurgy ................................................................................................................................................ 62

fusion materials .............................................................................................................................................................. 63

gas-cooled reactors ........................................................................................................................................................... 71

space nuclear programs ...........................................................................................................................................

advanced test reactor .................................................................................................................................................... 82

molten-salt power reactors .................................................................................................................................... 83

high flux isotope reactor .................................................................................................................................... 86

fabricating targets for the high flux isotope reactor ...................................................................................... 92

heavy-section steel technology and irradiation ............................................................................................... 94

liquid-metal fast breeder reactor ........................................................................................................................99

1975-1996: diversification and the high-technology years ..................................................... 103

structure and properties of surfaces ................................................................................................................104

fossil energy program ............................................................................................................................................. 106

synchrotron radiation beamline ...................................................................................................................... 109

shared research equipment program …………....................................................................................................... III

electron beam welder .......................................................................................................................................... 113

the high temperature materials laboratory ............................................................................................. 114

multiple ion irradiation ..................................................................................................................................... 118

conservation materials program ...................................................................................................................... 120

appendix I. chronology of division directors ..................................................................................... 125

appendix 2. selected photographs of division staff ........................................................................................ $|3|$ 


\section{introduction}

The division was formed in 1946 at the suggestion of Dr. Eugene P. Wigner to attack the problem of the distortion of graphite in the early reactors due to exposure to reactor neutrons, and the consequent radiation damage. It was called the Metallurgy Division and assembled the metallurgical and solid state physics activities of the time which were not directly related to nuclear weapons production. William A. Johnson, a Westinghouse employee, was named Division Director in 1946. In 1949 he was replaced by John $\mathrm{H}$ Frye Jr. when the Division consisted of 45 people. He was director during most of what is called the Reactor Project Years until 1973 and his retirement. During this period the Division evolved into three organizational areas: basic research, applied research in nuclear reactor materials, and reactor pro- grams directly related to a specific reactor(s) being designed or built. The Division (Metals and Ceramics) consisted of 204 staff members in 1973 when James R. Weir, Jr., became Director. This was the period of the oil embargo, the formation of the Energy Research and Development Administration (ERDA) by combining the Atomic Energy Commission (AEC) with the Office of Coal Research, and subsequent formation of the Department of Energy (DOE). The diversification process continued when James O. Stiegler became Director in 1984, partially as a result of the pressure of legislation encouraging the national laboratories to work with U.S. industries on their problems. During that time the Division staff grew from 265 to 330 . Douglas F. Craig became Director in 1992. 


\section{radiation materials science in $\mathrm{m} \& \mathrm{c}$}

That the various forms of radiation emanating from radioactive isotopes or from the nuclei of fissioning uranium would produce damage or change the form of the materials through which the radiation passed was known much before the Manhattan Project and the genesis of Oak Ridge.

Immediately after the war, some of the scientific staff of the project began publishing in the scientific literature speculations, mainly based on theoretical considerations, about the potential deleterious effects on the materials that might be used in constructing nuclear power plants.

\section{oak ridge involved in studying radiation effects}

The recognition of these possible effects on materials led to experimental and theoretical programs at the Atomic Energy Commission laboratories throughout the country, including ORNL. Initially, the Chemistry Division began to study the effects of gamma rays and neutrons on ceramics, and the Physics of Solids group (then part of the Metallurgy Division) began theoretical and experimental work on the effects of neutrons on metals.

During the early 1950s, it was recognized that these property changes would have significant effects on the design of nuclear power plants. The Metals and Ceramics Division then began to determine the influence of these effect.

Commercial alloys hardened and decreased in ductility in a way qualitatively similar to the earlier observations in pure metals. This "damage," however, tended to disappear as the temperature of the alloy was raised into the range useful in power plants.

A different form of damage of technological importance was discovered almost simultaneously in 1956 at ORNL and at the Harwell Laboratory in England. Bubbles of helium formed in the alloys as neutrons released alpha particles (helium nuclei) from the chemical elements within the alloy. In addition, changes occurred in the chemical reactions in the alloys and swelling occurred during exposure to reactor neutrons at high temperatures.

\section{what is radiation materials science?}

Radiation Effects, or more accurately, Radiation Materials Science is a broad term covering the phenomena that occur in materials exposed to radiation. The field has been built since the 1940s. Oak Ridge National Laboratory and, in particular, the Metals and Ceramics Division has played a dominant role in the creation and advancement of this field. The work can be visualized in three complementary activities. 
- Materials Science-This work consists of characterizing and understanding radiation effects phenomena; learning about radiationinduced defects and, through them, more about the basic properties of the materials in which they occur; and using radiation as a tool to explore the behavior of materials.

- Nuclear Materials Technology-This activity exists because many structural materials intended for use in fission and fusion reactors are vulnerable to radiation induced degradation of properties; selecting, modifying and designing materials that are resistant to radiation damage, with properties tailored to fission and fusion reactor applications.

- New Materials and PropertiesBecause the capability to irradiate materials is a dimension of materials science, like the capability of change temperature, virtually every property and process in any class of materials can be affected; enhancing materials performance in the wide range of materials technology applications.

\section{historical sketch}

Some effects of irradiation on solids were first observed in the 19th century. Certain minerals known to have externally crystalline shapes were found to be internally glass-like, or amorphous. These anomalies were later explained as the result of irradiation over geological times by decay products of the naturally radioactive elements uranium and thorium contained in the minerals.

The radiation effects field got its real start, however, in the 20th century during the Manhattan Project. Some 50 years ago, Eugene P. Wigner at the Metallurgical Laboratory at the University of Chicago realized the theoretical possibility of displacing atoms by irradiation with neutrons. Colleagues at Clinton Laboratories (later ORNL) Metallurgy Division carried out experiments in the Graphite Reactor to test the idea. A quote from Wigner's 1946 paper "Theoretical Physics in the Metallurgical Laboratory in Chicago," (Journal of Applied Physics 17) also marks the beginning of the field at ORNL. "The matter has great scientific interest because pile irradiations should permit the artificial formation of displacements in definite numbers and a study of the effect of these on thermal and electrical conductivity, tensile strength, ductility, etc., as demanded by the theory."

As a result, with the birth of the Clinton Laboratories Metallurgy Division in 1946, which eventually became ORNL's Metals and Ceramics Division, a radiation effects program came into being. In the early years, scientific understanding of radiation effects was very elementary; much of 
the work involved examining various properties by all available measurement techniques. Over the years, researchers used the Graphite Reactor, the Bulk Shielding Reactor, and the Oak Ridge Research Reactor to irradiate materials.

\section{radiation effects}

Over the years, Division researchers have examined three types of property changes and their underlying physical mechanisms: swelling, creep, and embrittlement. These property changes are caused by defects at the atomic level - "vacancies" (where an atom has been moved out of its space) and "interstitials" (where the atom has been moved into a space not its own). These defects are induced by being irradiated with energetic particles. This

irradiation could happen both through reactor neutrons, such as in fission and fusion reactors, and accelerator ions, such as in mechanistic studies and ion beam processing.

One energetic neutron or ion can displace an atom by "knocking" it out of its place, which subsequently displaces other atoms; this effect is much like that of knocking over a row of dominoes. The migration and interaction of these defects eventually can produce permanent changes in the structure and composition of the material.

Occasionally, vacancies and interstitials may recombine with each other, leading to no permanent changes in the material. Designers who are developing radiation-resistant alloys seek to maximize this effect. More often, however, drastic changes in properties occur as a result of microstructural changes - such as the formation of dislocation loops or cavities - or changes in local composition - such as separation of an alloy's constituents.

One of the most significant radiation effects is swelling. This occurs when cavities, which result from the aggregation of vacancies, form a volume that shows up as macroscopic swelling of the material. Alloys irradiated to high doses can, as a result of swelling, become so brittle that its ductility is reduced from tens to only tenths of a percent or less. Irradiation creep, another radiation effect generally occurs in materials that are stressed during irradiation. This shape change in the material can exceed the shape change induced by thermal creep.

\section{metallurgy division's role}

Alloys not designed to resist the effect of neutron irradiation are generally inadequate for use in fission and fusion reactors. Because of that, the Atomic Energy Commission mounted largescale efforts to design alloys for irradiation performance. The Metallurgy Division, and later the Metals and Ceramics Division, has 
played an important role in that research. In fact, the principles applied to improve alloy design have been derived largely from basic studies of the physical mechanisms and kinetics of irradiated materials.

In 1950, the Metallurgy Division's radiation effects groups, led by the late Doug Billington, became the Solid State Division, whose main purpose was radiation effects research. Later, Fred Young, now retired associate director of the Solid State Division, was active in influencing fundamental studies in the field. Later, the Metals and Ceramics Division reentered the field because of the emerging technological need for reactor materials resistant to neutron irradiation. Since that time, the Division has been involved in developing structural and fuel materials with appropriate irradiation properties for about two dozen different reactors.

In 1953, the Division was involved with the project to develop a nuclear reactor for aircraft propulsion; such a reactor required high-temperature performance. A high-temperature structural alloy, Inconel 600, was used for the reactor. After irradiation, the stress rupture resulted from helium produced by transmutation reactions involving boron-10 in the alloy; simply put, the gas accumulated at the grain boundaries in the alloy and weakened them.
The problem was solved by alloying with small amounts of titanium, which tied up the boron in the matrix and kept helium out of the boundaries. Jim Weir was prominent in these efforts to improve mechanical properties by microalloying; for his work, he received the Department of Energy's

E. O. Lawrence Memorial Award in 1973. After he became division director in 1973, the Division built up a large effort in radiation effects.

In the 1970s, the division developed aggressive programs for research in radiation effects under Jim Stiegler and Everett Bloom. These programs covered three areas: alloy development for liquid metal cooled fast reactor structures, alloy development for fusion reactor applications, and basic research on the physical mechanisms of radiation effects. At the same time, efforts were mounted in other countries, especially England, France, Japan, Germany, and the Soviet Union.

As of this writing the main efforts in radiation effects in the Metals and Ceramics Division are centered on microstructural and microcompositional changes and on their relationships to materials properties. In Arthur Rowcliffe's group, the main efforts are irradiating, characterizing, and testing developmental materials for fusion reactor applications, and providing feedback to aid in developing improved materials. In Randy 
Nanstad's group the emphasis is on the embrittlement and radiation-induced elevation in the ductile-to-brittle transition temperature in ferritic steel pressure vessel alloys. In Tim Burchell's group the emphasis is on radiation effects in carbon and carbon composite materials, including changes in mechanical and thermophysical properties. In Lou Mansur's group, the emphasis is on understanding the mechanisms of radiation effects to develop new and improved materials by means of combined theoretical and experiment research. The aims are to predict behavior during irradiation, develop principles for altering microstructure and composition to improve resistance to radiation effects, and explore the unique research opportunities made possible by the ability to displace atoms.

\section{theory and experiments}

\section{kinetic theory of radiation effects}

In the 1970s, the Division began work on the kinetic theory of radiation effects, which is based on the mechanisms and kinetics of defect reactions. This work guides the experimental program and builds on its results. Researchers have developed an extensive mathematical framework that describes defect diffusion and aggregation, the consequent evolution of microstructural features, and the macroscopic property changes that they in turn induce.
Many Metals and Ceramics coworkers have contributed over the years, including Alan Brailsford, Bill Coghlan, Roger Stoller, Man Yoo, Dora Pedraza, Lou Mansur, and Mike Hayns. The kinetic theory, which describes our best mechanistic and quantitative understanding of radiation effects, draws heavily on diffusion, thermodynamics, kinetics, phase transformations, and mechanics. Characteristically, the development of this theory has relied on close cooperation with experimenters, and has played both a guiding and supporting role in planning and interpreting experiments.

Using this theory, Division researchers concentrated first on understanding and modeling radiation-induced swelling, then on creep and embrittlement. These efforts have shown how swelling is related to competition between dislocations and cavities as sinks for point defects, described how cavities coalesce, helped understand how ion irradiations differ from one condition to another. Effects investigated included precipitates, dose-rate temperature shift, surface effects, and diffusional spreading.

One of the most important contributions of this theory has been the understanding of how gas atoms contained in a cavity can be crucial in triggering the onset of unstoppable growth of the cavities; i.e., the onset of swelling. Helium generated by 
transmutation reactions or injected by accelerator is crucial in this picture.

\section{irradiation creep}

Over the past two decades, Division researchers have also contributed to the theoretical understanding of irradiation creep. In some of this work, researchers have shown how irradiation creep is driven by steady excess flow of point defects to dislocations; this flow results in dislocations "climbing over" obstacles, which leads to dislocation glide, each event of which contributes irreversibly to irradiation creep. More recently, Roger Stoller, Martin Grossbeck, Alan Brailsford, Bill Coghlan, and Lou Mansur have carried out a series of theoretical and experimental studies focusing of creep contributions from transient (as contrasted with steady state) processes. Occasionally, fluctuations in vacancy and interstitial concentration, which can occur for several distinct physical reasons, can lead to more creep than do the more widely researched steady state processes.

\section{radiation-induced embrittlement}

Division researchers currently are examining the physical mechanisms of radiation effects; specifically, radiationinduced embrittlement. This work began with the discovery that at the High Flux Isotope Reactor, embrittlement due to neutron exposure was occurring in the reactor pressure vessel at a rate different than first anticipated. Ken Farrell, Roger Stroller, and Tahir Mahmood, working with Randy Nanstad's group and Frank Kam and coworkers, examined in detail several physical mechanisms that could be responsible for the apparent early embrittlement.

These researchers examined effects of the soft neutron spectrum, the extremely low damage rate, and the presence of an enormous gamma ray flux relative to fast neutron flux at the vessel. They found that the gamma ray flux, which was a heretofore unrecognized process of embrittlement, may be contributing most to the early embrittlement. The soft spectrum effect and the low damage rate are still being investigated. This work has stimulated new research worldwide on the mechanisms of pressure vessel embrittlement caused by radiation effects. In the Division, researchers continue to use not only neutrons to investigate the problem, but are irradiating materials with ions to better understand embrittlement. Ion irradiation allows researchers to incrementally control microstructural changes and, thus, to understand how each feature in the more complex microstructure arising from neutron irradiation contribute to the embrittlement process. 
radiation effects research in the Solid State Division

Radiation effects research in the Solid State Division (part of the Metallurgy Division until 1951) emphasized the more basic aspects of defect production; both theoretical modeling and fundamental experiment were conduced. Mark Robinson, Dean Oen, Tom Noggle, Ralph Coltman, and Jim Roberto (among others) were prominent in these efforts.

Although Solid State is no longer involved in radiation effects to that level, it has continued to play a lead role in the ion beam modification of materials. This field is closely tied to radiation effects because many of the results of ion irradiation stem from the highly defected structures and nonequilibrium states induced by irradiation. Bill Appleton, Woody White, Carl McHargue, Dave Poker, Jim Williams, and many others have made important contributions in developing this field.

Consequently, dividing lines between radiation effects research and ion beam processing are now dissolving. Solid State ion beam researchers are focusing more attention on displacement damage, microstructural changes, and phase changes; and Metals and Ceramics researchers who were active in applying ion beams to understand fundamental issues in radiation effects have recently launched important new work in the ion beam modification of solids.

\section{broader applications}

As has been obvious from the earliest research in Oak Ridge, the capability to irradiate materials is a powerful dimension of materials science that is much broader than its most well-explored subfield, materials for fission and fusion reactor applications. In 1990, Metals and Ceramics' efforts expanded greatly in ion beam modification with some very important work on the ion beam modification of polymers. Eal Lee, Monty Lewis, and Gopal Rao began work to improve surface mechanical properties of polymer materials.

Normally, polymers are specified for relatively mild materials applications. Applications requiring performance in hostile environments, such as high hardness or wear resistance, are usually reserved for high-strength alloys or ceramics. However, through use of energetic heavy ion beams, researchers found that the hardness of polymers can be increased one to two orders of magnitude, rendering these materials substantially harder than stainless steels.

Similarly, their wear resistance can be improved to the point where wear is negligible in standard tests. In addition, other improved properties - such as extreme resistance to chemical solvents, resistance to oxidation, and 
many orders of magnitude increases in electrical conductivity - can be achieved.

\section{research capabilities}

ORNL has extensive capabilities for research in these areas. The High Flux Isotope Reactor (HFIR) is used for highdose, elevated-temperature irradiations both for basic research and for alloy development activities.

For microstructural characterization, the Laboratory has a first-class center for state-of-the-art electron microscopy. The capability was built up initially under Jim Stiegler's leadership in response to the demands for microcharacterization of irradiated materials. The facilities continue to evolve and the extensive capabilities are now being applied to a wide range of materials science research. The Laboratory has extensive hot cell facilities for postirradiation examination and testing of irradiated materials.

Unique capabilities for ion irradiations have been developed. Energetic ions from accelerators can produce atomic displacements that are qualitatively similar to those produced by neutrons from reactors. However, ion irradiations offer many advantages for research. Damage can be produced at rate $10^{3}$ to $10^{4}$ times higher than in reactors and, in addition, more flexibility exists in controlling variables. Accelerator ex- periments are much less expensive and less difficult.

ORNL has been one of the pioneering laboratories in applying ion beams in radiation effects research. A triplebeam facility consisting of 5-MV, 2.5$\mathrm{MV}$, and 400-kV Van de Graaff accelerators has been developed. The highest energy machine is usually used for heavy ions such as nickel or iron to produce radiation damage, and the smaller machines are used to simultaneously inject helium or hydrogen (or both) for studying the effects of important transmutation products that would be produced during neutron irradiations. In addition, the smaller accelerators have been used extensively for ion beam processing research. Monty Lewis, assisted by Roy Buhl, Sy Cook, and Bill Allen, has largely been responsible for the full range of application of ion-beam research in our experimental program.

\section{conclusion}

Because virtually all work on radiation effects has taken place when modern high resolution atomic and microstructural characterization tools were available, the approach has been perhaps more mechanistically oriented than more traditional areas in metallurgy. Theoretical research has been closely coupled with experiments designed to uncover mechanisms and to improve basic understanding. 


\section{metallographic services}

Not long after its formation, the Metallurgy Division (now Metals and Ceramics) recognized the need for a laboratory devoted to Metallography, the microscopic observation and study of metallic structure. In April 1948, Bob Gray joined the Division to form the Metallography Group, despite misgivings from a change in the Division's building site during his interview and a change in operating contractor a month after he started work.

As the Division grew, so did the metallography operation, eventually comprising three groups: General Metallography, Radiation Metallography, and Electron Metallography, with as many as 37 people.

\section{failure analysis}

Failure analyses have been major challenges in metallography. Usually, the microstructures can reveal the origin of a failure and offer proof of changes that can often avoid future failures of that type. One of the first problems solved with the help of the metallography laboratory was the failure of uranium fuel slugs in the Graphite Reactor after an increase in the reactor's operating level. The uranium fuel got hot enough to alloy with and penetrate the aluminum jacket, leading to oxidation of the fuel. Many other failures have been examined and reported through the years.
Except to follow general investigative steps, failure studies follow no recipe. The many variables that influence a failure require that one must study the failure site in great detail while considering the design of the failed piece and the environmental influence.

Examples of reported failure analyses include fire-damaged pipe from the Strategic Petroleum Reserve, surgical implants, aluminum tubing pitted in stagnant water, a 16-in. cast iron water line, a transition weld joint, and a heat exchanger from a coal processing pilot plant.

\section{radiation metallography and vibratory polishing}

Before the 1950s, it wasn't unusual to study radioactive materials set up behind a temporary shielding of lead

- bricks. This widespread approach was used at times in metallographic studies, both in preparation and examination. The whole gamut of activities dealing with highly radioactive materials had to change as the need arose to study materials of higher activity. 


\section{designing and constructing a metallography laboratory}

Metallographers met with ORNL engineers who were experienced in the design of facilities for working with radioactive materials, giving input on specimen cutting, embedding, grinding, and polishing, etching, and the microscopy of materials. The need for a metallography facility in the High Radiation

Level Examination Laboratory (HRLEL) became apparent, and the shielding cells for performing most of the metallographic operations could be fabricated at ORNL. (See Fig. 1.)

Doug Billington made the following assignment to the metallography personnel: "Design and construct the necessary equipment and follow through with the development of techniques and conduct the necessary training of personnel to perform a service that would be equivalent to conventional nonradioactive materials"; then he came out with that characteristic chuckle and said "I think that is impossible, but try to come as close to that goal as you can."

\section{designing the metallograph}

The design and construction of a lightilluminated metallograph for the examination of highly radioactive materials was beyond the capabilities of the metallography personnel and ORNL engineers. This instrument had to confine particulates as well as alpha, beta, and gamma radiation. There was very little background information and experience to build on.

Dan Jones (Engineering Division) and Bob Gray (Metallurgy Division) made numerous trips to Bausch \& Lomb Optical Co., Rochester, New York, and W. J. Hacker Co. (Reichert Microscopes of America), East Caldwell, New Jersey, to assist in the early design stages for each company. This assistance was essential so the companies could supply bids for the construction of two shielded metallographs.

The metallographs would be contiguously affixed to the outside wall of a hot cell as separate "blister attachments." This location would protect the metallographs, with their sensitive optics, from the background radiation as well as the particulate matter that most definitely would be present inside a working cell. Also, the metallographs had to be accessible for service by a vendor's engineer.

The instruments would be attached to the outside of a 3-ft-thick wall of highdensity concrete, which would be the barrier to the area where the metallographic specimens would be prepared for microscopic study. After each specimen was prepared for microscopic examination, it would be transferred through an opening in the cell wall by an automatic relay system and placed 


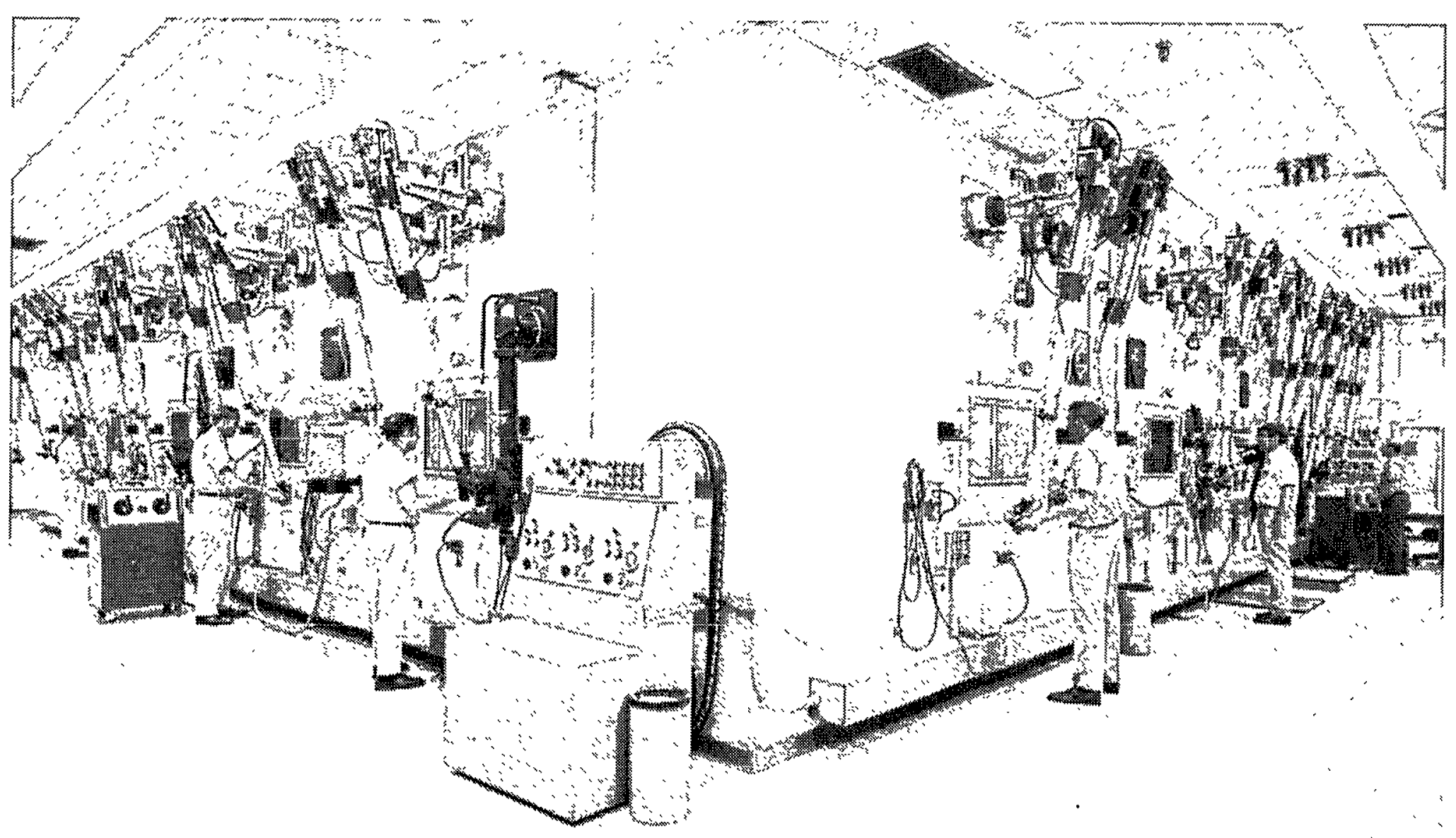

Fig. 1. The metallographic cells in the High Level Radiation Examination Laboratory are the four cells on the right. At the last cell on the extreme right is Larry Shrader. 
on the center of the stage of the metallograph for the microscopic examination.

\section{designing a microindention hardness tester}

Because no commercial company could provide a shielded microindentation hardness tester, Ed Hutto (ORNL Engineering Division) modified a conventional off-the-shelf Kentron MicroIndentation Hardness Tester with shielding features and operational methods similar to those for the Bausch \& Lomb metallograph. It was positioned on a mezzanine directly above the metallograph, and specimens were transferred to the hardness tester in the same way as to the metallographs.

\section{preparing radioactive metallographic specimens}

The preparation of radioactive metallographic specimens became a serious hurdle. It would seem to be straightforward: the metallographic specimen had to be cut, embedded, ground, and polished free of scratches and other artifacts that might prevent a valid interpretation of the microstructure. Cutting out the specimen and embedding it in a plastic mount would be relatively straightforward and not difficult to perform remotely.
Grinding and polishing, however, had always been considered a "hands-on" operation requiring an artistic touch that was essential to be performed by hand. This mindset had to be changed.

Several methods were attempted to mechanically simulate the age-old hand-held methods of supporting the embedded specimen, but they always met with disaster. Keeping the specimen surface flat and perpendicular to the wall of the right cylinder plastic mount - a must requirement for microscopy - was unsuccessful.

Finally, a commercial vibrator was adapted to polishing 24 specimens at once. Shakedown tests with nonradioactive specimens showed that this method of specimen preparation would diminish the load on metallographers and upgrade the quality and quantity of specimens to a considerable extent. In fact, this introduced a new era of metallographic specimen polishing that would have worldwide impact on the future of this discipline.

Considerable credit must be given to Ernie Long, Bill Leslie, and Bob Crouse along with Maurice Allen, Bill Farmer, Neil Atchley, Ray Gaddis, and Larry Shrader, who were great innovators in the development of vibratory polishing in the hot cells, in a glove box, and for general metallographic use. These polishers can be operated $24 \mathrm{~h}$ a day unattended. The quality of the speci- 
men surface is far superior to that of specimens prepared by hand.

\section{glove box metallography}

Glove box metallography became needed for studies of alpha-emitting materials such as plutonium. Metallography laboratory equipment was de signed and installed in a continuously connected series of glove boxes.

Nearly all the operations conducted in a normal metallographic laboratory cutting, embedding in epoxy resin, grinding, polishing, etching, microscopic study, photomicrography, photomacrography, and micro-indentation hardness testing were carried out in glove boxes dedicated to these specific operations. Always, a negative pressure was maintained in case of a slight leak. Nearly all operations had to be carried out on a somewhat Lilliputian scale because of the restricted working space in the glove boxes.

An alpha-shielded metallograph was required in the last enclosure of the glove box line. The optical alignment channel bar of an original Bausch \& Lomb research metallograph was cut into three sections: xenon lamp, optical metallograph, and bellows camera. The camera and lamp units remained outside the glove box, and the optical alignment - the channel bar - was replaced by a 1/4-in -thick steel plate, which became the top of the support table.

Encasing the metallograph in a plastic glove box extended the spaces between the three components by several inches. Interconnection of these three components required the design and construction of two sealed optical relays that passed through the glove box walls. The first relay transferred the light image to a forward position in the optical train. The second relay transferred the specimen image toward the camera with very little loss in light image and no detectable degradation of the quality of the photomicrography.

\section{did we meet doug's challenge?}

At this point it was reasonably safe to state we had come very close to accomplishing the "impossible challenge" issued by Doug Billington. If he could have been here, he probably would have chuckled with pleasure at the quality and efficiency achieved in the metallography of radioactive materials.

\section{color metallography}

The application of color metallographic techniques for revealing microstructures began in this laboratory in the mid-fifties. Some of the well-known metallographers in the United States and Canada had their start in the use of color by attending one of two teaching seminars held at ORNL in 1977 and 1978. 
Interference film metallography began in the 1960s in Germany, and we began using it fairly often. Jim Stiegler and Bob Gray developed a method of applying the interference layer to the surface of as-polished or lightly etched specimens. This procedure is particularly suited to specimens with dissimilar materials, such as a braze joint.

\section{electron metallography and related techniques}

Use of electron microscopy in the Division's metallography program was pioneered by Ernie Long and Warren Bridges with a 100-keV RCA instrument. Its low energy and the technique development of that time restricted its use to carbon replicas for specimen surface examinations. Electron metallography grew under the leadership of Jim Stiegler. Carus (Bud) DuBose developed techniques to thin specimens sufficiently for transmission microscopy without changing the internal structure.

Scanning Electron Microscopy (SEM) became another useful procedure in the examination of radioactive and nonradioactive materials. One of the first shielded SEM units in the United States was developed by Bob Crouse, built "in-house" for use in the HRLEL, and operated by Larry Shrader.

Electron Probe Microanalyzers, also, were installed in both the HRLEL and General Metallography and became very useful for the analysis of areas with dimensions of the order of $1 \mu \mathrm{m}$. One of the very first instruments in the United States for the analysis of radioactive materials was installed in the HRLEL.

\section{elevated-temperature hardness testing}

Elevated-temperature hardness testing was developed by George Hallerman and Tommy Henson during the 1960s. They modified a Rockwell Hardness Tester for service from 25 to $900^{\circ} \mathrm{C}$. They also supervised the design and fabrication of an elevated-temperature micro-indentation hardness tester that could be operated from 25 to $1000^{\circ} \mathrm{C}$ in a vacuum of $10^{-4}$ to $10^{-5}$ torr with a load range of $150 \mathrm{~g}$ to $3 \mathrm{~kg}$.

These instruments were used for screening metals and alloys to determine plasticities at elevated temperatures. Hallerman also developed an instrument for determining the crushing strength of 50- to 500- $\mu \mathrm{m}$-diam carbon-coated nuclear fuel particles for gas-cooled reactors.

\section{field metallography}

Field (in situ) metallography became very important for nondestructively determining the microstructures of plant components such as pipes, valve housings, weldments, and structural supports to predict life expectancy. The area in question can be monitored to 
determine any changes in the microstructure that would threaten its continued operation.

The area is prepared for examination with portable tools, by steps closely related to those followed in conventional metallography. After the final polishing step, the area is etched and then replicated with an acetate film previously softened by a suitable solvent. Also, a practice was developed by Bob McDonald to replicate larger areas from $2 \times 2$ in. up to $10 \times 10$ in. using room-temperature-vulcanizing (RTV) rubber. The acetate method and the RTV rubber method have complemented each other: the acetate method allows examinations up to $5000 x$ in small areas, while the RTV rubber technique permits examination of larger areas but at magnifications limited to $500 x$.

One of the early stages of crack formation that is searched for is grain boundary cavitation. As the name implies, cavities can form at the grain boundaries, near inclusions, or at any other discontinuity in the microstructure that could serve as a stress riser. A lineup of these cavities is a potential start of a crack that should be considered for part replacement before a catastrophic failure might develop. 


\section{fundamental and applied research}

Materials research in the current Metals and Ceramics $(M \& C)$ Division has generally meant studies supported by the Office of Basic Energy Sciences (BES) or its predecessor, Division of Physical Research (DPR) in the Energy Research and Development Administration (ERDA) and the Atomic Energy Commission (AEC). The goal of such research is the "fundamental" or "basic" understanding of the behavior of materials and has been a part of the Division's activities since its beginning.

ERDA supported "applied" or "longrange applied" (4420 program) research, along with "fundamental" (5000 program) research until 1954. Then the Division of Reactor Development of AEC supported "4420" or "applied research" on materials of interest to several reactor systems. These studies were transferred to the Liquid-Metal Fast Breeder Reactor (LMFBR), the Space Reactor, or the DPR "fundamental" research programs during 1963 to 1972.

The earliest budget document found in Laboratory Records lists the following tasks in the "5000" program: Fundamental Beryllium Research, \$22,000; Tensile Properties of Pure Metals, $\$ 1$ 1,000; Thorium Alloy Development, $\$ 22,000$; and Preferred Orientations in Uranium, $\$ 26,000$.

\section{fundamental research}

alloy behavior and design: experimental

Up to 1956 these studies were concerned with the development and properties of thorium alloys.

Zirconium alloy research was led by Jesse Betterton during 1952 to 1966. This work sought alloying principles to guide the development of useful materials with strong theoretical support from consultants. The choice of zirconium as the base material was influenced by the Laboratory's focus on the homogeneous reactor and the emerging light-water reactor (LWR) technology.

This group made major contributions to understanding the phase diagrams of $\mathrm{Zr}-\mathrm{Ga}, \mathrm{Zr}-\mathrm{Nb}-\mathrm{X}, \mathrm{Zr}-\mathrm{Mo}, \mathrm{Zr}-\mathrm{Cu}, \mathrm{Cu}-$ $\mathrm{Pd}, \mathrm{Zr}-\mathrm{Pb}$, and $\mathrm{Zr}-\mathrm{Cd}$. They pioneered the use of vapor pressure measurements to establish equilibrium conditions during annealing. George Kneip determined the low-temperature specific heats of $\mathrm{Zr}$, Ti, Hf, $\mathrm{Zr}$-Ir, and $\mathrm{Zr}$-Sn for the study of density of states. Fermi surfaces were mapped from galvanomagnetic measurements at 4.2 $\mathrm{K}$ for $\mathrm{Zr}$ and Be. Because of the interest in thorium metal, Larry Jetter, Carl McHargue, and Harry Yakel used $\mathrm{x}$-ray techniques to search for phase transformations in Th and Ce metals in 
the temperature range 4.2 to $300 \mathrm{~K}$. They found no transformation in thorium.

The alloy studies merged with the task Metallurgy of Superconducting Materials, which had been started in 1961 at the request of, and with the support of, the Sherwood Project (Fusion Energy). These studies became a part of the 5000 program in 1963. Under Gordon Love and later Carl Koch, extensive investigations of the effects of metallurgical structure and heat treatments on superconducting properties began. Alloy systems studied included $\mathrm{Zr}-\mathrm{Nb}$, $\mathrm{Zr}-\mathrm{Nb}-\mathrm{X}, \mathrm{Mo}-\mathrm{Re}, \mathrm{Nb}-\mathrm{Ir}, \mathrm{V}-\mathrm{Ga}, \mathrm{Nb}_{3} \mathrm{Sn}$, and other A-15 compounds. The group made significant contributions to the understanding of fluxoid pinning. A Materials Science Award was received for its definitive studies on stress effects on multifilament $\mathrm{Nb}-\mathrm{Ti}$ and $\mathrm{Nb}_{3} \mathrm{Sn}$ composites (Dewey Easton).

In 1979, a transition to the study of metastable materials began. Studies on the formation, structure, and properties of amorphous metal alloys (metallic glasses) defined the quench rates obtained in the arc-hammer and meltspinning techniques and pioneered the use of mechanical alloying to prepare amorphous alloys. An important conclusion from the low-temperature specific heat measurements of Don Kroeger is the existence of multiple amorphous phases with boundaries having characteristics similar to those between crystalline phases. This led to
. an understanding of annealing embrittlement of amorphous alloys and suggested ways to solve this major obstacle to the commercialization of such alloys.

In 1984, these studies were combined with those on intermetallic alloys to form the Alloy Behavior and Design (ABAD) task. This task, under the direction of first Carl Koch and then C. T. Liu, extended the studies on the role of boron in producing ductile, polycrystalline, intermetallic alloys such as $\mathrm{Ni}_{3} \mathrm{Al}$. Cal White established the relative rates of segregation of boron to free surfaces and to grain boundaries. Man Yoo studied theoretically dislocation and point defect behavior and the role of twinning in the deformation of such alloys.

\section{alloy behavior and design: theoretical}

Theoretical studies on electronic states were begun in about 1962 by Hugh Joy, who considered the electronic transitions in molten ionic materials as a part of the Spectroscopy of Ionic Media task. A separate task to develop solid-state theory for metals and alloys was formed in 1964 under the leadership of Sam Faulkner. The group focused on the Korringa-Kohn-Rostocker (KKR) method for calculating electronic states, combining it with various techniques such as Discrete Variational Method, Coherent Potential Approximation, multiple scattering, and the muffin-tin approximation. 
The early studies considered the electronic structure and relationship to various properties in $\mathrm{Cu}, \mathrm{Al}$, the third transition metals, and diamond. The problem of moving from ordered alloy structures to disordered alloys was attacked as the obstacle to a full theory of alloying. Success in these activities was noted by a Materials Science Award for "Modern Theory of Metallic Alloys" given to Faulkner, Malcolm Stocks, and Bill Butler in 1982. Notable achievements in calculation of electronphonon interactions were made by Butler and confirmed by measurements on niobium in the Physical Properties task. Studies were extended to the structure of clusters and surfaces by Gayle Painter. The interactions of various chemical species with surfaces were modeled with increasing accuracy.

By 1985, much of the activity turned to the ordered intermetallic alloys in support of the experimental program and on the structure of high-temperature superconducting materials. The surface studies were extended to include internal interfaces and questions of segregation of impurities.

Malcolm Stocks won a DOE award for Outstanding Sustained Research in 1989. Awards by DOE for Outstanding Scientific Accomplishment were granted to Chong-Long Fu and Man Yoo in 1991 and to Bill Butler, Xiaoguang Zhang, and Don Nicholson in 1995. Stocks et al. were granted the Gordon Bell Prize in 1990, the CRAY
Research Gigaflop Award in 1990, and a NATO Collaborative Research Grant in 1991.

deformation, annealing, and mechanical behavior

Initial studies were concerned with the inherent brittleness of beryllium metal (until 1951); the tensile properties of pure metals (i.e., is there a mechanical equation of state?) until 1952; and preferred orientation in reactor materials. Studies on preferred orientations in metals were active until about 1980 .

The interest grew out of the "Clinton slug problem," the dimensional changes during thermal cycling or neutron irradiation of extruded uranium rods used in the graphite reactor at Oak Ridge and the production reactors at Hanford. Bernard Borie and Larry Jetter developed the spherical $x$ ray specimen, which eliminated the need to correct for $\mathrm{x}$-ray absorption during data gathering. Jetter, McHargue, and Robin Williams developed the axis distribution chart or "inverse pole figure" to describe textures. This work provided the foundation for modern texture representation.

This effort established the importance of initial orientation on final texture (the mechanical stability of certain crystallographic orientations Roy Vandermeer), the role of inhomogeneous deformation or deformation band formation on texture (Richard Reed), and the effect of fabrication technique 
(extrusion, wire drawing, swaging, and rolling) on texture. Texture development in body-centered cubic (bcc) metals was studied with single crystals of $\mathrm{Nb}$ and $\mathrm{Ta}$.

The potential of bcc refractory metals and alloys for space power applications was of great interest in the 1960s. Deformation mechanisms were determined for $\mathrm{Nb}, \mathrm{V}$, and $\mathrm{Nb}-\mathrm{V}$ alloys.

Collaboration with the Electron Microscopy task (Jim Stiegler) established that dislocation velocity in niobium varied as the one-eighth power of stress and observed the effect of alloying on dislocation mobilities. These observations led to a proposal that the frictional stress is composed of the PierlsNarbarro stress and contributions identified as size and modulus effects.

In 1961, Deformation of Crystalline Solids $s_{2}$ under the direction of Robin Williams, became a part of this task. Williams and Alan Wolfenden studied stored energy in deformed fcc materials using a calorimetric technique and internal friction. Richard Arsenault studied the low-temperature creep of iron and determined the activation energy and activation volume for dislocation movement in bcc metals. Man Yoo (1967) extended the conventional elastic treatment of dislocations and dislocation-point defect interactions to include anisotropic elastic effects.
These studies led to an improved understanding of dislocation behavior in hcp metals and the relative contributions of slip and twinning to total deformation. Roy Vandermeer extended the studies of annealing, which had focused on textures, to the mechanisms of grain-boundary migration and the interaction of recovery and recrystallization as driving forces. The theory of impurity-induced grain-boundary drag during recrystallization and grain growth resulted from studies of impurity-grain-boundary interactions.

In the late 1970s, the effort turned to studies of impurity segregation to internal surfaces (Cal White). The observations provided input to the Alloy Behavior and Design task regarding grain-boundary segregation and embrittlement and to the Radiation Effects task on the segregation of impurities to internal voids (produced by both creep and irradiation). In 1984, these activities were merged with the ABAD task.

\section{ceramics research}

Research on ceramic materials began in the Division with the transfer of a 5000-funded task from Y-12 Physics in 1951. This task, under J. Warde, continued studies on these materials until 1958, when the support was transferred to various projects. From 1957 to 1976, studies on high-temperature reactions of metals and ceramics and spectroscopy of molten media under 
Pedro Smith were major activities in this task. The interest arose from ORNL's role in the Aircraft Nuclear Reactor Project (ANP) and the Molten Salt Reactor Experiment (MSRE). In 1976, the activities were transferred to the Chemistry Division.

During the period 1960 to 1981 , much of the effort was devoted to the synthesis of ceramic materials under the direction of Wayne Clark (Crystal Physics and Synthesis of High-Temperature Materials). The group had great success in growing high-purity, low-defectcontaining single crystals of ceramics such as $\mathrm{MgO}, \mathrm{UO}_{2}$, and various crystals doped with actinide elements.

These crystals formed the basis for numerous studies by other groups and the Pure Materials Program of the Solid State Division. A notable achievement, which received an IR-100 Award, was the growth of single crystals of metal oxides with oriented metallic fibers by directionally solidifying metal oxidemetal eutectics (Clark and Ted Chapman). These early ceramic matrix composites still hold promise for hightemperature applications.

Among the techniques developed for growth of ceramic crystals are hydrothermal growth; flame fusion; edgedefined, film-fed growth; and internalzone growth. Many of these techniques were successfully modeled in terms of fluid and heat flow.
In 1963, the Basic Sintering Studies (Chester Morgan) were transferred from the 4420 Program to the Fundamental Research Program. This task became Physical Ceramics in 1965, then Fundamental Ceramics (Bill Fulkerson) by merging with a 4420 Program concerned with UN in 1971, and finally Structural Ceramics including Erosion and Wear of Ceramics and Crystal Physics in 1981 (Vic Tennery and Paul Becher).

The sintering studies were concerned with the role of plastic deformation in the densification of $\mathrm{ThO}_{2}$ and $\mathrm{UO}_{2}$. Charlie Yust with L. Barrett (University of Tennessee) and Fred Rhines (University of Florida) used ideas taken from topology to describe the microstructural changes that occur during densification. Yust and $\mathrm{McHargue}$ studied deformation mechanisms and dislocation motion and substructure in $\mathrm{ThO}_{2}$, $\mathrm{UO}_{2}$, and $\mathrm{CaF}_{2}$ during high-temperature compression. Yust found that, contrary to popular belief, dislocations were generated and moved during the impact erosion of $\mathrm{Al}_{2} \mathrm{O}_{3}$.

The war that followed the breakup of Belgian Congo caused great concern about the cobalt supply to the United States. Because of the importance of high-precision machining to $\mathrm{Y}-12$ activities, this task began studies to develop alternate tool materials. Work with borides included experimental studies on $\mathrm{TiB}_{2}$. F. Yen developed a 
process for liquid-phase sintering with nickel, and a Materials Sciences Award was given to Vic Tennery, Cabel Finch, Charlie Yust, Wayne Clark, and Carl McHargue in 1982, for "Processing and Properties of $\mathrm{TiB}_{2}$ Ceramics."

In 1985, Paul Becher began studies on transformation-toughened ceramics and whisker-toughened ceramics. These studies, along with those on processing science, form the base for current activities.

\section{surface and solid-state reactions}

Studies on the oxidation of metals began in 1958 as a joint MetallurgySolid State investigation of the effect of irradiation on the oxidation of $\mathrm{Nb}$ and Be. John Cathcart and Fred Young concluded that there was no effect at the flux attainable in the Graphite Reactor.

In 1961, Cathcart began studies that defined the effects of crystallographic orientation on the stress produced in oxide films on copper and their role in oxidation rates. Richard Pawel extended these studies to refractory metals and showed that the stresses generated during oxidation could produce plastic deformation of the metallic substrate. In 1971, they turned their attention to uranium-base alloys, refractory-metal alloys, and stainless steels. The focus was on determining the rate-controlling step during oxidation.
In the period 1974 to 1980 , studies on the steam oxidation of Zircaloy were conducted to form the basis for decisions on the safe operation of LWRs that resulted from the Emergency Core Cooling System (ECCs) hearing of the Nuclear Regulatory Commission (NRC).

As the AEC began its transition to ERDA in 1975, the studies of this group turned to the attack of metallic alloys by mixed gases (i.e., sulfidation), an area of interest to the Fossil Energy Program. Studies on the sulfidation of iron and iron-base alloys and the adhesion of resulting films continued until 1984.

Studies on Solid State Reactions began under 4420 support in.1959 and became Diffusion in Solids under 5000 support in 1965. It was merged with the Surface Reactions task in 1976. The diffusion studies (Ted Lundy) considered self-diffusion and impurity diffusion in metals, alloys, and compounds of interest to the Division's programs.

The studies on $\mathrm{Cr}$ (John Askill), Ti and Ti-V alloys (James Murdock), beta-Zr (Ted Lundy), and $\mathrm{Nb}$ and $\mathrm{Ta}$ (Richard Pawel) definitively showed that "anomalous" diffusion occurs in some bcc metals. These studies stimulated an international conference on "Diffusion in Body-Centered Cubic Metals," which was held in Gatlinburg, Tennessee, in 1964. The proceedings were published by the American Society for Metals. 
The importance of grain-boundary and short-circuit diffusion in ionic solids was demonstrated for $\mathrm{UO}_{2}, \mathrm{TiO}_{2}, \mathrm{TiO}$, and UN. Cation self-diffusion, thermotransport, and concentration effects were defined for these materials. The diffusion of tritium and deuterium was measured for a series of oxides of interest for nuclear applications. In addition to the experimental studies, significant contributions were made to the theory of mass transport in solids under nonequilibrium conditions.

In 1984, the task became Structure and Properties of Surfaces and Interfaces. Carl McHargue and Bill Appleton (Solid State Division) continued under this support a study of the effects of ion implantation on the structure and properties of ceramics begun under a "seed money" grant.

With support from the Electron Microscopy task and collaboration with researchers in France, Phil Sklad and Pete Angelini showed that both damaged crystalline and amorphous surface layers can be produced by control of the ion implantation parameters. Damaged crystalline surfaces are harder than unimplanted surfaces, and amorphous surfaces are softer. The studies continue with emphasis on the chemical effects of implantation and the mechanical properties of nanostructures produced by ion-beam treatments. electron microscopy

Electron microscopy resided in the Metallography Group until 1961. The research efforts (directed by Stiegler, Ray Carpenter, and Jim Bentley) have always had strong interactions with other activities of the Division and the scientific community. The initial studies provided important information about the behavior of dislocations in bcc metals and alloys. The effects of temperature, solid-solution alloying, and interstitial impurities on the multiplication and movement of dislocations formed a base for explaining the twinning, slip, and fracture behavior of $\mathrm{Nb}$, $\mathrm{V}, \mathrm{W}$, and their alloys.

Although studies of neutron radiation damage in metals were conducted in the Division at its origin, the responsibility for such studies moved to the Solid State Division with its creation in the early 1950s. Until about 1969, the Metallurgy Division was confined to the study of postirradiation effects, e.g., annealing microstructures, damage from other energetic particles, and mechanical properties. The electron microscopy task permitted the Division to reenter the broader area of radiation damage.

Initially (1965 to 1970), the radiation damage studies focused on electron irradiation of aluminum and its alloys, voids produced in aluminum by quenching or irradiation, and the 
annealing of radiation-produced microstructures. Ben Loh initiated theoretical studies on the interaction of vacancies, interstitials, insoluble gas atoms, and internal interfaces.

By 1970, a large body of knowledge on the behavior of irradiation-produced defects in $\mathrm{Al}, \mathrm{Mg}, \mathrm{Fe}$, graphite, $\mathrm{B}_{4} \mathrm{C}$, and stainless steel had been amassed. Such studies provided the base for evaluation of High Flux Isotope Reactor (HFIR) components (Ken Farrell) as well as the development of the low-swelling family of stainless steels for the LMFBR.

Once the Radiation Effects task began, the microscopy task turned its focus to development of new techniques and equipment for microanalysis. The activities emphasized Analytical Electron Microcopy and in situ studies in the high-voltage electron microscope (HVEM). During the period 1976 to 1982 , energy dispersive $\mathrm{x}$-ray analysis and electron energy loss spectroscopy (EELS) were brought to a high state of development. Extension of EELS to include EXELFS in 1988 to 1989 allows important information regarding the local surroundings of specific atoms to be defined.

In situ studies in the HVEM included oxidation of $\mathrm{V}$ and $\mathrm{V}-20 \% \mathrm{Ti}$, deformation of aluminum, and hydriding of hydrogen-storage materials. Advanced imaging techniques were brought on line as this task developed the knowledge base for their application.

In 1984, development and use of the Atom Probe (Mike Miller) were added to the task. Both advanced equipment and techniques are developed and state-of-the-art techniques are applied. The latter continues the tradition of collaborative research both inside and outside ORNL.

\section{research in $x$-ray diffraction}

$\mathrm{X}$-ray diffraction techniques have played an important role in the Division since its creation. Initially, the studies were conducted under the supervision of M. Bredig (Chemistry Division). The 5000 Program began support of a task led by Benard Borie in 1959. Borie and Cullie Sparks advanced the analysis of diffuse scattering from alloys through their studies of ordered alloys; temperature diffuse scattering; thermally excited, forbidden reflections; various anomalous scattering events; and resonance effects.

Their measurements on thin copper oxide layers with Cathcart confirmed stress generation in films as thin as $10 \mathrm{~nm}$ and defined the stress gradient that exists between the metal-oxide interface and the free surface.

Harry Yakel determined the effects of neutron irradiation on the lattice spacing and crystal structures of $\mathrm{B}_{4} \mathrm{C}, \mathrm{BeO}$, graphite, and other compounds of interest to the Division. Recognizing the 
importance of synchrotron-radiationproduced $x$ rays, Yakel and Sparks conducted many $x$-ray scattering experiments at the Stanford Synchrotron Beam Line, including determination of site occupancy in sigma and tau phase in the $\mathrm{Fe}-\mathrm{Cr}$ and $\mathrm{Fe}-\mathrm{Cr}-\mathrm{S}$ systems. Experience gained from these studies formed the basis for the ORNL beam line presently in operation at the National Synchrotron Light Source at Brookhaven National Laboratory. Cullie Sparks and Gene Ice developed new and much improved optics for this facility.

Small-angle $x$-ray scattering (SAXS) was pursued by Robert Hendricks in the period 1973 to 1982 . These studies pioneered the use of position-sensitive detectors and produced an ultrafast data acquisition and processing system that is the heart of the ORNL 10-m SAXS system. Studies of voids in quenched and irradiated metals and graphite, the mesostructure of coal (voids and mineral distributions), and polymers resulted from its use. The facility was later transferred to the management of the Solid State Division as part of the National Small-Angle Scattering Center.

\section{physical properties research}

Accurate physical property data are required for the safe design of most systems of interest to AEC, ERDA, or the Department of Energy (DOE). Such data also can give important informa- tion about the electronic structure of solids. The physical property task (David McElroy) began as part of the 4420 (AEC Reactor Division) Program in 1959, and transferred to the Fundamental Program in 1963 and to the Conservation Program in 1984. A constant activity has been the development of accurate measuring techniques and equipment. The result is a laboratory with a wide range of facilities whose operating features are well analyzed.

The studies can be characterized largely as electron conduction (in metals) and phonon conduction (in insulators). The accurate measurements of the thermal conductivity in $\mathrm{UO}_{2}$ and the analysis of heat-conduction mechanisms contributed to the definition of operating conditions for LWRs set by the NRC and for the analyses used in the ECCS hearings. Similar analyses were made for potential nuclear fuel compounds such as UN, ThN, and (U,Th)N. Total hemispherical emittance measurements (Tom Kollie) of materials such as $\mathrm{Pt}, \mathrm{Nb}-1 \% \mathrm{Zr}$, and INOR-8 provide a design base for their use in radiators and for safety analyses.

Electron conduction was studied in a wide range of metals and metallic alloys, and the relationship between electrical and thermal conduction was explored. The accurate measurements of phonon contributions to the conductivity of niobium (Robin Williams) provided an important confirmation to 
the theoretical studies of Bill Butler (Theory Group). With the increasing emphasis upon energy conservation, the group turned its attention to the thermal-conduction mechanisms in grossly inhomogeneous materials (fibers, gels, etc.). The studies then became a part of the Conservation Program.

\section{microstructure of coal}

As part of the program reorientation to support nonnuclear energy programs, the feasibility of using electron and optical microscopy to study the structure of coals was explored during 1975 to 1981 . Larry Harris demonstrated the usefulness of electron, conventional light, and infrared microscopy to define the amount and distribution of cavities and mineral microphases in a variety of coals. He found that these microstructural features affected the behavior during various coalconversion processes.

\section{research in welding and joining}

As a result of a national workshop organized and hosted by the Division in 1977, research on "Engineering Materials Science" was initiated by the DPR, ERDA. Among the first of these new programs to be funded was "Research in Welding and Joining" under the leadership of Stan David. The behavior of various austenitic stainless steels has been the focus of study.

An important factor in understanding weld microstructures has been the electron microscopy of John Vitek. Initial studies were concerned with weld-pool solidification and the effect of composition, residual elements, and cooling rates on the resultant microstructures. The stability of the weldformed microstructures during long-time aging has been investigated in detail. As an understanding of weld pool solidification process was gained, an increased emphasis was placed on modeling heat transfer and its effect on microstructures.

These studies have led to a capability of predicting microstructures and phase distributions for a variety of welding processes. Laser welding and rapid solidification have been investigated. Experimental studies of the microstructures produced in single crystals of $\mathrm{Fe}-$ $15 \mathrm{Ni}-15 \mathrm{Cr}$ of various initial crystallographic orientations have confirmed the solidification models proposed by this team.

In 1982, the James F. Lincoln Gold Medal of the American Welding Society was presented to Stan David for these studies. A number of other awards have been granted to David, Vitek, and co-workers for results arising from this task.

\section{applied research}


"Applied" research was sponsored by the DPR of the AEC from the start of the Metallurgy Division until about 1954. Tasks included in this program were Creep of Uranium (1950 to 1954), Physical Metallurgy of U-Al Alloys (1950 to 1952), Corrosion Studies (at Y12 until 1952), and Ceramics Research (1951 to 1958). In 1959, the Division of Reactor Development, AEC, initiated long-range applied research $(4420$ budget category). The initial program in the Metallurgy Division was composed of Physical Properties, Sintering Studies, Reactions in Solids, and Zirconium Metallurgy.

With the exception of Zirconium Metallurgy, these tasks were transferred to the Fundamental Program of the DPR, AEC, by 1965. Additional tasks in Materials Compatibility (1963 to 1970), Fuel Element Development (1963 to 1971), Mechanical Property Research (1963 to 1966), Nondestructive Testing (1963 to 1971), High Temperature Materials (1963 to 1966), Tungsten Metallurgy (1964 to 1965), Joining Research (1967 to 1973), and Uranium Nitride (1964 to 1966) were supported by this program. Eventually, all tasks were transferred to other programs (mostly, DPR, LMFBR, and Space) or phased out.

\section{zirconium metallurgy}

Most of the 4420 activities are covered in other sections. Zirconium Metallurgy (M. L. Picklesimer) had its origins in the Homogeneous Reactor Experiment of ORNL and was continued until 1968 because of its importance to LWR technology. The main subtasks were preferred orientation and anisotropic properties; hydride precipitation; oxidation; and alloy development in the $\mathrm{Zr}$ $15 \mathrm{Nb}-\mathrm{X}, \mathrm{Zr}-\mathrm{Mo}, \mathrm{Zr}-\mathrm{Cu}$, and $\mathrm{Zr}-\mathrm{Pd}$ systems. Several patents were issued to Picklesimer and Phil Rittenhouse for fabrication schedules designed to use the preferred orientations and anisotropy of properties in design of reactor components.

Hydride precipitation was found to be very sensitive to orientation and residual stresses, and the precipitates could be made to assume orientations that would have the least effect on stresses encountered in service. David Hobson and Rittenhouse extended the studies from rolled sheets to tubing. Studies on oxidation of Zircaloy-2 and high-purity zirconium in oxygen and water (Picklesimer and John Banter) formed a base for the ECCS hearings and the NRC rulings on LWR safety. 


\section{the roofs over our heads}

Housing of the Metallurgy/Metals and Ceramics Division has taken many forms and locations over the last 50 years in keeping with changing missions of the Division. Some buildings have been quite large and designed to provide the special requirements for equipment or for containment of radioactive materials. Other locations were portions of existing buildings adapted to fill Division needs but, in some cases, closer to the proverbial broom closet in size.

Following the end of World War II, a small amount of work on nuclear weapons continued, but development of nuclear energy for conventional power generation and for research reactors evolved rapidly. Little was known of the effects on materials of exposure in a nuclear reactor. Thus, new facilities such as those for the development of an aluminum-clad aluminum-uranium fuel element for the Materials Test Reactor (MTR), were needed.

\section{the rolling mill}

The rolling mill, building 3012 $\left(11,000 \mathrm{ft}^{2}\right)$, was constructed in 1947 and was built for the express purpose of fabricating MTR-type fuel plates (Fig. 2). This barnlike structure contained melting and casting, furnacing, and multipurpose rolling equipment. The rolling mill and its personnel subsequently provided fuel assemblies for several swimming-pool-type research reactors and conducted workability studies on tantalum, beryllium, and other metals.

Before the rolling mill became available, preliminary work on MTR plates was done in an annex to the graphite reactor building (building 3001). Scope of the work included brazing of plates, a study of corrosion of aluminum alloys in hightemperature water, and primitive metallography.

\section{metal casting and fabricating}

Concurrent with the formation of the Metallurgy Division in 1946, Quonsetstyle building $2000\left(23,000 \mathrm{ft}^{2}\right)$ was designed; construction was completed in 1948. Its floor plan accommodated a wide range of metal casting and fabri-

cation equipment; laboratories for measurement of mechanical, physical, and chemical properties and metallographic examination; and office space. The once-through ventilation and exhaust system was designed to contain the toxic radioactive materials to be handled and was equipped with cyclone separators and absolute filters.

The principal radioactivity to be contained was alpha emission with a lesser degree of beta and gamma radiation. Subsequently, building 2024 


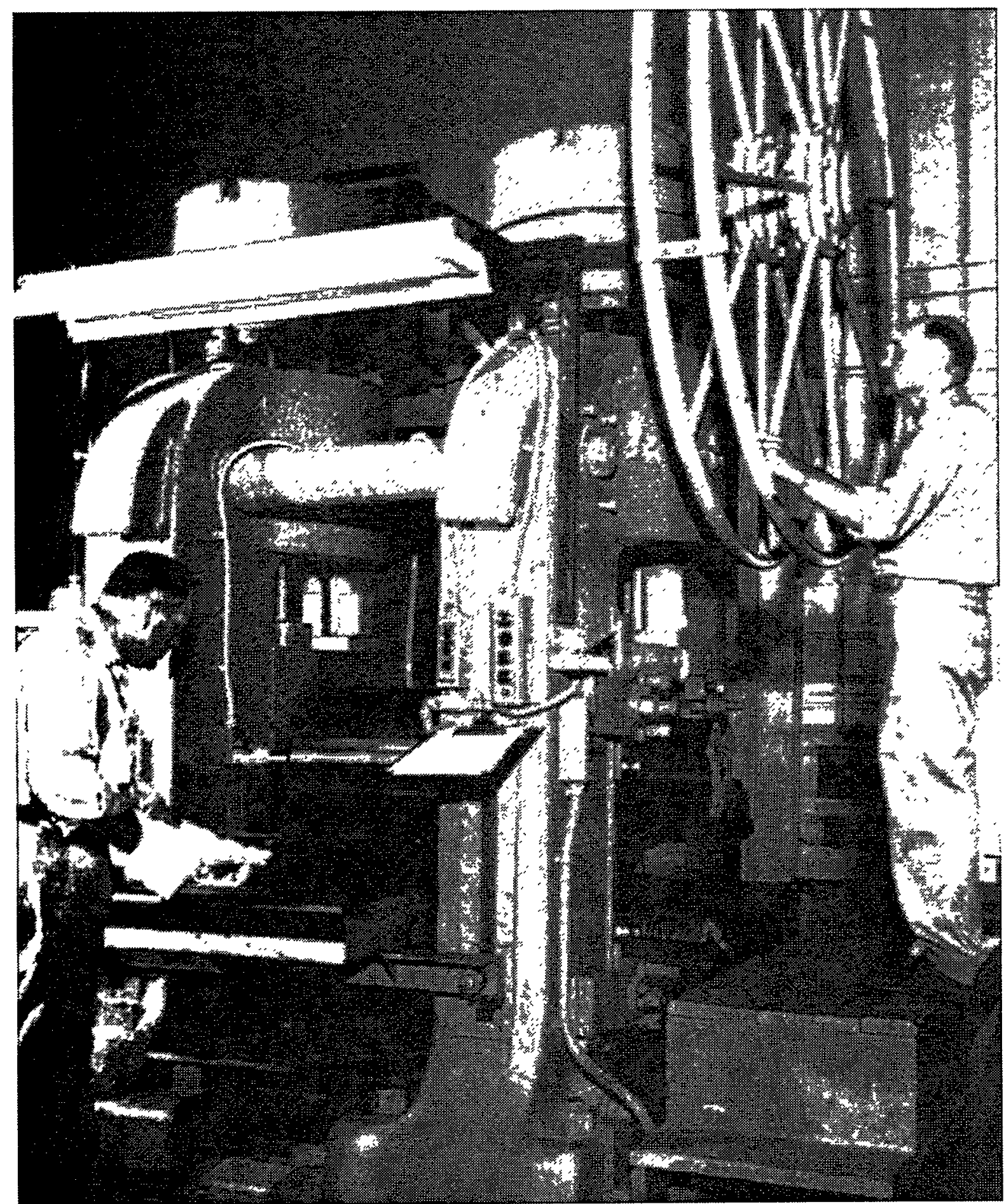

Fig. 2. H. J. Wallace and Ed Turnbill rolling fuel plates in the Rolling Mill (Building 3012). 
$\left(10,300 \mathrm{ft}^{2}\right)$ was added between buildings 2000 and 2001 to provide more office and laboratory space.

\section{the ceramists}

Metals were not the materials of choice for all parts in some nuclear reactor designs. Oxides of beryllium and uranium were studied in early conceptual designs, as in the Aircraft Nuclear Propulsion (ANP) and Gas-Cooled Reactor (GCR) programs. Ceramists joined the Division in about 1950 or 1951 to work with these and other nonmetallic materials.

Originally they were somewhat remotely housed at Y-12 in building 9766, a vintage frame building shared with a machine shop. The ceramists' equipment was located in two large bays, that contained powder conditioning apparatus, presses, gas-fired furnaces, and a large electric furnace supplied with a hydrogen atmosphere.

In 1951-52, building 9766 and subsequently 9204-1 (1954) also housed a metallographic laboratory that filled the needs of division personnel located at Y-12. They also provided the Reactor Chemistry Division with interpretive information for corrosion test capsules and thermal convection loops containing molten fluoride salts for the Molten Salt Reactor experiment. Personnel in the laboratory moved to X-10 in 1960 .

\section{test loop buildings}

The high thermal density of ANP-type reactor designs required rapid heat removal, a role uniquely filled by liquid metals or molten salts. Candidate coolants included $\mathrm{Li}, \mathrm{Na}, \mathrm{K}, \mathrm{NaOH}$, and fluoride salts. Of particular interest was NaK, a eutectic mixture of sodium and potassium, which, along with the other alkali metals, is very pyrophoric.

Compatibility with reactor materials was measured in thermally driven test loops. Building 2005 (about $4000 \mathrm{ft}^{2}$ ), one of many frame structures built to serve the Manhattan Project, was adapted in 1950 to house multiple test loops as well as the Division's earliest equipment for studies of welding, brazing, and nondestructive inspection.

The experimenters performing the loop tests were frequently involuntarily involved in spectacular pyrotechnic displays due to a loop failure or during posttest cleaning of the loop and test coupons. To minimize the chance of injury during loop and coupon cleanup, building $3534\left(450 \mathrm{ft}^{2}\right)$, a small brick building, was built near White Oak Creek and was better equipped to handle this potentially risky step.

\section{mechanical properties testing}

As the scope of mechanical properties measurements was increased, arrange- 
ments were made with the Chemical Technology Division to use the basement of building 3019 (1500 ft') and creep-test stands were installed. Eventually, this work was relocated to building $2011\left(2800 \mathrm{ft}^{2}\right)$, and nondestructive testing (NDT) equipment was moved from building 2005 to the 3019 basement and subsequently, to the yet to be built wing of building 4500 s.

Building 2011, which contained the original steam plant for the $\mathrm{X}-10$ site, was the most unusual second-hand building acquired by the Division. Following construction of a new powerplant, building 2011 was vacated. After the boilers were removed, creep and fatigue machines were set up to observe the effects of liquid metals and liquid salts on metal samples. The effects, if any, of impurities in a helium coolant on candidate High Temperature Gas Cooled Reactor structural materials were also measured. This accommodation was no doubt considered temporary, but lasted 40 years to 1993. The location, just south of the cafeteria, is marked by a $180-\mathrm{ft}$ concrete smoke stack.

\section{new buildings}

Recognition that exposure to the reactor environment causes changes in both physical and mechanical properties of materials and a continuing increase in the number of personnel in the division led to an early restructuring of the Division and the addition of two major new buildings.
In 1951 a portion of the Division's staff left to form the Solid State Division for study of the fundamentals of radiation damage and eventually to occupy building $3025\left(59,000 \mathrm{ft}^{2}\right)$, which contained several hot cells. Effects of radiation on the engineering properties of reactor materials were studied in the then Metallurgy Division.

The High Radiation Level Examination Laboratory, building $3525\left(27,000 \mathrm{ft}^{2}\right)$, was built for this work. Responsibility for the building was shared by the Metallurgy and the Operations divisions. The hot cells in building 3525 were equipped for metallographic examination and measurement of the mechanical properties of irradiated specimens. All operations in the cells were done remotely with master and slave manipulators.

\section{fusion reactor studies}

The Division provided support in 1958 to the Fusion Energy Division to address materials problems associated with fusion reactors. Metallurgy staff members were initially located in building 9204-3 (assigned space was about $550 \mathrm{ft}^{2}$ ), but later relocated to building 9201-2 (about $2900 \mathrm{ft}^{2}$ ).

\section{more new buildings}

Division personnel had increased from about 45 in 1946 to over 200 in 1960. This and the penalty to performing the Division's work of having personnel so widely separated were successfully 
used to persuade Congress to budget funds for a new home for the Division. The new home was provided in two adjacent buildings. One became the westernmost wing of building $4500 \mathrm{~s}$. Its approximately $65,000 \mathrm{ft}^{2}$ is distributed among fairly conventional laboratory and office space on two floors plus more open work space in the basement.

The second was building 4508, which contains approximately $99,000 \mathrm{ft}^{2}$. As designed, virtually the entire building could be operated as a contamination zone. Architecturally, the building can be described as a box since it has no windows, with a single exception. The reasons for choice of a windowless design have been lost with the passage of time, but it provided a more assured secondary containment and reduced construction cost.

\section{fabricating plutonium reactor fuels}

By the 1960s, the need for information in the Fast Breeder Reactor Program on the fabrication and irradiation behavior of plutonium-bearing reactor fuels was recognized. The Interim Plutonium Laboratory (IPL) was assembled on the first floor of building 4508 within the confines of the Ceramics Laboratory. Placement of the IPL within building 4508 was made possible by the building's secondary containment design.

The IPL was equipped with very high quality glove boxes and a purge system which provided a box working atmosphere having very low oxygen and water contents (in the parts per million range). The inert atmosphere was required for work with PuN and UN. The boxes were equipped to synthesis, press, and sinter pellets of these nitrides.

\section{fuel cycle alpha facility}

A companion laboratory, the Fuel Cycle Alpha Facility (FCAF) was assembled for fabrication of $\mathrm{PuO}_{2}$ and $(\mathrm{Pu}, \mathrm{U}) \mathrm{O}_{2}$ fuel pellets and for coating sol gel derived microspheres with pyrolytic carbon. Special target materials for the High Flux Isotope Reactor were also developed and fabricated. This laboratory was initially located in the basement of building 3019 then was moved and enlarged in building 4508 . Two additional and unique fuel-rod-loading techniques, vibratory compaction and slug injection, were also studied in the FCAF.

\section{radon "scares"}

An unusual natural phenomenon occasionally causes complications for personnel working in contamination zones. Workers in these laboratories routinely check their hands and clothing for the presence of radioactivity and shoe covers and clothing are scanned on exiting the laboratories. Air sampling is continuous. Monitoring is done to detect accidental release of activity from a glove box. 
During weather inversions radon, which is a naturally occurring release from the ground, is not dissipated as rapidly as in fair weather. The daughter products of radon decay include additional decay by alpha emission.

Under some conditions, the radioactivity in the air drawn into a building for air conditioning can be sufficient to cause the monitors to alarm. Or the decay-product activity deposited by rain can be track into a laboratory. The laboratory personnel and their health physicist are faced with determining during inversions if there has been a release from a glove box or if its just one of mother nature's pranks.

\section{the division's mission evolves}

The shift of the Division's work away from nuclear reactor systems has nearly eliminated the need for the containment feature of 4508 . However, the internal architecture of the building makes it very compatible with the installation and operation of engineering equipment. The 13-ft ceilings throughout the building plus a multistory high-bay area are particularly helpful in this regard. Building 4508 provided space for relocation of the Ceramics Group from Y-12 in 1961. This move improved communication with the ceramists and gave better recognition of the increasing importance of their contribution to the Division's work. Concurrently, the division was renamed the Metals and Ceramics Division.

A major addition to the Division's housing is building $4515\left(65,000 \mathrm{ft}^{2}\right)$, the High Temperature Materials Laboratory (HTML) built in 1987. It is primarily a concrete structure featuring natural lighting for offices and corridors. The roof contains extensive sky lighting. The laboratory space is fairly conventional, but the equipment in the laboratories is state of the art. Work conducted in the HTML is dedicated to exploiting the high-temperature properties of ceramics to improve the performance and efficiency of heat engines. 
$1946-1960$

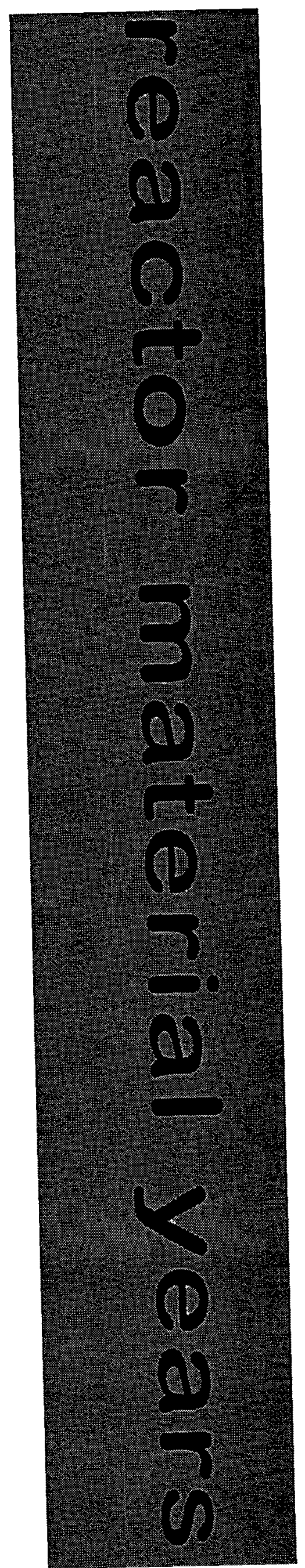




\section{ornl graphite reactor}

\section{background}

During World War II, a national effort of unprecedented magnitude was mounted to ascertain whether fissionable ${ }^{235} \mathrm{U}$ and ${ }^{239} \mathrm{Pu}$ could be produced in the quantity and purity required for use in atomic bombs. This mammoth undertaking was conducted in utmost secrecy under the Manhattan District of the U.S. Army Corps of Engineers.

The ORNL Graphite Reactor, formerly called the Clinton Pile and X-10 Pile, played an important role in early verification of a viable route for the production of plutonium. The major objectives of the reactor and associated separation plant, therefore, were essentially twofold: (1) to demonstrate that a reliable, self-sustaining chain reaction could be established with natural uranium to yield sizable quantities of plutonium by neutron transmutation and (2) to demonstrate the effective chemical separation of the resulting plutonium. The reactor was built in 1943 in less than ten months.

The ORNL Graphite Reactor, the world's second nuclear reactor, was considerably larger than the first selfsustaining, chain-reacting pile erected and operated by Enrico Fermi and his collaborators in Chicago in December 1942. It was conceptually designed by a cooperative effort between a research team at the Metallurgical Laboratory of the University of Chicago and indus- trial engineers from E. I. du Pont de Nemours and Company; construction was performed by the du Pont organization. The reactor was replete with cooling system and control system as well as heavier shields, emergency shut-down capability, and means for manual charging and discharging of fuel.

The reactor had a design-rated thermal power of $1000 \mathrm{~kW}$, a significant scaleup from the $0.2-\mathrm{kW}$ power level of the Chicago Pile. Subsequent improvements in the fuel elements and installation of higher capacity fans allowed the power output to be increased to $4000 \mathrm{~kW}$.

The prototype reactor that evolved was an air-cooled unit fueled with natural uranium metal, moderated with graphite blocks stacked to form a cube, $20 \mathrm{ft}$ on a side. The fuel slugs rested on the bottom of diamond-oriented channels. of 1-3/4-in.-square cross section that extended horizontally through the graphite with sufficient excess space to permit air cooling. Each channel contained up to 52 slugs, and a complete reactor core loading consisted of about 42,000 slugs of unalloyed uranium.

The fuel elements were cylindrical slugs of natural uranium metal, 1.1-in. diameter by 4 in. length, canned in aluminum to protect from oxidation and prevent escape or release of poisonous fission products. 


\section{procuring reactor core materials}

The procurement of highly purified reactor core materials was a critical problem throughout the project. In 1942, the lack of a commercial source for uranium metal delayed somewhat construction of the CP-1 at Chicago and the Clinton Pile. The mining and concentrating of uranium ore, reduction to metal, and the shaping into rod form on a compressed schedule were most challenging and difficult tasks and were successfully accomplished by a host of dedicated people at various firms.

The procurement of graphite was quite different from that of metal because graphite was commercially available in large quantities; hence, the graphite problem resolved to simply upgrading purity and obtaining priority to purchase, both of which were overcome. Following a suggestion made by the National Bureau of Standards, a highly purified graphite with a neutron absorption some $20 \%$ less than that of regular commercial grades was produced in sufficient quantity to meet the demand.

\section{developing the fuel elements}

Severe limitations of unalloyed uranium had to be overcome before it could be used as nuclear fuel. It exhibits poor corrosion resistance, is dimen- sionally unstable when thermally cycled, and swells on neutron bombardment. Some of the difficulties associated with nuclear application arise from the occurrence of uranium in three allotropic forms; namely, the alpha, beta, and gamma phases, each with substantially different crystal structure.

The low symmetry of the orthorhombic system leads to considerable anisotropy in alpha uranium, and heating and cooling cause distortion. Fortunately, heat treatment in the beta temperature range refines the grain size and randomizes the grain structure enough to provide acceptable dimensional stability.

Two types of fuel elements were manufactured for the ORNL Graphite Reactor. The original unbonded slugs were simply canned by inserting a beta-heattreated uranium slug into a deepdrawn aluminum can, placing a cap on the open end, and forcing the assembly through a sizing die to remove the ambient air and to provide a good thermal contact between the uranium and the aluminum. The closure at the cap was welded to ensure leak tightness.

An alternative process was developed to bond the uranium slug to the aluminum protective sheath to improve inreactor performance. The new process was similar to the old except that the uranium slug was dipped into a molten 
bath of aluminum-silicon alloy to form a diffusion barrier at the interface. The coated slug, can, and cap were then assembled while submerged in a second aluminum-silicon alloy bath of eutectic composition to form a thermally conducting bond and tight closure.

In addition, Jack Cunningham devised a similar technique to manufacture aluminum-clad, hollow uranium fuel slugs for exposure of various experiments to fast neutrons and to permit the insertion of instrumentation for reactor control.

The performance of the unbonded and bonded slugs was monitored and analyzed by Charley Cagle, Bob Adams, and Ed Boyle. Generally, the in-reactor behavior of the unbonded slugs was unsatisfactory. Even though only 50 out of 160,000 slugs failed, the consequence was indeed serious. The slugs swelled, blocked the flow of air, and, in some instances, stuck in the coolant channel.

The difficulty encountered in removing ruptured slugs necessitated slugs more resistant to failure. Several investigations sought the nature and cause of failure. Thermal cycling experiments by Bill Pellini, for instance, indicated that about $10 \%$ of the failures were due to improper heat treatment, while Larry Jetter, Robin Williams, and others traced the cause of the remaining failures to either small leaks at the weld closure or diffusion of uranium through the can wall.

Tests made at various temperatures in the regime of interest revealed that at $250^{\circ} \mathrm{C}$ uranium will diffuse through a 30-mil-thick aluminum can wall in approximately 4 days. Similar life tests on bonded slugs showed that the aluminum-silicon alloy diffusion barrier effectively retarded uranium migration. In fact, bonded slugs heated for longer than $1000 \mathrm{~h}$ at $550^{\circ} \mathrm{C}$ showed no sign of interdiffusion. As might be expected, the bonded slugs performed very well and were used for the remaining service life of the reactor.

\section{contributions of the graphite reactor}

Before being retired in November 1963, the reactor made a significant contribution to the advancement of nuclear science and engineering. It was the very first reactor in the world to generate large quantities of thermal energy, in the 1000 - to $4000-\mathrm{kW}$ range, and thus confirmed the conversion of mass into energy on a grand scale. Moreover, it was the first nuclear reactor to demand an elaborate system for removal of heat and thus prevent meltdown of the reactor core materials.

It also provided an early incentive for the establishment of a uranium metal industry in the United States as well as for the production of nuclear-grade graphite. The cylindrical uranium slugs (sheathed in an aluminum container) 
developed for powering the reactor is now known as the "classical fuel element."

During its 20-year life, the reactor was the first nuclear research tool to produce gram quantities of fissionable ${ }^{239} \mathrm{Pu}$, urgently needed for determination of the basic physical and chemical properties of this heavy metal as well as for other scientific investigations. Finally, the reactor served as the primary source of supply of a wide variety of radioisotopes used in the life and physical sciences.
In recognition of these major contributions, it was designated a Registered National Historic Landmark in 1966 under the provisions of the Historic Site Act of 1935 by the U.S. Department of the Interior, National Park Service. It was also declared an ASM National Historic Landmark in 1969 by the American Society for Metals and listed among the most renowned facilities in the world having made unique contributions to the advancement of materials science and technology. 


\section{materials testing reactor and other tank-type reactors}

The main thrust on the atomic bomb project began to abate in 1945, the nuclear community at Clinton Laboratories (now Oak Ridge National Laboratory) turned its attention to harnessing fission energy for the betterment of mankind. The effort quickly revealed a pressing need for a versatile experimental reactor to provide intense sources of radiation for engineering tests to expand our knowledge of reactor technology as well as to enhance fundamental knowledge.

Several conceptual designs led to the Materials Testing Reactor (MTR). This "reactor designer's" reactor was heterogeneous (the fuel not mixed with the coolant), provided a high neutron flux, and was fueled by enriched uranium in a beryllium-reflected reactor, moderated and cooled by light water. The beryllium reflector ring laterally surrounded the core to minimize neutron leakage.

The professional members of the Engineering Materials Section of the Technical Division (forerunner of the Metals and Ceramics Division) were responsible for these reactor components that have found widespread use in tanktype reactors throughout the industrial world.

Individual assemblies of MTR fuel elements (Fig. 3) were positioned as desired on a $5 \times 9$ grid array to form the active core of the reactor. The fuel lattice of 40 by $70 \mathrm{~cm}$ in horizontal cross section was surrounded laterally by a solid beryllium reflector ring approximately $138 \mathrm{~cm}$ in its outside diameter.

The active lattice and reflector, as well as the shim-safety rods and drives, were housed in a cylindrical aluminum tank with a wall thickness of $2.5 \mathrm{~cm}$. All component parts within the tank were removable so that they could be replaced as necessary. They were cooled with ordinary water, which moderated fast neutrons to thermal energy and removed heat generated during reactor operation.

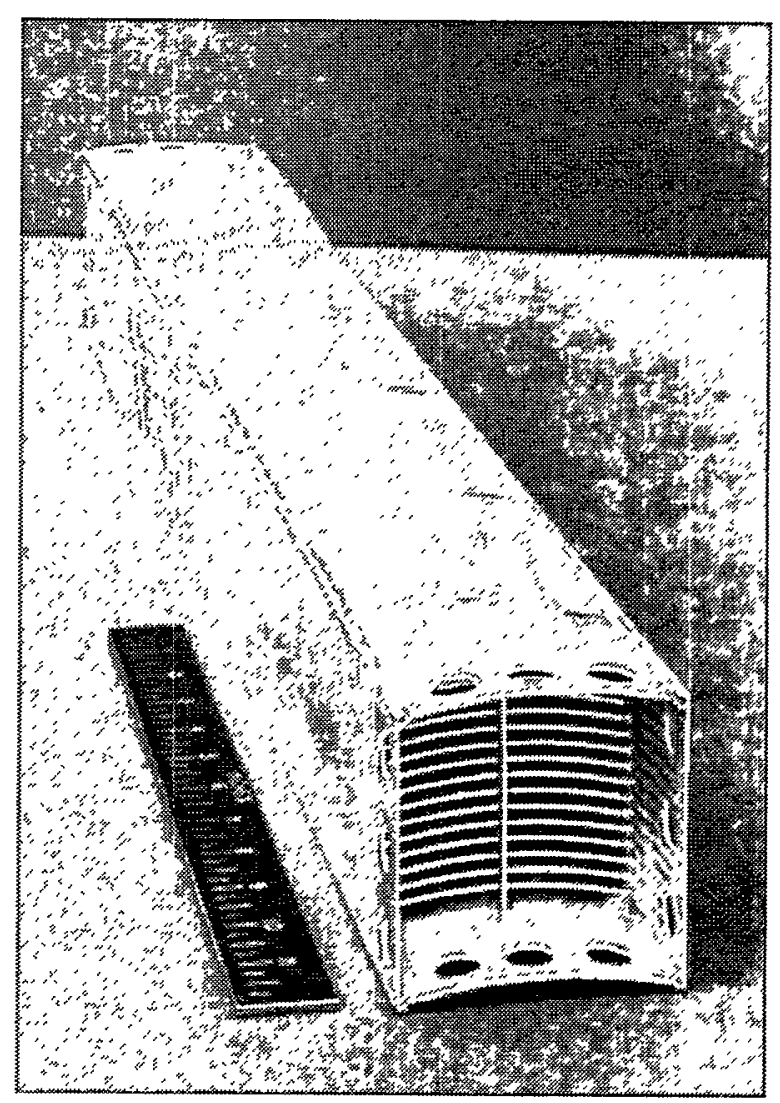

Fig. 3. Brazed MTR fuel element without end fittings. 


\section{fuel technology}

The MTR-type fuel element represented a marked deviation from the classical natural uranium slug or rod in service at the time. It featured the use of highly enriched uranium operating at both high specific fuel power and high specific power density to maximize neutron fluxes for irradiation testing.

The fissile material was incorporated in the form of a uranium-aluminum alloy for several reasons: (1) to disperse the ${ }^{235} \mathrm{U}$ fuel uniformly in a suitable diluent to maximize heat transfer surface area, (2) to maintain dimensional stability under severe neutron bombardment by employing a radiation-resistant alloy, and (3) to further enhance heat removal by use of a diluent and cladding material with good heat-transport properties and the needed chemical compatibility to promote metal-to-metal bonding.

Aluminum was chosen for cladding because of its low neutron absorption cross section, availability, low cost, ease of fabrication, and adequate mechanical and chemical properties. Furthermore, aluminum conducts heat well and possesses the necessary strength to withstand the thermal gradients and attendant stresses encountered in reactor service.

After casting and grain structure refinement by hot working, the resulting wrought alloy was simultaneously framed and clad by roll bonding using the "picture frame" technique so as to hermetically seal the fuel from the cooling water and retain the fission products. An exploded view of the component parts, which made up the composite plate before hot rolling, is shown in Fig. 4. The finished fuel plate, therefore, consisted of a fuelbearing or core section of uraniumaluminum alloy, which was clad on all faces to form a composite plate with a three-ply cross section.

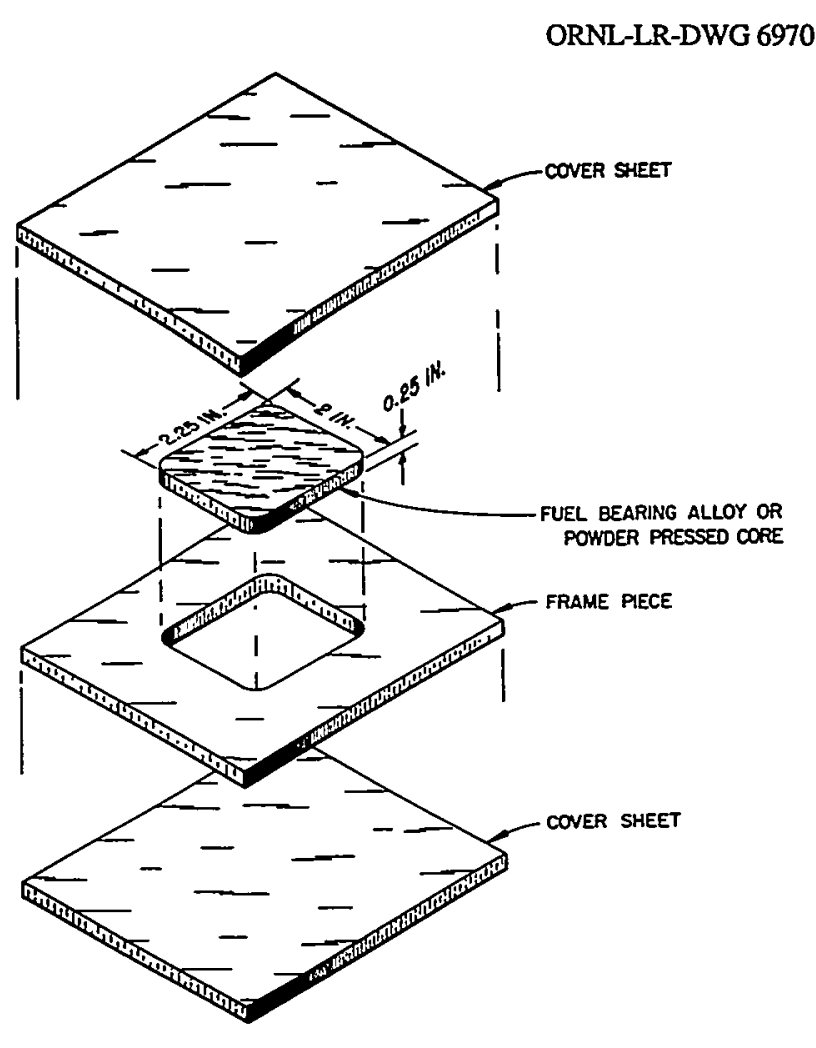

Fig. 4. Exploded view shoing makeup of composite fuel plate before rolling. 
Such composite plates were assembled in parallel array, spaced to allow water to flow freely between them, and brazed into a pair of side or spacer plates to form an integral unit. At the suggestion of Eugene Wigner, then ORNL Research Director, the fuel plates were curved to prevent bowing of adjacent plates in the opposite direction and thus avoid hot spots due to uneven cooling.

The first core loading of MTR-type fuel elements was manufactured and delivered to the Low-Intensity Test Reactor (LITR) in the spring of 1950. The LITR, which in many aspects was a full-scale mockup of the MTR, was constructed in the late 1940s to perform, initially, hydraulic and mechanical tests for verification of design parameters and, subsequently, to conduct planned critical experiments.

The fuel loading consisted of 21 standard elements (each containing $140 \mathrm{~g}$ $\left.{ }^{235} \mathrm{U}\right), 4$ partial elements containing various amounts of enriched fuel, and 3 shim-safety rods with in-line fuel sections for operational control. The metallurgical work was performed under the leadership of C. D. Smith with technical assistance from George Adamson and Fred Drosten. The reactor achieved criticality in 1950 and was subsequently upgraded for higher power operation.

\section{beryllium reflector}

The late selection of beryllium metal for reflector service in the evolution of the
MTR design presented the materials engineers in the Metallurgy Division with an urgent and challenging task. There was, at the same time, essentially no commercial demand for the metal, except for small quantities of beryllium-copper alloy; hence, the capacity of the existing beryllium industry was severely limited. Beryl ore was in rather short supply, and means to reduce this beryllium-bearing ore to metal of the desired purity and size for reflector application did not exist. The situation was exacerbated further by the anisotropic mechanical properties and brittleness associated with the hexagonal crystal structure of beryllium.

Jack Cunningham investigated two approaches to produce the desired beryllium metal: (1) melting and casting followed by extrusion to yield a wrought product and (2) preparation of powder and high-temperature sintering under vacuum to a dense product. Both approaches were pursued with equal vigor.

Attempts to upgrade purity of commercially available, impure pebbles by melting under vacuum were partially successful, but the resulting castings exhibited a rather coarse, columnar grain structure. Extrusion of the best quality cast ingot yielded material that invariably contained internal cracks and a coarse grain structure that gave rise to grain pullout during machining. 
Brush Beryllium Corporation, working under subcontract, scaled up powderprocessing equipment and successfully hot-pressed massive bodies, 14 X 14 X 60 in. The new powder product, designated QMV, was dense and finegrained. Furthermore, it was isotropic compared with extruded stock and could be reproduced from lot to lot reliably.

At this point in the development of the MTR beryllium reflector, the situation had vastly improved. Yet, two problems remained to be solved: (1) the poor resistance of the powder product to corrosion in ordinary water and (2) removal of the sizable quantity of heat generated in large beryllium pieces by neutron absorption and gamma ray bombardment so as to avoid cracking in service because of excessive thermal stress.

James English and Arnie Olsen found that the hydrolysis of beryllium carbide (which is present as an impurity) contributed significantly to corrosion of sintered beryllium powder. The subsequent tightening of specifications to minimize the presence of carbon (as well as neutron-absorbing elements like boron and iron) ultimately resulted in purer sintered powder with improved corrosion resistance.

The switch from ordinary to demineralized water for cooling the reactor gave an added margin of safety. The problem of heat removal from the large reflector blocks was solved when Jack Cunningham developed a modified rifle drilling technique to produce $3 / 16$-in.diam coolant channels with the required straightness.

The significance of this development is apparent when one considers that the requirement on length-to-diameter ratio for the MTR reflector coolant holes was considerably more stringent than that in the production of small-bore rifle arms. Furthermore, this was the first time that holes of this nature had been drilled in a refractory metal like beryllium. Needless to say, these metallurgical developments paved the way so that the MTR reflector could be manufactured from the new, nuclear-grade, QMV beryllium powder product.

The large beryllium pieces for the MTR reflector were produced at Brush Beryllium Corporation and machined at the Y-12 plant. Over 100 vertical, horizontal, and diagonal experimental holes were provided in the beryllium reflector for irradiation testing of material samples and reactor components.

\section{mtr fuel production, research, and development}

When the MTR began full-power operation in May 1952, 23 fuel assemblies and 4 fuel-shim rods, prepared under the technical guidance of Jack Cunningham and Richard Beaver, were loaded in a 3 by 9 configuration. 
Each fuel assembly contained $140 \mathrm{~g}^{235} \mathrm{U}$, and each fuel section of the shim rods contained $110 \mathrm{~g}{ }^{235} \mathrm{U}$, giving a total of $3.66 \mathrm{~kg}^{235} \mathrm{U}$ in the active core.

This loading operated at 30-MW rated thermal power until it automatically shut down because of reactivity losses due to fuel depletion and buildup of fission-product poisons.

Over the next two years, several modifications were made to gain excess reactivity to compensate for the rising load of experiments inserted and to extend fuel life: (1) an increase in the ${ }^{235} \mathrm{U}$ content, (2) thinner fuel and side or spacer plates, (3) use of duplex-clad plate containing $12 \%$ silicon-aluminum braze alloy on one side to place the brazing alloy exactly where needed to minimize entrapment of brazing flux as well as to obtain sound joints, and (4) switch from sand casting to permanent mold casting to reduce final machining cost.

These alterations were made one at a time with in-reactor testing of a fullsize element embodying each change to verify performance before use in a full core loading.

Increasing the fissile content in the fuel assembly from 140 to $168 \mathrm{~g}$, with a corresponding $20 \%$ fuel increase in the shim rods, increased total energy output from the core loading to 740 from $376 \mathrm{MWd}$.
In May 1954, the fissile content of an individual assembiy was revised to obtain more efficient performance. These changes greatly reduced the number of new fuel assemblies required and correspondingly reduced the number of new fuel assemblies that had to be chemically processed to recover the remaining ${ }^{235} \mathrm{U}$.

In the fall of 1954, an increase in fission product activity was detected in the cooling water, the source of which was traced to blemishes and a few minor breaks in the cladding of the outside fuel-bearing plates. The fault was corrected by a small adjustment in the dimensions of the end-box castings to prevent minor buckling. Thereafter, the MTR operated without difficulty.

The initial and subsequent loadings for powering the MTR, as well as the components for operational control, were manufactured at ORNL.

\section{engineering test reactor and related tank reactors}

The fuel and control components for the Engineering Test Reactor (ETR), located at the National Reactor Test Station (NRTS) in Idaho, are products of materials research in the Metals and Ceramics Division. Like its MTR sister, the ETR is a light-water moderated and 
cooled reactor with a beryllium reflector. It provides a large volume of inreactor test space.

Numerous fuel loadings for other tanktype reactors have been manufactured at ORNL, including the fuel rods for the CP-3 reactor and the fuel plates and the concentric fuel tubes for the CP-5 at Argonne National Laboratory, the plate-type fuel elements for the 5-MW Omega West Reactor at Los Alamos, and the plate-type fuel assemblies for the 1-MW Brookhaven Medical Research Reactor.

In addition, the Division manufactured seven special loadings to investigate stability in boiling water reactors (BORAX 1 and 2) and various loadings to study power transients in special power excursion reactor tests (SPERT-1 and -2). Finally, special materials were encapsulated for production of transplutonium elements in the MTR for basic research.

\section{epilogue}

There are many reasons why the MTR project was perhaps the most significant nuclear technological development of the past 50 years. First, the prototype reactor with many ingenious features was conceived, designed, constructed, and placed in full operation in less than seven years. Second, more than any other test unit, the MTR contributed mightily to the establishment of the engineering base that underpined our heavy commitment in the nuclear industry to light water reactors for power generation. Third, it served the Army and Navy exceptionally well in their utilization of nuclear science and engineering. And finally, it contributed greatly to the advancement of not only nuclear technology but also to the advancement of many branches of science, including the production of radioisotopes for research in the various fields of life science. 


\section{aircraft nuclear propulsion-aircraft reactor test}

nuclear propulsion for aircraft

Early in the development of nuclear energy, the military recognized that nuclear propulsion could enable an aircraft to stay aloft for long missions without refueling. Therefore the Manhattan Project contracted with the NEPA division of Fairchild Engine and Aircraft Corporation for a study "Nuclear Energy for the Propulsion of Aircraft (NEPA)" as a contractor of the Air Force.

In 1949 the Atomic Energy Commission designated ORNL to represent it in a program involving other government agencies and various industrial concerns to develop nuclear aircraft, succeeding NEPA. General Electric was selected to develop a direct cycle system, and the Pratt and Whitney Aircraft Corporation (P\&W) was selected to pursue an indirect cycle system, in which a liquid metal carried the reactor heat to the propulsion machinery.

ORNL's major materials contributions were to the latter system. Examples of early work were determining suitable materials for the containment of heat transfer agents, developing high-temperature fuel elements, and conducting neutron physics and shielding studies.

\section{aircraft reactor experiment}

Because of the high power density that an ANP reactor would have to produce,
ORNL felt that a liquid-fueled or liquidmoderated reactor with a negative temperature coefficient of reactivity should be pursued. Extensive corrosion studies showed that liquid moderators, i.e., $\mathrm{NaOH}$ or LiOH or hydrides, could not be used and that liquid fuels, uranium dissolved in $\mathrm{Pb}$ or $\mathrm{Bi}$, or slurry fuels also were ruled out because of corrosion and mass transfer. Therefore, development work was concentrated on fused-salt mixtures containing uranium.

From 1952 to 1957 , there was close cooperation between ORNL, ANP, and $P \& W$ personnel. A large contingent of P\&W employees were on loan to ORNL and assigned to various activities from design, physics, shielding, engineering, chemistry, and metallurgy.

This combined effort led to the Aircraft Reactor Experiment (ARE), which was a circulating fused-salt reactor, contained in Inconel, moderated with $\mathrm{BeO}$, and cooled by sodium. The fuel and moderator coolant transferred the energy to helium and the helium dumped the energy to water (Fig. 5).

The ARE went critical on November 3, 1954, at 3:45 p.m., and was carefully shut down at 8:04 p.m. on November 12, 1954, by Major General Donald J. Keirn, U.S. Air Force, Chief Aircraft Propulsion Officer, AEC, Washington, D.C. During the ARE's run, reactor kinetics were studied at various power levels, and the reactor was cycled 21 times from low power to full power of $2.5 \mathrm{MW}$. 


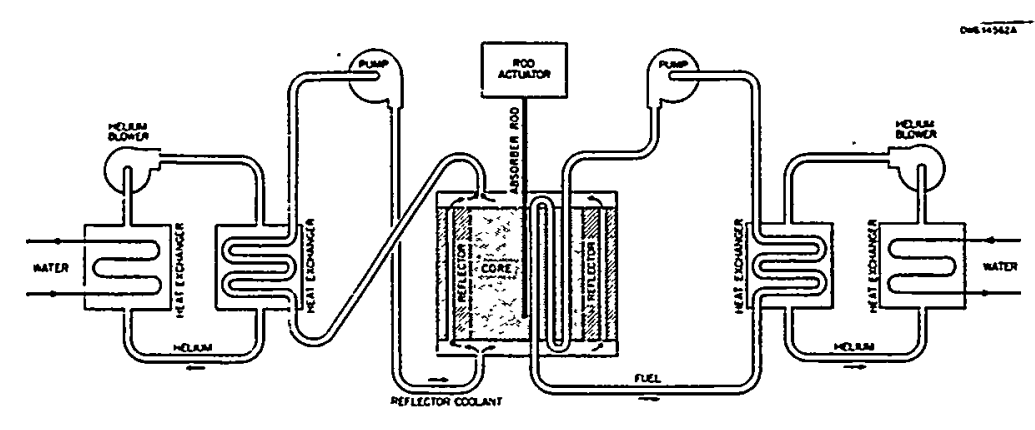

Fig. 5. Schematic diagram of the Aircraft Reactor Experiment.

\section{aircraft reactor test}

The efforts of the combined P\&W and ORNL team then centered on a more realistic reactor for an aircraft. These studies led to the Aircraft Reactor Test (ART). The ART was designed to be a high-power-density, circulating fusedsalt reactor with a beryllium moderator and reflector, fabricated from Inconel with an intermediate heat exchanger transferring energy to $\mathrm{NaK}$ and then disposing of the energy through high-performance radiators to air.

This reactor was to be the culmination of years of corrosion testing, both static and dynamic, through capsule tests, thermal convection loops, and pump loops, with and without neutron flux, and designing, building, and testing all types of hardware including pumps, valves, heat exchangers, duplex-metal heat exchangers and radiators, and radiators with highconductivity fins for increased heat transfer. The ANP-supported work on circulating fuel reactors was suspended in September 1957. The ART was never built, but much of the hardware was procured, including the largest single piece of beryllium fabricated up to that time, heat exchangers, and a spunfabricated Inconel container for the beryllium island. Much of the engineering and materials knowledge gained was later used on the Molten Salt Reactor Experiment (MSRE).

\section{metallurgy's role in the anp}

From September 1957 until the ORNLANP Program was terminated on June 30, 1961, research at ORNL centered on shielding, materials, radiation damage, and experimental investigations of systems and components for nuclear propulsion power plants. The ANP at ORNL was the biggest manpower research and development effort in ORNL's history, employing more than 5000 man-years of effort from October 1949 to June 1961. 
The Metallurgy Division (now Metals and Ceramics) had an extensive role in the ANP under the direction of William D. Manly at ORNL, and the following laboratories were built and staffed during this period: Welding and Brazing, High-Temperature Reactions, Nondestructive Testing, Powder Metallurgy (later called Fabrication), General Corrosion, Dynamic Corrosion, and Mechanical Properties. In addition to the laboratories, metallurgists were assigned to the design, experimental engineering, and procurement functions of the program.

The Welding and Brazing Group (Peter Patriarca and Gerald Slaughter) developed novel tube-and-header welding techniques for heat exchangers. It also developed brazing alloys and placement methods to back-braze tubeto-header joints and braze high-conductivity fins to tubes for radiators. Proper techniques for heavy-section welding of nickel-base alloys and stainless steels were another achievement.

The Nondestructive Testing Group (Robert Oliver and Robert McClung) developed ultrasonic, eddy current, $x$ ray, and dye penetrant inspection methods for materials as varied as 4in.-thick nickel-base alloy plates to thin-walled (0.015-in.), small-diameter tubing for heat exchangers and radiators.

The Mechanical Properties Laboratory (Robert Oliver and Donald Douglas) determined the effects of various environments; i.e., air, helium, vacuum liquid metals, and fused salts; on the creep and rupture strength of materials; it also looked at complex stress field effects on mechanical properties. Early work started on effects of irradiation on creep and stress rupture properties of alloys, and also design stress loads were developed for the reactor designers.

The Fabrication Group (Sloan Bomar and John Coobs) found the proper combination of materials for control rods, pump seals, and valve seats. It developed the high-conductivity radiator fins and coordinated all the activities that led to new alloys.

\section{early metallurgical work}

The first metallurgical work on the ANP Program at ORNL was basic compatibility studies of construction materials with various high-performance heat transfer agents such as $\mathrm{Li}, \mathrm{Na}, \mathrm{NaK}$, and $\mathrm{Pb}$ followed by $\mathrm{NaOH}$. The Division developed purification and handling techniques for the coolants. The early ANP materials program was directed by Ed Miller. He was followed in 1951 by Bill Manly. Early key investigators in the corrosion area were George Adamson, Antoin Brasunas, Gene Hoffman, and Pedro Smith.

As the program progressed, the corrosion testing evolved from static cap- 
sules, through thermal convection loops, to full-scale pump loops with heat exchangers and radiators. As a result of this work, the compatibility of materials for these heat transfer agents was catalogued, and interesting phenomena, such as isothermal dissimilarmetal transfer and temperature-gradient mass transfer, were experienced and studied.

\section{corrosion studies}

The corrosion studies (Gene Hoffman and Jack DeVan) with fused fluoride salts led to understanding the basic mechanism of corrosion, which was the selective leaching of chromium from the solid-solution Inconel alloy. The Inconel specimens showed subsurface voids not connected to the surface, which were formed by the collection of vacancies. This led to the careful removal of impurities from the fused-salt bath to study the reaction.

\section{development of inor-8}

As a result of these studies, an alloy development program, under Henry Inouye, was undertaken that led to INOR-8 (composition Ni, bal.; Mo, 17; Cr, 5; C, 0.06), which had chromium sufficient to form an adherent spinel oxide film but low enough to minimize chromium removal in the fused salts, and sufficient molybdenum to provide good strength.

The residual elements $\mathrm{Mn}, \mathrm{Si}$, and $\mathrm{Al}$ were controlled for fabricability and weldability. INOR-8 development was a team effort of corrosion, fabrication, welding, and alloy development personnel at ORNL with assistance from metallurgists and alloy developers from the International Nickel Company.

\section{metallurgical engineering}

In looking back at the ANP from a metallurgical engineering standpoint, it was a very exciting time with very interesting challenges in the field of corrosion - liquid metal, fused salt, and oxidation; alloy development; powder metallurgy; unique fabrication including welding and brazing; and nondestructive testing. All these specialties provided information that led to the design, procurement, and final inspection of many uniquely designed, complex pieces of reactor hardware. The personnel of the Metallurgy Division were up to the challenge.

\section{flow of knowledge}

One of the more interesting aspects of the ANP was the extent of interplay that developed among the designers; heat transfer, fluid flow, and structural engineers; and the various materials specialists. An example of this interaction was the design, construction, and testing of thin-walled, small-diameter heat exchangers - the tubes failed at the tube-to-header joint. Careful study determined that the drag coefficient of the liquid on the tube, coupled with 
temperature fluctuations, developed a cyclic load on the joint. Back-brazing this joint produced a much stronger, load-bearing joint that solved the problem. Another example was to develop an efficient liquid-metal-to-air radiator incorporating a high-thermal-conductivity fin. This was accomplished by cladding OFHC copper with stainless steel with a diffusion barrier between the copper and stainless steel. This fin was then brazed to the Inconel tubes.

\section{impacts of anp program}

With the startup of various laboratories, each functional laboratory had at least two missions: One was to apply its expertise to the various problems faced by Laboratory projects, and the second was to conceive and conduct applied research within its specialty. This mixture led to the growth and excellence of the technical staff.

As a result of all the interplay with designers and experimental engineering groups, the materials effort was appre- ciated and used by project personnel. As a result of working with the many disciplines on the ANP, metallurgists were accepted as full team players.

The corrosion studies, alloy development for containing fused salts, as well as component development of pumps, valves, and heat exchangers, were used in the Molten Salt Reactor Program for the MSRE, which is the subject of another article in this document. The extensive compatibility studies in the ANP and MSR programs from 1952 to 1972 on a large number of refractory alloy-liquid metal combinations were the basis of the SNAP-50 Program, which used lithium as the heat transfer agent contained in $\mathrm{Nb}-1 \% \mathrm{Zr}$ alloy, and they are presently being utilized in the development of advanced nuclearpowered systems for future U.S. space missions.

The subassembly, design, construction, and test procedures for complicated hardware developed on the ANP Project were used in later reactor projects. 


\section{homogeneous reactor project}

Participation in the Homogeneous Reactor Project (HRP) by the Metals and Ceramics (M\&C) Division started as a small effort under Ed Miller. He directed the materials program from 1951 to 1955 and was followed by George Adamson from 1955 to 1960. The purpose was to furnish materials support to the reactor designers and engineers in developing and fabricating homogeneous reactor systems. (A homogeneous reactor is one in which the fuel is in the coolant.)

The HRP was a major ORNL program originally directed by John Swartout, who was followed by Beecher Briggs in 1956. The HRP was aimed at developing a power reactor fueled by a circulating aqueous solution of uranyl sulphate $\left(\mathrm{UO}_{2} \mathrm{SO}_{4}\right)$. With the addition of a thorium oxide slurry as a blanket, it possessed the potential of becoming a breeder reactor.

As might be expected in such systems, corrosion and fuel solution stability were the major problems. The primary responsibility for each was assigned to established groups in the Reactor Experimental Engineering Division located at the Y 12 facility.

The HRP was divided into three phases:

- A small, low-power reactor, Homogenous Reactor Experiment (HRE), to demonstrate overall feasibility and solution stability.

- A moderate size, two-region reactor, the Homogeneous Reactor Test
(HRT), to demonstrate engineering feasibility and operating performance

- An intermediate size, power breeder prototype.

The program in M\&C was a projecttype organization incorporating, at various times, engineers experienced in metal fabrication, welding, inspection, physical metallurgy, alloy development, and mechanical properties. It varied in size from three to ten technical personnel functioning originally in a single group and ultimately in two groups, research under Marion Pickelsimer and engineering assistance under Sloan Bomar.

The HRE operated successfully for two years in the early 1950 s as a tworegion reactor with a light water solution of $\mathrm{UO}_{2} \mathrm{SO}_{4}$ as the fuel and heavy water as the blanket. It consisted of an 18-in.-diam, type 347' stainless steel, spherical core vessel surrounded by an A-105 steel pressure vessel.

The design pressure was 1000 psi, with an operating temperature of $250^{\circ} \mathrm{C}$, and it operated for $1950 \mathrm{~h}$ while critical and $720 \mathrm{~h}$ at powers of $100 \mathrm{~kW}$ or more. The cost of constructing the reactor system was only slightly more than $\$ 1$ million plus fuel and heavy water. Metallurgical efforts were limited to providing advice to the designers and fabricators.

The second phase of the program, involving the building and operation of 


\section{4}

the HRT, was the heart of this program. The HRT was a $5000-\mathrm{kW}$, two-region reactor with a 1/4-in.-thick, 32-in.diam Zircaloy-2 (a Zirconium alloy) core vessel and an SA-212 pressure vessel, $5 \mathrm{ft}$ in diameter, internally clad with stainless steel. A solution of $\mathrm{UO}_{2} \mathrm{SO}_{4}$ in heavy water circulated through the core, and heavy water circulated in the blanket or reflector region. Its design operating conditions were $300^{\circ} \mathrm{C}$, a pressure of $2000 \mathrm{psi}$, and a power density of 17 $\mathrm{kW} / \mathrm{L}$.

\section{Glen Elder and Ed} Miller of the M\&C Division played a major role in developing and implementing fabrication techniques for both vessels. The commercial fabricator was Newport News Shipbuilding and Drydock Company of Newport News, Virginia (Fig. 6).

Unusual fabrication practice for the pressure vessel involved forming the hemispherical heads and welding the girth closure, of necessity from the outside. For the core tank, the unique accomplishment was fabricating large plates and forming and welding them to form the Zircaloy vessel.

At the time this work was done, the technology of zirconium was limited to fabrication, largely in dry boxes, of plate and tubular fuel elements. Techniques were needed for both straight and cross rolling in air to obtain plates large enough to form the core tank. The tank was assembled by welding 15 preformed plates and tubes and then light machining to finished size.

Even with this active metal, welding techniques were developed for making all welds in air by a consumable insert root pass with helium-filled trailering shields on the torch to protect the Zircaloy from oxidation. A specific trailer was for the Homogeneous Reactor Test. made for each joint configuration. Achieving the necessary welding reproducibility and tolerances required developing and qualifying special Heliarc welding procedures with consumable root inserts for use in assembling the reactor stainless steel piping 
system. This was accomplished by a joint effort of the M\&C Division and the Plant and Equipment (P\&E) Division.

As the HRT approached startup, the M\&C program grew and changed to developing new materials aimed at the more demanding large reactors. These material studies were primarily of the fabrication and properties of titanium and zirconium alloys. A major program under Marion Picklesimer worked on the morphology, transformation kinetics, mechanical properties, and fabrication of new zirconium alloys. The result was a family of zirconium alloys with 15 to $30 \% \mathrm{Nb}$ and minor other additions.

These alloys showed both improved mechanical properties and corrosion resistance over Zircaloy-2.

The HRT was operated at low powers for about $500 \mathrm{~h}$ early in 1958; the power was then raised in $1000-\mathrm{kW}$ steps to the design level of $5000 \mathrm{~kW}$. Shortly after design power was reached, a 2-in. hole developed in the lower diffuser portion of the core tank. Also some of the diffuser screens had come loose from the vessel.

The M\&C Division played a major role in examining and analyzing the condition of the core vessel. The high radiation levels restricted access to a 2-in. opening under a pool of water. Periscopes built by the P\&E and Instrument and Controls Divisions were used to examine the inside of the vessel, revealing the hole and the loose screens.

Clarence Wodtke and Plant and Equipment personnel developed a miniature Heliarc cutting torch that entered the core and cut all the diffuser screens into strips of a size that could be removed and also cut samples from around the tank failure.

Using his knowledge of the morphology of zirconium alloys, Pickelsimer examined samples in a hot cell and established that failure of both the screens and vessel was the result of melting. $\mathrm{He}$ also established, by determining temperature profiles, that the incidents of melting were of short duration. The hot spots had been caused by high heat generation in uranyl sulfate, which had separated from the fuel solution onto metal surfaces in regions of flow perturbations.

After the cause of the core vessel failure was determined and the damaged screens were removed, a cover plate was bolted over the hole to retard mixing of the core and blanket solutions. Operation was resumed with some uranium in the blanket. It continued until the HRP was terminated in 1960. 

$1950-1975$
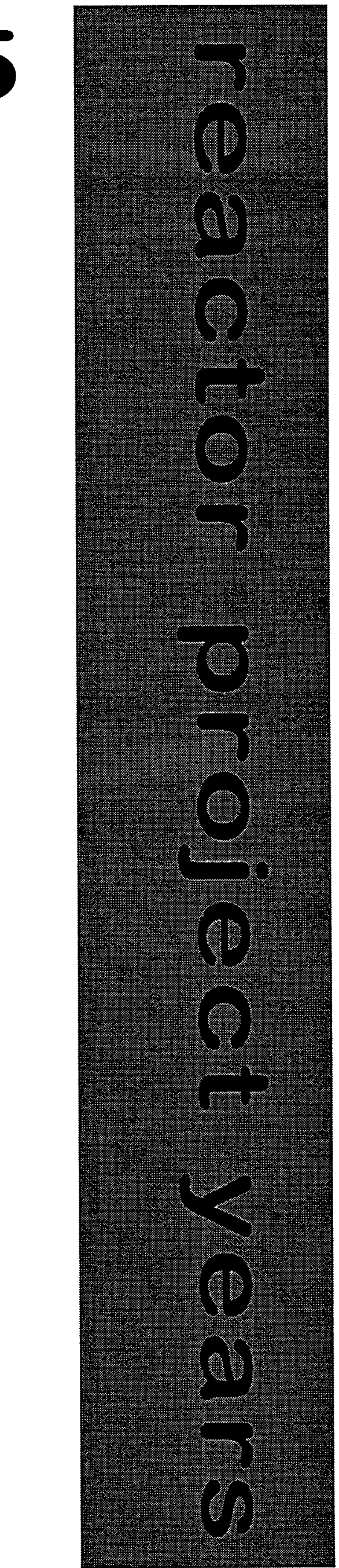


\section{the army package power reactor program}

In 1954, ORNL was assigned responsibility to assist the Atomic Energy Commission (AEC) in the Army Package Power Reactor (APPR) Program. The U.S. Army was interested in supplying nuclear electrical power to remote locations. A major requirement was to keep the power unit small and the parts sufficiently compact to be readily packaged and transported to the remote locations (thus, the program title).

This required the use of uranium highly enriched in the ${ }^{235} \mathrm{U}$ isotope to achieve a high power density. A detailed conceptual design by ORNL, for the first time, considered a dispersion of highly enriched $\mathrm{UO}_{2}$ and a burnable poison in stainless steel for a power reactor. The architect-engineer (ALCO Products, Schenectady, New York), designed the reactor generally following the ORNL conceptual design.

The AEC assigned ORNL as a consultant to help establish the final design, as well as to develop and manufacture the 45 fuel elements and 7 neutron absorbers required for the 10-MW training reactor (APPR-1) at Fort Belvoir, Virginia.

Al Boch was the ORNL Director of the APPR Program, Jack Cunningham was the M\&C Division Program Manager, and Richard Beaver was the Project Leader of fuel element and neutron absorber development and manufacturing. The fuel element consisted of 18 thin austenitic stainless steel plates spaced 0.133 in. apart and metallurgically joined to thin austenitic stainless steel side plates.

The refractory compound $\mathrm{UO}_{2}$ was selected because it is chemically inert in contact with austenitic stainless steel, exhibits good resistance to $232^{\circ} \mathrm{C}$ pressurized water, is relatively insensitive to radiation damage, and retains fission gas well.

Boron was selected as the burnable poison because its nuclear burnout characteristics closely match those of the fuel; $\mathrm{B}_{4} \mathrm{C}$ was selected because of its availability and prior experience with it dispersed in stainless steel. However, tests of such dispersions revealed incompatibility when heat treated above $150^{\circ} \mathrm{C}$. Other compounds, including boron nitride and zirconium diboride, were found unacceptable. Restricting fuel element manufacturing temperatures to below $1150^{\circ} \mathrm{C}$ solved the problem.

By July 30, 1956, except for the $\mathrm{Eu}_{2} \mathrm{O}_{3}$ neutron absorbers, manufacture of the first core loading was completed (38 stationary fuel elements, 7 control rod fuel elements, and $7 \mathrm{Be}-\mathrm{Fe}$ neutron absorbers). Along with the additional $\mathrm{Eu}_{2} \mathrm{O}_{3}$ neutron absorbers, they were shipped in December 1956, five months ahead of the original intended schedule. More than 1200 fuel plates were manufactured with negligible rejections. No fuel elements or neutron absorbers were rejected. APPR-1 
achieved full-power operation in April 1957. As a conclusion to the program, detailed specifications were prepared to enable procurement of the $\mathrm{UO}_{2}$-stainless steel fuel elements and the $\mathrm{Eu}_{2} \mathrm{O}_{3}$ neutron absorbers. These were used to procure the core loading for the package reactor at Fort Greeley, Alaska.

The ORNL program and the M\&C Division project established that the platetype fuel elements (using a dispersion of $\mathrm{UO}_{2}$ in stainless steel) and neutron absorbers (using a dispersion of $\mathrm{Eu}_{2} \mathrm{O}_{3}$ in stainless steel) can be produced on a commercial scale and made useful for small, compact reactors that need to achieve a high power density.

The M\&C Division received a personal commendation from Alvin Weinberg, Director of ORNL, for its achievements on the APPR Program. 


\section{geneva conference
display reactor}

\section{introduction}

The U.S. research reactor exhibited in operation at the first International Conference on Peaceful Uses of Atomic Energy won undisputed honors as the Best Display at the conference, which was held from August 8 to 20, 1955. As a consequence, this greatly enhanced the prestige of the Nation and the Laboratory in nuclear science and engineering.

In early 1955, when the Atomic Energy Commission (AEC) requested ideas for display of recent advances in nuclear science and technology at Geneva, the Laboratory was preoccupied with the preparation of a host of technical papers for presentation. In response, however, many display ideas came forth from Laboratory personnel, including the suggestion by Tom Cole that the Laboratory display a full-scale operating research reactor.

In a short span of about four months, a research reactor of the "swimming pool" variety was designed, constructed, and tested by ORNL personnel. Meanwhile, work had been started on a special building in Geneva, Switzerland, to house the reactor and associated display panels, and by June 7,1955 , it was completed.

The disassembled reactor was packaged and shipped by air freight to Geneva, where it was reassembled and tested before the official opening on
August 8. President Eisenhower was among the tens of thousands of visitors who observed the characteristic blue glow, known as the Cerenkov effect, caused by the slowing down of highenergy radiation in water with the release of some energy as visible light. Upon seeing this dramatic demonstration of conversion of mass into energy, Mrs. Enrico Fermi called the

U.S. display "the prettiest reactor ever built."

\section{project completed}

Despite the problems encountered in the manufacture of partially enriched ${ }^{235} \mathrm{U}$ fuel components, the project was completed on schedule and thus permitted successful demonstration of an operating research reactor at the first Geneva Conference.

\section{far-reaching benefits}

The Division and ORNL saw many benefits that accrued to mankind, in general, as well as to the

\section{U.S. Government.}

- The display of a partially enriched ${ }^{235} \mathrm{U}$ pool reactor with associated technical panels served as an excellent vehicle for technology transfer in such diverse fields as education in nuclear science, reactor design, research in nuclear engineering, study of radiation effects, production of radioisotopes, activation analysis, neutron therapy, biomedi- 
cal research, radiation detection, and protection of personnel.

- The display focused on promoting peaceful uses of atomic energy in keeping with the spirit of the conference as well as in accord with the U.S. offer to assist other free nations in obtaining similar research reactors by contributing one-half the cost and furnishing the partially enriched uranium fuel required.

- Compliance with the nonproliferation policy of the government to limit enriched uranium for export to a non-weapons grade containing less than $20 \%$ enrichment in ${ }^{235} \mathrm{U}$. 


\section{thorium metallurgy}

During the period of optimism regarding the development and application of nuclear reactors, there was much interest in the potential of thermal reactors using ${ }^{233} \mathrm{U}$ as the fuel. Many of the concepts were based on breeding or conversion using ${ }^{232} \mathrm{Th}$ as the fertile material.

Two reactor experiments initially using solid ${ }^{235} \mathrm{U}$ fuel and thorium as the fertile material for conversion to ${ }^{233} \mathrm{U}$ and two experiments using fluid fuels were planned in the late 1950 s. The CETR (Consolidated Edison Pressurized Water - Thorium Convertor Power Reactor) was designed by Consolidated Edison of New York and scheduled to become operational by 1960 . This reactor would have used a uranium-zirconium alloy fuel and thorium metal clad in zirconium as the fertile material. The SGR (Sodium-Cooled, Graphite-Moderated Power Reactor) was designed by Atomics International to use uranium- thorium alloy fuel and thorium metal as the fertile material.

Because of this potential of using thorium in the fuel or as the fertile component, the Atomic Energy Commission sponsored a large program to develop the metallurgy of thorium in the period 1949 to 1956 . By 1956, the basic physical metallurgy of thorium and a limited number of its alloys had been established at ORNL.

During this period, the Division of Physical Research of the Atomic Energy Commission supported research in the Metallurgy Division of ORNL at a level of one to five persons per year. The work included studies on preferred orientation and anisotropy of mechanical properties, mechanical properties of thorium alloys at room and elevated temperatures, recrystallization studies, fabrication and cladding studies, and limited alloy development. 


\section{fusion materials program}

In the fusion reaction, nuclei of light elements, such as isotopes of hydrogen, combine to form heavier elements and, in the process, release large amounts of energy in the form of energetic particles whose kinetic energy can be converted to heat. The fusion reaction that is easiest to attain is that of the two hydrogen isotopes, deuterium and tritium. This reaction produces

17.6 MeV carried by a 3.5-MeV alpha particle and a $14.1-\mathrm{MeV}$ neutron.

For this reaction to occur at sufficiently high rates to produce useful energy, a mixture of deuterium and tritium gas must be heated to temperatures in excess of $150 \times 10^{6 \circ} \mathrm{C}$. At this temperature the deuterium and tritium atoms are ionized, forming a plasma consisting of the atomic nuclei and electrons.

The plasma is confined by magnetic fields within a vacuum chamber. Deuterium is readily available in nature. Tritium, however, is an unstable isotope of hydrogen, having a half-life of only 12 years, and is thus not naturally occurring. In a fusion reactor tritium will be produced by capturing the fusion neutrons in lithium.

The International Thermonuclear Experimental Reactor (ITER) is planned for operation shortly after the turn of the century. The basic components of a magnetically confined fusion reactor core, progressing outward from the plasma are the first wall of the vacuum chamber and the divertor. The divertor serves to remove helium "ash" from the plasma.

About $20 \%$ of the energy of the fusion reaction, the energy carried in the alpha particle, must be removed as a heat flux through the surface of the first wall and divertor. The blanket structure has two primary functions: recovery of the $14.1-\mathrm{MeV}$ energy contained in the neutron and containment of the tritium breeder for producing tritium.

The blanket and shield together serve to reduce neutron and gamma radiation levels at the toroidal field (TF) magnets and beyond. The TF magnets produce the magnetic fields which contain the plasma. For reasons of efficiency, the TF coil will be superconducting. Beyond the fusion core is a system for converting the heat of the fusion reaction into electricity or for use as process heat.

\section{beginnings of the fusion program}

The U.S. Fusion Program had its beginning in the early 1950s. According to recollections of Bill Manly, the Oak Ridge National Laboratory Metals and Ceramics (M\&C) Division and its predecessor, the Metallurgy Division, first became involved in fusion in 1956 when a meeting was held at the Atomic Energy Commission in Washington, D.C., to consider the development of fusion power reactors. Demonstrating 
that the fusion reaction could be achieved and controlled in a plasma of deuterium and tritium was expected to be accomplished in the very near term, i.e., a few years.

The next logical step was to build a reactor that would harness the fusion reaction to produce electricity. Attendees at this meeting from ORNL included program managers Ed Shipley, Arthur Ruark, and Bill Manly of the Metallurgy Division. The meeting proved to be a harbinger of the future fusion program; most of the meeting was devoted to discussions of plasma physics, and only at the very end, when little time remained, did the group turn to Manly and ask what materials could be used for construction of the blanket.

At that time, the thought was to use the fused fluoride salts of $\mathrm{Na}-\mathrm{Li}-\mathrm{Be}$ as the tritium breeding medium. These salts would have to be contained in a nickel-base alloy. After listening to the problems of confining the plasma, building magnets, particles bombarding the surface of the plasma chamber, etc., Manly said: “After listening to you for two days, my thoughts are when you solve those problems, we will fix the fused salt/nickel-base alloy problem on a Sunday afternoon." With the intervening nearly 40 years of research, the plasma physics has proved to be much more difficult and has required much more time than originally anticipated.
Today, however, in terms of plasma parameters and experiment size, we are close to the goal of building a fusion reactor, although the time scale remains decades. Ironically, as we approach the conditions that will exist in a reactor, there is an increasing realization that the materials problems are also much more formidable than previously thought.

\section{the sherwood project}

In 1958, Manly introduced Bob Clausing to the fusion program. The program was classified Secret and had the code name Sherwood Project. When Manly introduced Bob Clausing to Ed Shipley, Director of the Sherwood Project, he told him he had brought one of the Divisions' youngest scientists to fusion because he figured that the materials problems would take a very long time to solve.

Clausing initially worked with the Sherwood Project to solve problems of welding, brazing, and fabrication having to do with the construction of fusion experiments. However, in a relatively short time, he became involved, along with Dick Strehlow and Bob Beacon, in the development of improved vacuum pumps for pumping hydrogen.

This group made very significant improvements in titanium sublimation pumping technology. Clausing continued to work on the fusion program 
through the early 1980 s, focusing on techniques for cleaning the first wall and studying hydrogen recycle so as to reduce the amount of impurities in the plasma.

Clausing and coworkers were the first to use oxygen glow discharges to remove hydrocarbons followed by hydrogen glow discharging to remove the oxides formed during the oxygen cleaning process. A surface analysis station for studying the composition of first wall materials was designed and built by Robert Clausing, Lee Heatherly, and L. C. (Doc) Emerson.

\section{the surface analysis station}

This surface analysis station was used on fusion experiments throughout the world, including T-12, Kurchatov Institute of Atomic Energy, Moscow (June-July 1978); Doublet III, General Atomics, San Diego, California (19781979); TEXTOR, KFA, Jülich, Germany (1982); and JET Joint Undertaking, Culham, England (1983).

A second surface analysis station was designed, built, and attached to the fusion devices located in Oak Ridge including ISX, ISX-B, and EBT at Y-12. This occurred over a period of several years during the late 1970s and early 1980s.

\section{structural materials for fusion reactors}

Research and development (R\&D) of structural materials for fusion reactors had its beginnings in June 1969, with a meeting to discuss technologies needed for the development of fusion power reactors. Attendees at the meeting included Herman Postma, Jim Weir, Bill Wiffen, Don Steiner, and Art Fraas. Materials, specifically performance of materials in the neutron radiation and chemical environment of a reactor, were identified as the key or critical issue.

\section{hfir irradiation}

In 1970, the first irradiation experiment funded by the fusion program was initiated in the High Flux Isotope Reactor (HFIR). This experiment, conducted by Bill Wiffen, investigated the effects of irradiation on the properties of niobium alloys, envisioned at the time as the best choice for a structural material for a lithium- cooled fusion reactor.

\section{6 oil embargo}

From 1974 to 1976 , the U.S. Fusion Program experienced a significant expansion as a result of the oil embargo and energy crisis. At this time, materials and technology were elevated to mainstream components of the program. 
organization of the program

In 1976, Dr. Klaus M. Zwilsky, Chief of the Materials and Radiation Effects Branch of the Office of Fusion Energy, organized the Fusion Reactor Materials Program along four major task areas:

(1) Alloy Development for Irradiation Performance (ADIP), (2) Damage Analysis and Fundamental Studies (DAFS), (3) Plasma-Materials Interaction (PMI), and (4) Special Purpose Materials (SPM).

Program plans for each area were prepared by Technical Task Groups composed of personnel from the various Department of Energy (DOE) laboratories and contractors.

Chairmen of the four task groups were:

(1) ADIP - James Stiegler, ORNL;

(2) DAFS - D. G. Doran, Hanford Engineering Development Laboratory; (3) PMI - W. Bauer, Sandia National Laboratories; and (4) SPM - James Scott, ORNL. Other ORNL staff involved in this early program planning process were Everett Bloom and Bill Wiffen, of the M\&C Division.

The assumptions used in developing the program plans were (1) construction of an experimental power-producing reactor about 1990 and (2) a demonstration plant by the end of the century. Interestingly, it was assumed that the structural material would be austenitic stainless steel, and the database required for design of the reactor would be generated primarily in fission reactors using techniques such as spectral tailoring.

Spectral tailoring is a technique used to approximate irradiation damage in austenitic stainless steels that will occur in a fusion spectrum by irradiating in a mixed-spectrum fission reactor and stepwise adding a thermal neutron absorber around the experiment to reduce the thermal neutron flux. This approach was initially suggested by Jim Horak of the M\&C Division.

\section{development of alloys}

Since there was no single alloy system that would meet the requirements of the various proposals for a commercial reactor, it was viewed as necessary to have a parallel path approach for development of suitable structural materials. Initially, four paths were pursued: (1) austenitic stainless steels, (2) nickel-base superalloys, (3) refractory metal alloys, and (4) innovative concepts (e.g., ordered alloys).

As research results became available, the nickel-base alloys, niobium, molybdenum alloys, $\mathrm{Fe}-\mathrm{Ni}-\mathrm{V}$ ordered alloys, and titanium alloys were dropped from the program. In the planning activity of the 1970s, it was envisioned that a fusion neutron source would be built and operational about 1990 for the development and qualification of alloys for the demonstration and power reac- 
tors. The fusion neutron source remains a high priority for materials R\&D.

\section{use of ferritic steels}

At the outset of the program, it was assumed that ferritic steels would probably not be satisfactory as a fusion reactor structural material because of their ferromagnetic properties. In the late 1970s, however, it became apparent from experiments conducted under the Liquid Metal Fast Breeder Reactor (LMFBR) Program that this class of alloys exhibited excellent resistance to irradiation-induced swelling and high-temperature helium embrittlement, and this caused the fusion program to reexamine their possible use.

Design studies indicated that the field perturbations introduced by the presence of ferromagnetic structural materials would be small and that, although they could not be ignored, the additional structural loads introduced by the action of the magnetic field on the ferromagnetic structure could be accommodated. Thus, in 1978, the program began an evaluation followed by an R\&D effort on ferritic/martensitic (FM) steels as potential structural alloys.

\section{fusion reactor design}

In the late 1970s, Hopkins and coworkers at General Atomic began to study "low-activation" fusion reactor designs.
These designs were intended to feature the potential advantages of fusion in the areas of maintenance, safety, and radioactive waste as compared to fission reactors.

The fusion reaction does not produce radioactive nuclides, and it is not selfsustaining as is a fission reaction when a critical mass of fissionable material is available. Any radioactivity produced in the fusion reactor derives from the capture of neutrons in the materials from which the reactor is constructed.

advantages of fusion over fission

The characteristics of any radioactivity (e.g., type, half-life, biological hazard potential, decay heat, and pathways for disposal) are dependent on the materials of construction. This leads to important potential advantages of fusion in the areas of safety and environmental impact, for it appears possible to develop materials that are optimized from the viewpoint of safety (i.e., reduced afterheat, reduced volatility, etc.) and environment (i.e., reduced longhalf-life radionuclides for safer disposal and/or possible recycle).

\section{candidate structural materials}

Three material systems have the greatest potential to yield a structural material with attractive safety and environmental characteristics: martensitic (FM) steels containing 9 to $12 \% \mathrm{Cr}$, vanadium-based $(\mathrm{V})$ alloys, and silicon carbide-silicon carbide composities 
(SiC/SiC). Three structural material options are pursued for two basic reasons. First, none of these three options has the physical, mechanical, and chemical properties to make it a viable candidate in all design options (i.e., coolant-breeder combination, operating temperature, wall loading, etc.)

Martensitic steels are most attractive in a water-cooled, ceramic-breeder system. Vanadium alloys are the most attractive candidates for an $\mathrm{Li}$ or $\mathrm{Li}-\mathrm{Pb}$ coolant/breeder, and SiC/SiC composites are proposed for very high temperature, helium-cooled designs. Secondly, three options are being pursued because it is not clear which of the options can be developed to have adequate properties for fusion power reactor applications.

\section{plasma facing materials}

Early on it was realized that the plasma facing materials (first wall and divertor/limiter armor) would have to have remarkable properties: low atomic number, good thermal shock resistance, high melting temperature, and high thermal conductivity. For machines such as ITER, neutron irradiation stability would be a further requirement.

Graphite and carbon-carbon composites have been widely used as plasma facing materials. In the late 1980 s, ORNL became involved in the irradia- tion of carbon-carbon composite plasma facing materials under the PMI program. Walt Eatherly and Ray Kennedy collected candidate carboncarbon materials for irradiation in the HFIR. Evaluations of the neutron irradiated carbon-carbon composites were performed by Tim Burchell and Walt Eatherly.

\section{international fusion research}

Fusion research has always been international in nature. The Tokamak was, of course, discovered in the U.S.S.R. Even in the early years, during the cold war, scientific exchanges between scientists in the United States and U.S.S.R. took place.

The first such exchange involving the materials program was that of an Atomic Energy Commission (AEC) delegation traveling to Russia in November 1974. Jim Horak of the M\&C Division was a member of the delegation. This trip laid much of the groundwork for future exchanges and collaborations with the U.S.S.R. and subsequently Russia.

In the early 1980 s, primarily through the efforts of J. L. (Jim) Scott, a significant collaboration was developed between ORNL and the Japan Atomic Energy Research Institute (JAERI). In this collaboration, irradiation experiments are carried out in the HFIR. All aspects of the program are collabora- 
tive, i.e., funding, planning, analysis, publication of results, etc.

In 1995, the third phase, 1995 to 1999 , of this collaboration was initiated. The Japanese universities, i.e., Monbusho, have had a collaborative program on fusion materials research that began with experiments on the RTNS-II (Rotating Target Neutron Source) at Lawrence Livermore National Laboratory in the 1970 s.

The focus of this collaboration moved to the FFTF (Fast Flux Test Facility) and the EBR-II (Experimental Breeder Reactor), and for Phase III (1995 to 2002) will involve experiments in the HFIR at ORNL.

\section{contribution of metals and ceramics personnel}

Members of the Division have made valuable contributions to the eventual development of fusion not only through their contributions to fusion science and technology and publication of this work in the open literature, but also through their participation in international workshops and the organization of technical meetings and symposia. The first International Working Session on Fusion Reactor Technology was held in Oak Ridge in 1971. Don Steiner of ORNL was the organizing chairman, and Bill Wiffen of the Division was on the organizing committee and a session chairman.
In 1975, the International Conference on Radiation Effects and Tritium Technology for Fusion Reactors was held in Gatlinburg, Tennessee. Don Steiner of ORNL was general chairman, Warren Grimes of Chemical Technology Division and Jim Scott of M\&C Division served on the organizing committee, and Bill Wiffen of M\&C and Jack Watson of Chemical Technology Division served on the program committee.

In 1979, the First Topical Meeting on Fusion Reactor Materials, cosponsored by the American Nuclear Society, DOE, Electric Power Research Institute, and the Nuclear Metallurgy Committees of the American Institute of Mining, Metallurgical, and Petroleum Engineers and the American Society for Metals, was held in Miami Beach, Florida. This meeting was the predecessor of the International Conference on Fusion Reactor Materials (ICFRM).

ICFRM-1 was held in Tokyo, Japan, in 1984; ICFRM-2 in Chicago, Illinois; ICFRM-3 in Karlsruhe, Germany; ICFRM-4 in Kyoto, Japan; ICFRM-5 in Clearwater, Florida; ICFRM-6 in Strasa, Italy; ICFRM-7 in Obninsk, Russia, in 1995; and ICFRM-8 will be held in Japan.

Members of the Division have played key roles in the organization of each of these conferences. ICFRM-5 was hosted by ORNL with Everett Bloom serving as general chairman. Others from the Division who contributed to the confer- 
ence organization included: Arthur Rowcliffe, chairman of the organizing committee; Louis Mansur, organizing committee; Tim Burchell, Ted Reuther, Pete Tortorelli, and Steve Zinkle, program committee; Ron Klueh, chairman of the publication committee; Francis Scarboro, secretary to the publication committee; Roger Stoller, publication committee; Phil Maziasz, publicity committee; and Judy McKinney, conference secretary and treasurer.

\section{looking ahead}

ORNL has completed almost four decades of research toward the goal of harnessing the energy that powers our sun-nuclear fusion. Since the 1970s, materials and other technologies have been recognized as essential if this goal is to be achieved.

We have made much progress in understanding the effects of the fusion operating environment on the properties of materials, and we have identified material systems that have many of the fundamental characteristics that will be required to make fusion a safe and environmentally attractive energy source.

Now, our challenge is to develop these materials so that they have the mechanical properties, corrosion resistance, and radiation damage resistance to make fusion an economic energy source.

Today's ORNL team has the mix of youth and experience to do the job. That team consists of the Structural Materials Group, the Irradiated Materials and Examination Testing Facility, the Carbon and Insulating Materials Technology Group, the Corrosion Science and Technology Group, the Fracture Mechanics Group, and the Materials Joining and Nondestructive Testing Group. All are making major contributions.

Other divisions who are collaborating in these efforts include the Engineering Technology Division, Research Reactors Division, and Fusion Energy Division. 


\section{gas-cooled reactors at ornl: thirty-plus years of history and progress}

\section{characteristics of gas- cooled reactors}

Today's High Temperature Gas-Cooled Reactor (HTGR) design is a versatile power reactor with a variety of attractive features that make it efficient and safe. It is a thermal reactor that uses a graphite moderator, ceramic-coated fuel particles, and helium gas coolant.

Because it can attain high temperatures, the HTGR can achieve high thermal efficiencies using the steamturbine (ST) cycle, the gas-turbine (GT) cycle, or combined cycles. It can also be applied to the cogeneration of process steam and electricity or to fossilfuel conversion processes for producing hydrogen, ammonia, and methanol, and for converting coal to liquid and gaseous fuels.

Because of the special properties of graphite, helium, the fuel used, and the low power density of the core, the HTGR is inherently a very safe reactor. By decreasing the power level of a unit to $450 \mathrm{MW}(\mathrm{t})$ or less, the peak fuel temperatures during very severe accidents can be limited to values where fission products are essentially retained within the core, an inherently safe configuration.

These latter units are termed Modular HTGRs (MHTGRs), and have been the focus of the USDOE HTGR program since 1985. More recently, DOE has also supported studies of a modified version of an MHTGR for application to a New Production Reactor (NPR) for the production of tritium, termed the MHTGR-NPR; the latter was selected as one of two NPR candidates in August 1988. Much of the base technology for the MHTGR and the MHTGR-NPR is common to both reactors, including fuels, metals, and graphite materials development. ORNL has been and remains an important participant in base-technology development, and the M\&C Division has had and continues to have a key role in fuel and materials development essential to the success of the HTGR.

\section{early days - the experimental gas- cooled reactor (egcr)}

The first work on HTGRs in the U.S. was initiated by General Atomics (GA) in about 1955. In 1957 Congress directed the Atomic Energy Commission (AEC) to initiate development work on a power reactor system that would compete with the Magnox gas-cooled reactors being developed and built in the U.K. A system using the inert gas helium as coolant was chosen as the best candidate for a high-temperature, high-efficiency system. The project was to culminate with the design, construction, and operation of a 40-MW(e) demonstration reactor at Oak Ridge called the Experimental Gas Cooled Reactor (EGCR). The project was thus 
identified as the mission for the substantial reservoir of technology and talent on high-temperature materials at ORNL.

\section{reactor design}

Further work and study led to important decisions on materials and system design. The reactor design selected was a graphite-moderated steam-generating system using stainless-steel-clad fuel elements. The fuel rods would contain $\mathrm{UO}_{2}$ fuel pellets similar to those used successfully in pressurized-water reactor systems. However, the fuel rods were larger in diameter because of the lower specific power of a graphitemoderated system, and the $\mathrm{UO}_{2}$ pellets were designed with a hollow core to allow void volume for accumulation of fission gases.

\section{role of the division}

The Metals and Ceramics Division under the leadership of Bill Manly assumed a major role in the project. One of the Division's important functions was to select and specify the materials for components of the reactor core and steam generators and to participate in the design of those components.

Materials and operating conditions were selected by extrapolating from well-documented technology. The major task, then, was to demonstrate that the chosen materials would perform adequately at the design conditions. This led to several test programs in which the Division played a leading role:

1. compatibility of structural components with graphite in a helium environment of controlled purity

2. mechanical properties testing of materials under appropriate environmental conditions

3. development of fabrication techniques for cored $\mathrm{UO}_{2}$ fuel pellets, fuel rods, and other components, including the steam generators

4. irradiation testing of prototype fuel rods under controlled conditions

5. development of nondestructive testing techniques for the component materials.

\section{materials compatibility}

The work on materials compatibility was led by Jack DeVan, using facilities operated by the Reactor Division at $\mathrm{Y}$ 12. Stainless steels and other alloys were exposed in contact with graphite in high-pressure helium at temperatures up to the maximum operating temperature. The concern was that, in the absence of oxidizing conditions, stainless steels might not develop a protective oxide layer and, therefore, might corrode severely. This could lead to spalling of surface layers, contamination of the system, and even structural failure of the components. The tests were conducted at conditions such that the impurities inherent in the graphite would contaminate the helium in the system. Tests for up to 
$5000 \mathrm{~h}$ demonstrated, however, that protective layers did develop on the metal surfaces, preventing spalling and sample degradation.

Mechanical properties of the type 304 stainless steel cladding material were tested in facilities set up and commissioned at ORNL by Don Douglas and Jim Weir. An important part of this testing program involved creep-rupture tests of prototype fuel rods.

\section{design of fuel elements}

The design of the fuel rod with a cored $\mathrm{UO}_{2}$ fuel pellet presented special fabrication problems that were addressed and solved by Al Taylor and Robbie Robbins of the Ceramics Laboratory. The initial effort to produce pellets within the tolerances of density and dimensions without supplemental sizing operations was only partially successful.

Other fabrication problems that were addressed and solved included the methods for sealing the fuel rods and for fabricating the steam generators. These problems were addressed by the Welding Laboratory under the leadership of Pete Patriarca and Gerry Slaughter.

\section{development of weld testing methods}

An important supporting function for the work on component fabrication and the specification of structural materials was the development of methods for testing welded closures and for ensuring the integrity of the structural materials themselves. This vital function was performed by the Nondestructive Testing Laboratory under the leadership of Robert Oliver and Robert McClung. The group perfected and demonstrated procedures that were incorporated into specifications for the reactor components.

\section{irradiating prototypical fuel elements}

A vital element in testing and demonstrating the performance of the fuel element was the successful irradiation testing of prototypic fuel elements. An extensive testing program was conducted by the Irradiation Testing Group of the Reactor Division under the leadership of Don Trauger.

Facilities at the Engineering Test Reactor (ETR) and the Oak Ridge Research Reactor (ORR) were used to test prototypic fuel rods at design temperatures and to maximum fuel burnup.

The Division prepared the test specimens, conducted postirradiation examinations, and interpreted the results. The tests employed partially enriched $\mathrm{UO}_{2}$ pellets that had been fabricated by the Ceramics Laboratory. These pellets were loaded into carefully inspected capsules that were shortlength versions of a typical fuel rod. 
The irradiation testing program demonstrated that, although the pellets developed radial cracks during irradiation, the resulting structure was stable. Therefore, the fuel rods were expected to perform adequately as designed.

\section{development of fuel element specifications}

The results from all the fabrication and testing programs were used to develop specifications for the fuel elements and other components. The fuel element specifications were prepared under the leadership of John Coobs, and data from the Welding Laboratory were used in preparing specifications for the steam generators.

Completion of the fuel element specifications was followed by awarding a contract for fabrication and delivery of the fuel elements. The vital function of monitoring the performance of this contract was completed by Gerry Tolson, and the fuel elements were delivered on schedule.

\section{constructing the reactor}

The Title II design and construction of the reactor and auxiliary systems proceeded about as scheduled. However, the reactor concept was perceived by the nuclear industry as competing directly with its PWR and BWR systems, which had evolved from a base of technology developed for the nuclear submarine reactors.
The result was a lack of interest and participation by industry and this was a major factor in the cancellation of the project in 1964. Construction was completed and the fuel was delivered and on site when the decision was made to stop work. Thus, no operating experience was gained on the system in spite of the vast efforts expended in the development and testing programs.

\section{then and now - the htgr}

Aside from the EGCR concept, early work at ORNL involved the evaluation of coated particle fuels for pebble-bed gas-cooled reactors (PBRs). During 1960 several PBR design studies were carried out, and experimental work began on coated-particle fuel development and performance.

Although work on a proposed PBR experiment was terminated in 1963, the coated fuel development and fission product behavior efforts started under that program were continued as part of the Gas-Cooled Reactor Program (GCRP). That effort was for HTGRs using prismatic block fuel elements (i.e., prismatic graphite blocks containing coolant holes and fuel holes, with fuel rods located in the fuel holes, Fig 7).

Work on fueled-graphite development and associated fission-product behavior has continued since that time, with the M\&C Division playing a vital role in the development of high-quality coatedfuel particles. Since 1986, ORNL has 


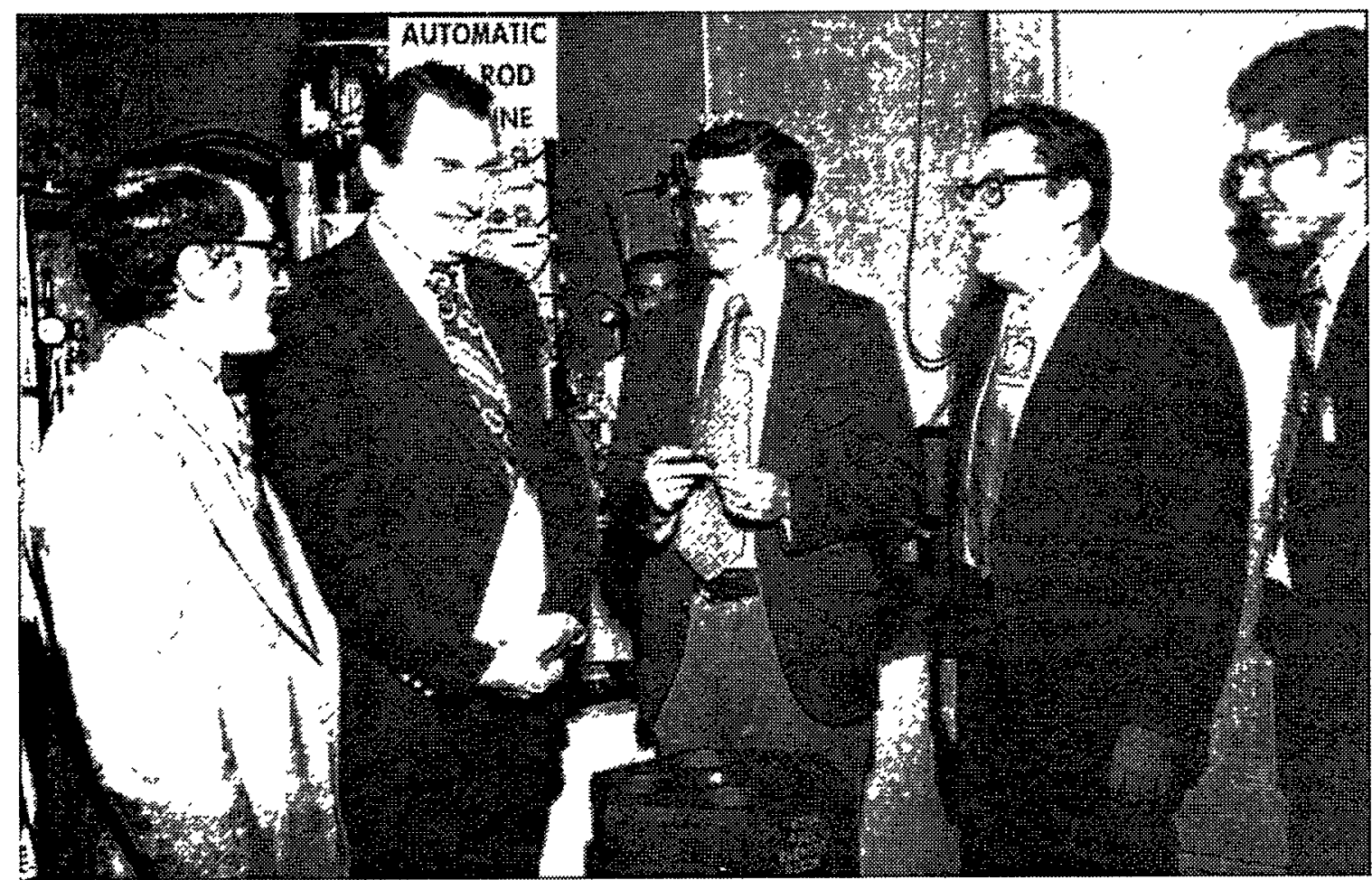

Fig. 7. Discussing product of device for automated fabrication of green HTGR fuel rods. Left to right: T. N. Washburn, Manager Fuels and Processes Section, Metals and Ceramics Division, ORNL; T. A. Nemzek, DOE; R. A. Bradley, Fuel Cycle Engineering Group, Metals and Ceramics Division, ORNL; W. O. Harms, Director, LMFBR Programs, ORNL; E. A. Womack, DOE.

been the "lead laboratory" for HTGR base-technology development; previously, base-technology development was shared between General Atomics and ORNL.

\section{contributions of the division to the project}

One of the many important contributions made by the M\&C Division in the 1960s was the demonstration that coated fuel particles needed to be distributed within a carbonaceous matrix to form a fuel rod, rather than loaded directly as coated particles. In the latter case, the coatings failed from "bridging" and associated stresses during fuel irradiation.

Jim Scott of the M\&C Division was heavily involved in this work. In the 1970 s and 1980s key facilities were developed for determining the performance of high quality fuel. ORNL, particularly the M\&C Division, pioneered the development of equipment and procedures for examination of individual irradiated coated particles.

These included use of electron microprobes, scanning electron microscopes, 
gamma spectroscopy, and postirradiation gas analyzers. Mike Kania, Ken Valentine, Ernie Long, and Terry Lindemer made key contributions to the above.

ORNL analysts, with major contributions from the M\&C Division and in collaboration with scientists from General Atomics and the Research Center in Jülich, Germany, quantified major failure mechanisms for coated-particle fuels. ORNL scientists from the Chemical Technology Division

(Terry Lindemer) and M\&C Division (Bob Lauf) predicted the phases present in oxide, carbide, and oxycarbide fuel kernels as a function of initial composition and burnup.

These predictions have been matched with qualitative metallographic results to develop fuel models explaining how these phases influence kernel and coating performance during irradiation.

\section{other htgr work}

In other HTGR work in the early 1960s, ORNL performed reactor physics analyses and fuel-cycle evaluations and participated with General Atomics in reactor physics and fission product behavior measurements in the Peach Bottom HTGR (the first HTGR built in the United States).

Also, ORNL performed design and fuelcycle evaluations of large HTGRs, evaluated graphite behavior, and in 1966 initiated work on Prestressed Concrete
Reactor Vessels (PCRVs). The application of low-power MHTGRs has subsequently resulted in use of steel reactor pressure vessels rather than PCRVs.

\section{metals studies}

Key metals studies, led by Herb McCoy and Joe Strizak, have included obtaining mechanical property information on metals of interest as a function of temperature and environment. The development of a large number of materials test rigs in cooperation with other materials programs in the M\&C Division contributed significantly.

A subsequent key development was the ability to control impurity levels in the simulated coolant environment seen by the metal specimens by adding impurities from a "tank farm" without the need for a large volume of hot graphite or a recirculating loop to maintain a proper environment. Recent materials development within the M\&C Division is providing data on the performance of reactor vessel steels at the temperatures, neutron exposures, and neutron spectra representative of the MHTGR. Mechanical property data also continue to be obtained for alloys to be used in the heat transport system, steam generator, control-rod cladding, and other metal internals of the reactor.

\section{expansion of the htgr program}

The HTGR program expanded in 1970 when the Thorium Utilization Program 
was incorporated and dedicated to HTGR fuel-recycle development; headend reprocessing and fuel refabrication development were emphasized. A. L. (Pete) Lotts headed that effort from the start. Nearly all the fuel refabrication efforts were carried out by the $M \& C$ Division.

Remotely maintained "coaters" were developed for coating fuel kernels, and the "slug-injection" process was developed for remote refabrication of HTGR fuel rods. John. Sease led these important developments. In the slug-injection process, a mixture of coated fuel particles and graphite particles was poured into a mold, and a solid "slug" of cold matrix material (pitch and graphite powder) was placed above the particles. After heating, the "molten slug" was injected into the particle bed; cooling resulted in a removable fuel rod.

\section{irradiation testing program}

Various HTGR particle-fuel types were irradiation tested by the $\mathrm{M} \& \mathrm{C}$ Division with assistance from the Engineering Technology Division; key M\&C scientists and engineers involved were Frank Homan, Ernie Long, Terry Tiegs, and Mike Kania.

The irradiation testing program in the 1970s supported both HTGR basetechnology and the HTGR fuel-recycle programs. Various fuel particles were tested involving various types of kernels and coatings, and a reference fuel-recycle particle was recommended and adopted by GA. Overall, M\&C personnel helped develop fuel-recycle equipment and processes, evaluated fuel cycle performance, irradiated candidate fuels for recycle application, and evaluated fuels for recycle application.

\section{experimental graphite development}

The continuing ORNL experimental graphite development program for the HTGR began in 1974. Important M\&C Division studies performed under Walt Eatherly and Ray Kennedy were the irradiation behavior of graphite, irradiation creep measurements, oxidation studies, and measurement of physical properties using eddy-current and sonic-velocity measurements.

Numerous grades of graphite were tested, and their mechanical and physical properties were measured before and after irradiation. The statistical variation in physical and mechanical properties within and between graphite billets has been quantified. Tim Burchell has led the more recent graphite studies.

\section{project termination}

Technology development activities were terminated at the end of FY 1995. Closeout and cleanup efforts were supported in FY 1996 and 1997. 


\section{space nuclear programs}

The programs on developing nuclear power systems for space constitute the longest continuing activity utilizing the Division's expertise in mechanical properties, materials joining, corrosion and other disciplines developed during the Aircraft Nuclear Propulsion Program from 1950 through 1960.

Starting in the early 1960 s, a number of space nuclear reactor programs evolved under Bill Harms and William Thurber until their abrupt termination in 1973. These included a series of Space Nuclear Auxiliary Power (SNAP) Programs - SNAP 8, SNAP 50, SNAP 10; ORNL's Medium Power Reactor Experiment (MPRE); and NASA's Advanced Lithium Reactor Program.

Approximately ten years after their termination, activities on space reactor materials technology began again under R. H. Cooper with the SP-100 Project and the Multimegawatt (MMW) Space Power Program.

\section{early snap reactor programs}

Starting in the early 1960 s, the country had a growing commitment to creating a human presence in space. This commitment established the need for a reliable source of electric power in space and created a number of space reactor programs. ORNL's major interest was in liquid-metal-cooled fast reactors tied to the Rankine power conversion cycle. Achieving the design objectives of these programs was paced by the resolution of fuels and materials limitations. Because the coolants and working fluids in these systems used mercury, sodium, potassium, or lithium, the expertise in the Division in liquid-metal corrosion developed during the ANP Program placed us in a strong position to address these issues. During this period, the Division was a leader in the design, fabrication, and operation of static, refluxing, thermal convection, and pumped-loop systems for the characterization of the compatibility of alkali metals with stainless steels and refractory alloys.

By 1968, ORNL had accumulated over $100,000 \mathrm{~h}$ experience with stainless steel systems containing boiling potassium or circulating sodium or lithium. This experience evolved into the design and operation of alkali-metal corrosion tests of refractory alloys of niobium, tantalum, and molybdenum and bimetallic systems made up of both stainless steels and niobium or tantalumbased alloys. From these activities, the M\&C staff identified the role of impurities in potassium and sodium that control the life-limiting compatibilities involving stainless steels and refractory alloys. This experience led to identifying the performance-limiting role of oxygen in the compatibility of niobium and tantalum alloys with lithium.

In support of these alkali-metal testing activities, the predecessor to the Materials Processing Group led in development of methods for melting and fabri- 
cation of complex components from such tantalum-based alloys as $\mathrm{T}-111$ and ASTAR $811 \mathrm{C}$ and niobium-based alloys as $\mathrm{Nb}-1 \% \mathrm{Zr}, \mathrm{FS}-85$, and D-48. The Welding and Brazing Group developed specialized laboratory and field methods for joining refractory alloys to avoid alkali-metal compatibility and mechanical property problems.

Another major role of the division was in characterizing the mechanical properties of the high-temperature structural materials used in these systems.

The designs of the SNAP 50 and the advanced lithium-cooled reactors were based on the use of uranium nitride fuel due to its high thermal conductivity and uranium metal content. However, in the early phases of these programs, other organizations encountered unpredictable swelling and fission gas release in the manufacture of reliable uranium nitride fuel. ORNL developed and demonstrated a hydride-dehydridenitride process for the manufacture of high-quality fuel. This process provided the control of trace elements and nitrogen purity necessary to achieve consistent irradiation performance.

Another major activity during 1966 to 1973 was the optimization of tungsten and tungsten-alloy fabrication methods. During this period, we developed a unique duplex extrusion process for fabricating high-quality tungsten and tungsten-alloy tubing. The efforts demonstrated the capability to manu- facture thin-wall, small-diameter tubing from tungsten, tungsten-rhenium alloys, and tungsten-thoria alloys. Paralleling this effort was development of chemical vapor deposition methods to produce small-diameter tubing and sheet from tungsten and tungsten alloys. The high-temperature mechanical properties of products produced by both methods were evaluated extensively during this period. These activities were initiated in support of the SNAP reactor concepts but later were applied to the fabrication of highperformance emitters for thermionic converters considered for space applications coupled to either reactor or isotope heat sources.

\section{sp-100 project}

The creation of the Strategic Defense Initiative (SDI) in the early 1980 s established needs for space-based surveillance and weapons systems requiring long-lived, reliable sources of electrical power. The need for systems requiring power ranging from tens of kilowatts to hundreds of megawatts rekindled the space nuclear reactor power program in 1983. The first of these programs was the SP-100 Project, which was oriented toward the development of a system providing approximately $100 \mathrm{~kW}$ of electric power. The project, which began in 1983, focused on niobium-based alloys, in particular on the characterization of the hightemperature mechanical properties, fabrication optimization, and charac- 
terization of oxidation and alkali-metal compatibility.

\section{multimegawatt space power program}

The need for space-based systems capable of providing hundreds of megawatts of power resulted in the initiation of the Multimegawatt Space Power Program in 1985. Although the program was in existence for only four years, it provided opportunities to initiate broader activities in the area of refractory alloy mechanical property testing, fabrication, and compatibility testing. During this period, we developed a materials properties handbook focused primarily on tantalum-, molybdenum-, and tungsten-based alloys and fabricated the first thin-wall, small-diameter tubing of the tantalum alloy ASTAR $811 \mathrm{C}$.

\section{space nuclear propulsion programs}

A major emphasis of the country in the mid- to late 1960s was the development of nuclear rockets for space. The major focus of these efforts was the NERVA and Rover Programs. Although the NERVA Program never represented a major piece of work for the Division, our alloys, high-temperature testing, nondestructive examination, and fuel expertise were utilized. Initially, we characterized the mechanical properties of candidate nozzle materials, which included Inconel and type 347 stainless steel. Later, we were called upon to develop an eddy current method for inspecting the coolant passages in the NERVA reactor's beryllium reflector and to characterize the outgassing properties of reactor fuel. As with the nuclear electric reactor programs, the NERVA program was terminated in 1973.

\section{isotope power program}

This portion of the space power program began around 1967 under Ralph Donnelly and Tony Schaffhauser and continues today. In the 1960 s the materials program was diverse, supporting characterization of molybdenum, tantalum, and superalloys for a broad range of mission applications. In practically all cases, these alloys were evaluated as candidate claddings for isotope power system using plutonia or curium oxide fuels. As a result of these early activities, the Division manufactured fuel cladding materials used in two Lincoln Experimental Satellites and one Pioneer Satellite.

In the early 1970s, the Isotope Space Power Program desired fuel cladding materials with better high-temperature strength, ductility, and oxidizing tolerance than could be provided by molybdenum and tantalum alloys. From these objectives, development focused on platinum, tungsten, and iridium-based alloys began In 1973, an iridium alloy containing about $0.3 \%$ tungsten appeared to show the best 
potential. The Division used this alloy to fabricate the fuel cladding for the isotope power systems used on the Voyagers 7 and 8 missions during the mid-1970s. Continued alloy

development activities under C. T. Liu led to the iridium DOP-26 alloy, which contained $0.3 \%$ tungsten and parts per million quantities of thorium and aluminum to improve ductility at high strain rates. Manufacture of iridium alloys was resumed with some improvements in the 1980 to 1983 period to fabricate the fuel cladding used for the isotope power system on NASA's Galileo Mission, launched in 1989, and on the European Space Agency's Ulysses Mission, launched in 1990. From 1983 to 1990 , the process for fabricating the iridium DOP-26 alloy fuel cladding was enhanced to improve the metallurgical quality of the materials while reducing the unit cost.

Efforts began again in 1990 to manufacture fuel cladding for NASA's Cassini Mission now scheduled to launch in 1997.

In the late 1970 s we optimized the use of a low-density carbon-carbon composite invented by the Y-12 Plant for use as a thermal insulator in isotope power systems. The material, carbonbonded carbon fiber ( $\mathrm{CBCF}$ ) is made by bonding short carbon fibers with a phenolic resin and then carbonizing the composite. This optimization has provided hardware flown on the Galileo and Ulysses missions and to be flown on the Cassini mission in 1997. 


\section{advanced test reactor}

The Advanced Test Reactor (ATR) is a 250-MW reactor located at Idaho Engineering Laboratories, Idaho Falls, Idaho. The core is in the shape of a four-leaf clover to provide a maximum number of irradiation facilities. The fuel elements are pie shaped at a $45^{\circ}$ angle. This requires 19 fuel plates, each a different width. The fuel plates are 49.5 in. long but vary in width from 2.136 to $3.974 \mathrm{in}$.

Because of our experience in developing the High-Flux Isotope Reactor fuel element, the Department of Energy gave responsibility for developing fabrication techniques for these ATR elements to the Metals and Ceramics Division. The project was directed by R. J. Beaver.
Oak Ridge National Laboratory successfully developed a fabrication process using a $\mathrm{U}_{3} \mathrm{O}_{8}$ dispersion in 6061 aluminum. Using only three powder metallurgy dies with various ratios of longitudinal and cross rolling yielded the 19 acceptable plates.

The plates were attached to the side plates using, for the first time, a constant pressure, dual-head, roll-swaging operation. To help equalize pressures, staggered holes 2 in. long and three plates wide were machined across the side plates.

The first 19 fuel elements were made at ORNL with depleted $\mathrm{U}_{3} \mathrm{O}_{8}$ and were used for hydraulic tests. At that time the fuel was changed to $\mathrm{U} \mathrm{Al}_{3}$ and the process transferred successfully to a commercial fabricator. 


\section{molten-salt power reactors}

The molten salt reactor technology drew heavily from the work done in support of the Aircraft Nuclear Propulsion (ANP) Project. The earlier ANP work demonstrated the basic chemical compatibility of the graphite, lithium fluoride-beryllium fluoride salts, and high-nickel structural materials. The uranium fuel was present in the form of uranium tetrafluoride, which was soluble in the salts just mentioned. The physics of the system was governed largely by the geometry of the graphite and the composition of the salt. The heat generated in the fuel salt by fissioning was removed by contact with a non-uranium-bearing coolant salt. The heat in the coolant salt could be used to make steam for the generation of electricity, for waste heat applications, or for other processes.

A demonstration reactor was designed, built, and operated at ORNL. This reactor was named the Molten-Salt Reactor Experiment (MSRE) and began operation in 1965. The reactor produced about $8 \mathrm{MW}$ of thermal energy, which was dissipated through an aircooled radiator. Numerous skills were needed, so personnel from several divisions were involved, but materialsrelated problems were numerous, and the Metals and Ceramics (M\&C) Division personnel under the direction of Jim Weir and Herb McCoy were heavily involved.

Most nickel-base alloys contain fairly large concentrations of chromium to impart good oxidation resistance, but the fluoride salts are reasonably aggressive toward chromium.

Further, an alloy to operate in fluoride salts did not need high chromium for good oxidation resistance, but the air side of a reactor vessel would require moderate resistance to oxidation. Thus, the concentration of chromium was a compromise of $7 \%$, which gave acceptable corrosion resistance in air and in fluoride salts.

Corrosion considerations also dictated that the alloy be based on nickel rather than iron. Phase diagram studies had shown that several percent of molybdenum was soluble in nickel, so this highly refractory element was added to give the alloy good strength. The alloy selected on the basis of detailed research and applied experience had the nominal composition of $\mathrm{Ni}-7 \% \mathrm{Cr}-4 \%$ $\mathrm{Fe}-16 \% \mathrm{Mo}$.

This was a new alloy, and its production in large heats and complex shapes required considerable work on the part of several commercial alloy vendors and of M\&C metallurgists. Commercial names of INOR-8, Hastelloy $N$, and Allvac $\mathrm{N}$ were applied to the alloy.

The sizes and low permeability requirements of the core graphite required that it be produced by special methods, and these were monitored by M\&C personnel. A surveillance program allowed samples of metal and graphite to be removed periodically from the reactor for examination (Fig. 8). 


\section{4}
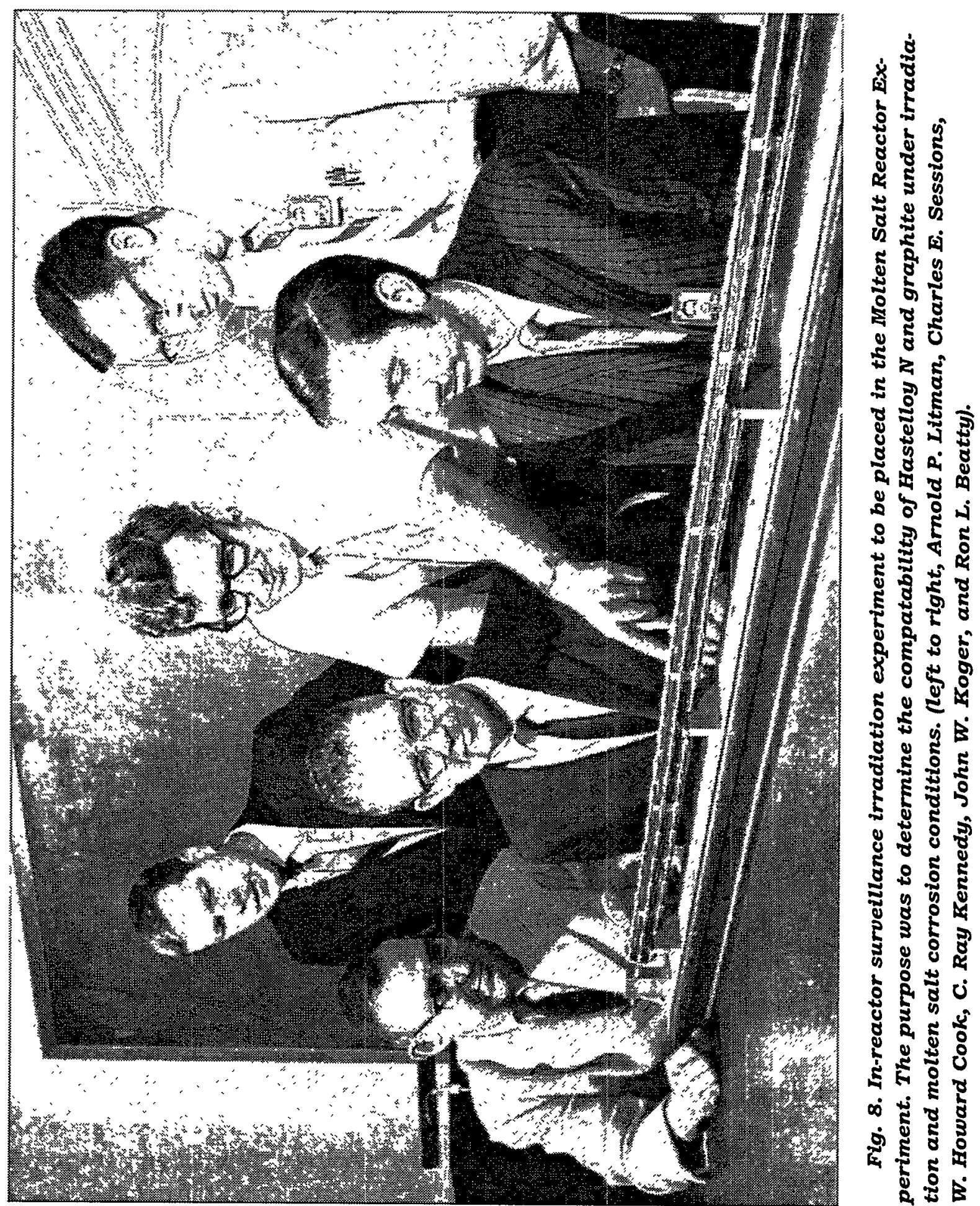
The MSRE operated for more than $20,000 \mathrm{~h}$ from 1965 to 1969 . The reactor was run as an experiment, and members of the M\&C Division were part of the research team that was concerned with the day-to-day operation. During the operation of the MSRE and other associated research, several important observations were made.

- The reactor operated well and demonstrated the basic compatibility of the new metal alloy-graphite-fluoride salt system.

- The reactor could operate on numerous fuels including several isotopes of uranium and plutonium.

- The new nickel-base alloy was embrittled by neutron irradiation.

- The new nickel-base alloy was penetrated and embrittled to a very short depth by the fission product tellurium.

Since chemical methods had been developed for extracting the fission products from the fuel salt, the potential of molten-salt reactors as breeder reactors was recognized. Over the period of 1970 to 1976 , some development was carried out relative to molten-salt breeder reactors. The primary salt contained uranium and thorium, so it served as the fertile and fissile material. The fission products were to be kept at an acceptable level by gas purging and by bismuth metal extraction. A secondary coolant salt was to transport the heat from the core to produce steam for electricity generation.

The breeder concept presented several new materials problems, including (1) development of a graphite with improved resistance to irradiation, (2) development of a nickel alloy with improved resistance to neutron irradiation and penetration by fission product tellurium, and (3) development of materials for containing the liquid bismuth used for fission product removal. Reasonable progress was made in each of these areas by M\&C personnel, but resources were not considered adequate to continue work on this reactor concept. In 1976, work ceased on molten-salt development at ORNL. 


\section{high flux isotope reactor program}

\section{6}

The High Flux Isotope Reactor (HFIR) is an ORNL reactor providing an intense neutron source. Its main objective is to produce research quantities of transuranium elements, permitting scientists to explore the properties of these exceedingly rare elements. The reactor also provides highly active elements for medical use and reasonably sized, very high neutron flux research facilities. At the time the reactor went critical, it provided the highest flux then available to engineering researchers.

The reactor design is based upon a flux-trap principle with a central cylindrical island containing tubes of the transuranium isotopes being irradiated. The tubes are surrounded by a light-water-moderatedand-cooled fuel region consisting of two annular fuel elements (Fig. 9).

The fuel core is surrounded by a thin, two-cylinder control region and a beryllium reflector. The desire to minimize development, capital, and operating costs led to the selection of aluminumclad fuel plates, normal water coolant and moderator, and a beryllium reflector arranged in a cylindrical core.

As designed, the reactor produced a flux of $5 \times 10^{15}$ neutrons $\mathrm{cm}^{-2} \mathrm{~s}^{-1}$ with an average power density of $2000 \mathrm{~kW} / \mathrm{L}$ and a total power of
$100 \mathrm{MW}$. This power is generated within a volume the size of a small garbage can. Aluminum is the structural material for all core components. The reactor was designed and developed and is still being operated by ORNL after going critical in 1965. During the initial design, development, and procurement phases, the project was directed by Charles Winters. He was followed by Al Boch for procurement, construction,

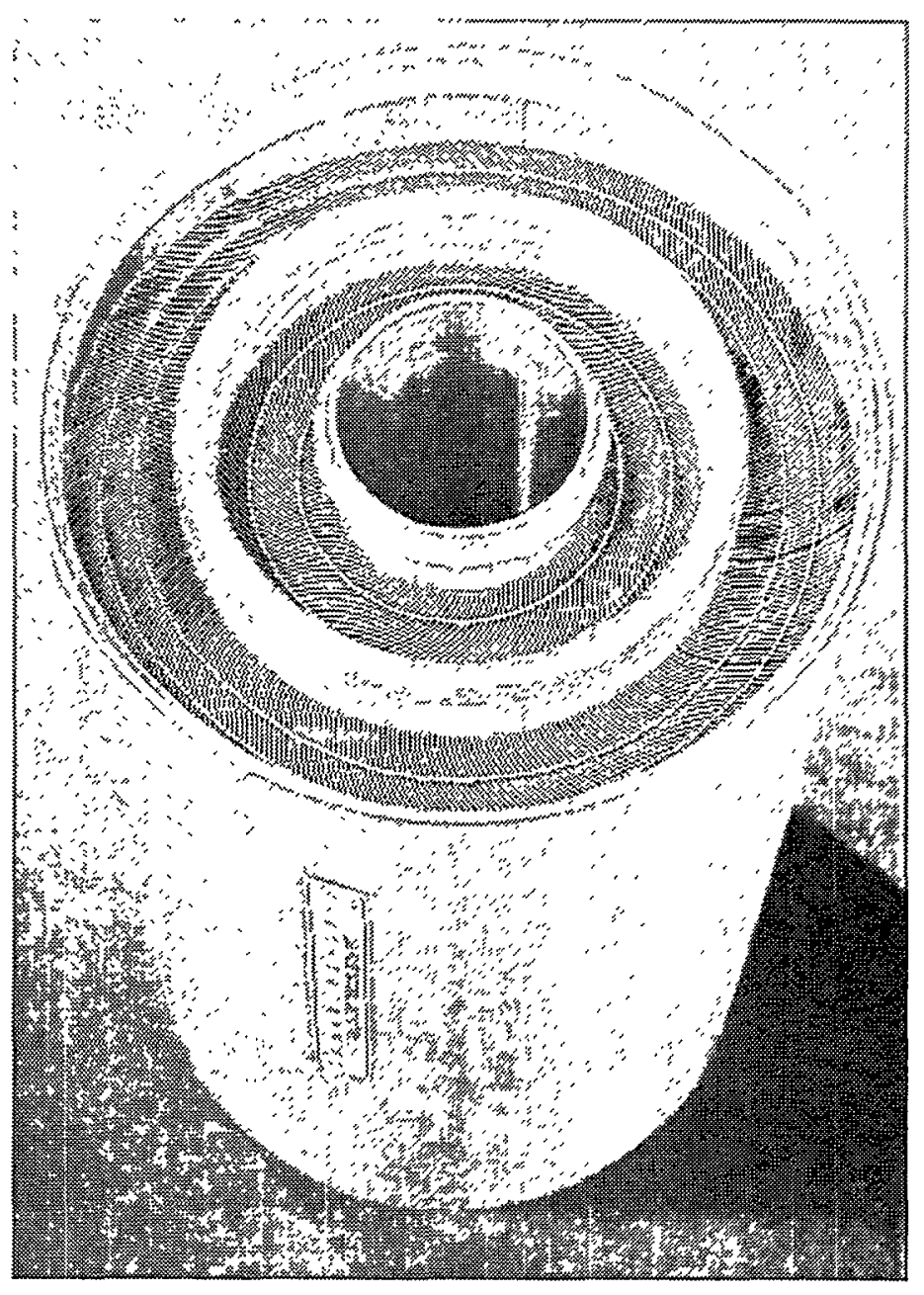

Fig. 9. Fuel element for the High Flux Isotope Reactor. 
and the initial phases of reactor operation.

The Metals and Ceramics (M\&C) Division played a major role in the development and fabrication of all reactor core components. A large program within the Division during the 1960 s consisted of three separate efforts, all including both conceptual and production development.

These included (1) fuel elements, (2) control rods, and (3) target rods. The M\&C laboratories involved in- cluded Metal Forming under Richard Beaver, Carl Leitten, and Bill Martin; Metallography, Robert Gray; Nondestructive Testing, Robert McClung; Powder Metallurgy, Joseph Hammond; Remote Fabrication, A. L. (Pete) Lotts and John Sease; and Welding and Brazing, Gerald Slaughter. The M\&C Program Manager for the conceptional stages was Al Taboada, followed by George Adamson, assisted by Richard Beaver (Fig. 10).

The HFIR was a challenging, interesting, and logical program for the M\&C

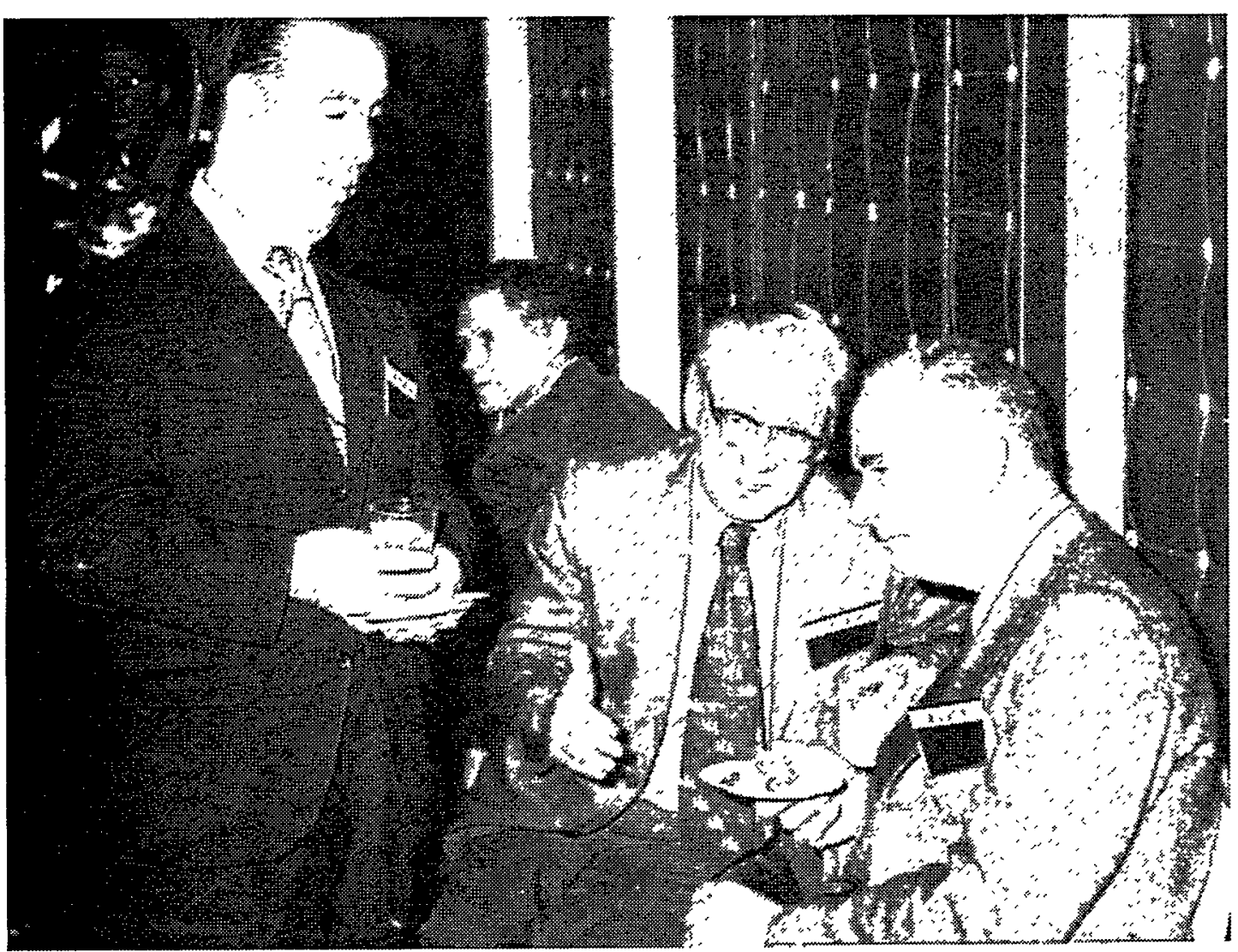

Fig. 10. Some people involved in the development of the HFIR. (Left to right foreground) George Adamson, Dick Beaver, and Al Boch. 
Division. It was based on work previously accomplished during the development of smaller research reactors, reported in other articles in this series, but required a considerable extrapolation of the technology.

The M\&C contributions on fuel and control elements are presented below. Target fabrication is the subject of a separate article.

\section{fuel elements}

The aluminum fuel core for this reactor consists of two concentric, aluminumbase fuel elements, the inner containing 171 curved plates and the outer 369 plates (Fig. 9). Uniform cooling is assisted by the plates being formed into an involute configuration providing the maximum exposed plate surface with water channels of uniform width. The fuel plates are welded to tubular side plates from the reverse side. The major materials problems with the HFIR fuel core faced and solved by the M\&C Division fell into the following categories:

1. meeting very tight uranium content specifications for spots as small as $0.080 \mathrm{in.}$ in diameter with a fuel core having a nonlinear profile across the plate,

2. fabricating stronger fuel plates than are normally obtained with conventional 1100 aluminum base plates,
3. fabricating and forming the plates to tight dimensional tolerances and with a low blister and nonbond rejection,

4. joining fuel plates into an element with reliable bonds and uniform water channel spacing, and

5. design, development, and fabrication of dies and fixtures suitable for industrial production.

With the use of aluminum as the structural material and the high average power density, $2000 \mathrm{~kW} / \mathrm{L}$, one of the prime design and material problems was temperature control, especially control of hot spots. The development of fuel cores, consisting of powdered $\mathrm{U}_{3} \mathrm{O}_{8}$ in powdered aluminum in a configuration with a nonuniform fuel thickness across the width, went a long way in reducing flux peaking and thereby the maximum plate temperature (Fig. 11). Bill Foster of M\&C and $J$ Reynolds of the Instrumentation and Controls Division (I\&C) jointly developed a through-transmission, $\mathrm{x}$-ray attenuation instrument that could measure and plot such uranium concentrations across an entire fuel plate.

To yield the desired stronger fuel plates, 6061 aluminum is used as both the frame and cover plate material. Use of such an alloy, however, caused increased nonbond and forming problems. Obtaining acceptable nonbond 


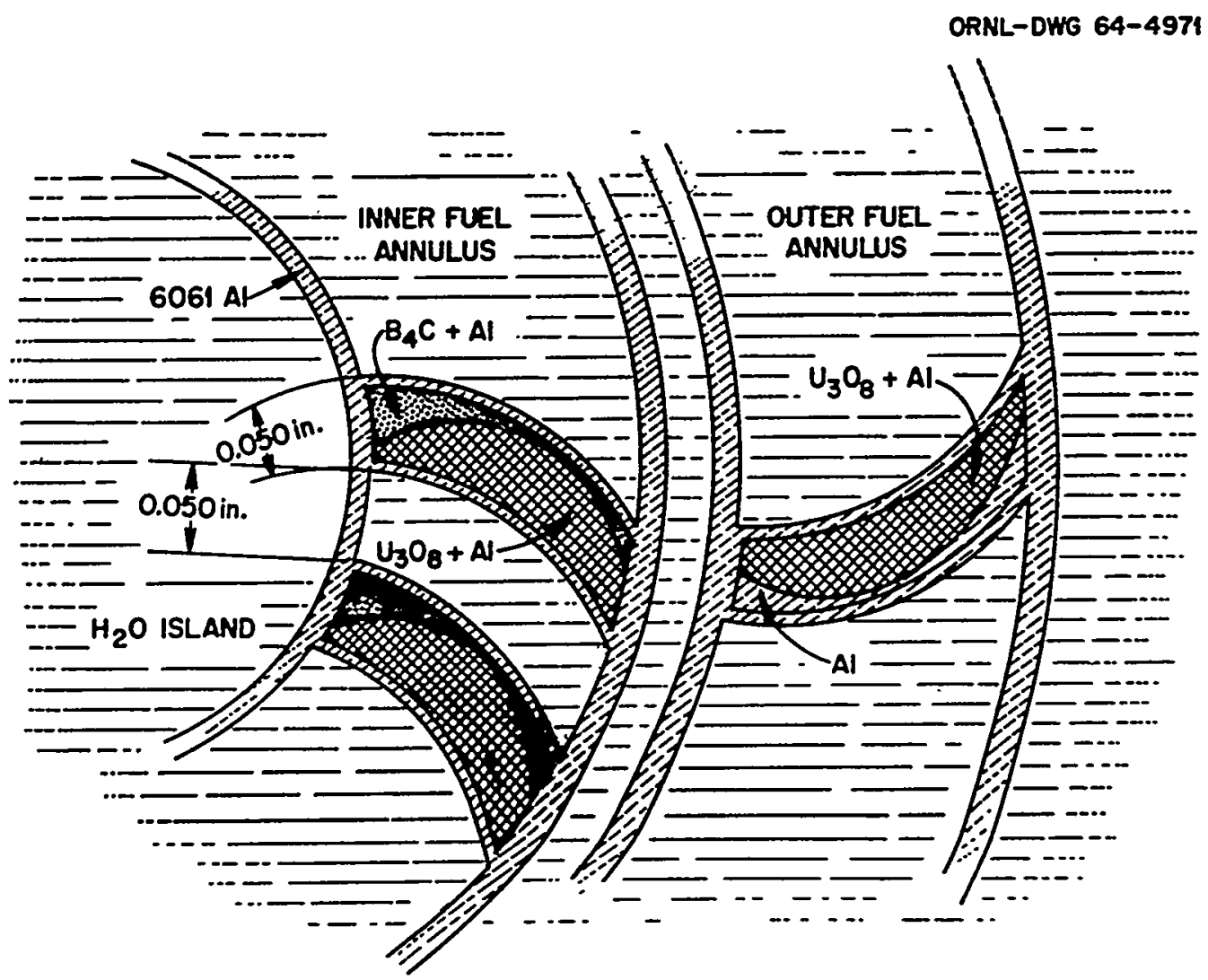

Fig. 11. Cross section through fuel plates, showing curvature to help cooling and fuel loading to reduce flux peaking.

yields required the development of a new 6061 aluminum cleaning technique.

The powder-dispersion fabrication practices, the aluminum cleaning techniques, and the homogeneity scanner have all become the basis of techniques now used worldwide for the fabrication of aluminum-base fuel plates.

A problem that caused many headaches and one of the last to be solved was that of obtaining uniform and reproducible curvature in the formed plates necessary to meet the tight plate-spacing requirements. Forming utilizes a low-pressure marforming operation in which a formed steel die presses the plates into a polyurethane pad.

Variations in curvature across and, especially, along a plate, were the usual problem, which was ultimately solved by incorporating a $20 \%$ cold-working sequence and a dead, soft anneal as a final step.

The most difficult operations in the HFIR fabrication are assembly and 
welding. The major problem is to assure a reliable plate tie-in while controlling weld shrinkage. The weld shrinkage affects both the overall dimensions of the annular element and water channel spacing. Fuel plates are slid into grooves machined in tubular side plates and are partially held in position by strips of Teflon filling each channel.

The plates are attached by welds made in grooves cut into the opposite side of each tube. The edges of the plates, which do not contain fuel, protrude into these grooves and are fused into the side plates. Completely automatic tungsten inert gas welding procedures with specially designed heads are used.

Each element contains 96 circumferential welds yielding 25,920 joints. After welding, to show that the water channels have not been deformed, every channel spacing is measured and recorded. This is accomplished by a five-coil, eddy-current thickness gage inserted into five specified tracks down the length of every channel.

Under the direction of Rodney Knight the fabrication techniques developed at ORNL were successfully transferred to two commercial fabricators, first to Texas Instruments in Attleboro, Massachusetts, and then to Babcock and Wilcox of Lynchburg, Virginia. An important portion of the original work at ORNL and Texas Instruments was the development and testing of the many dies and fixtures required. This was a costly operation, but after fabrication of 200,000 fuel plates, except for sharpening, the majority of the original tooling is still being used.

\section{control plates}

The HFIR reactor control system is unique since it consists of two cylindrical arrangements of plates located between the fuel core and the beryllium reflector. The cylinders are 66 in. long, $1 / 4$ in. thick, and approximately $18 \mathrm{in.}$ in diameter.

The inner cylinder is formed from four plates welded together, while the outer has four plates that are mechanically attached to each other. Each plate consists of four regions of differing neutron absorber characteristics. Both ends are all aluminum and therefore transparent to neutrons or "white."

The center contains two regions of differing absorption: a short "grey" section from a dispersion of tantalum powder in aluminum and a longer "black" section from a dispersion of europium oxide in aluminum. All parts are clad with 6061 aluminum, and all except the "black" section contain 1/4in. holes on 1-in. centers for pressure equalization. The primary materials problems involved fabricating these large composite plates to close tolerance (and free of nonbonds) and then forming them into cylinders.

The forming was complicated by the brittleness of the europium oxide- 
aluminum matrix core. The materials efforts were managed by Richard Beaver with the fabrication by M\&C Division and the explosive forming jointly with the Y-12 Plant.

The large plates were fabricated in a single operation, with the large cores achieved by stacking smaller ones in three layers. With the many joints, it was necessary to condition the europium oxide and to weld and evacuate the cores before both hot straight and cross rolling were used to obtain the large dimensions. 


\section{fabricating targets for the high flux isotope reactor}

The HFIR target elements provide targets of various transuranium elements for irradiation in the flux trap region of the HFIR to produce research quantities of transplutonium elements, such as americium, curium, and californium. The target assembly for the HFIR consists of 31 target elements 35 in. long with an active length of 20 in.

In the reactor the target assembly is centered in the fuel assembly, and individual target elements are irradiated for about 18 months. Initially the transuranium target material was ${ }^{242} \mathrm{Pu}$. Subsequent targets were fabricated from transuranium materials with higher atomic number reprocessed from the initial targets. M\&C involvement was the development of the processes for making the initial plutonium targets in a glove box fabrication line and the development of the processes and equipment for fabricating the transplutonium targets elements in a remotely operated and maintained hot cell facility.

In the target elements the transuranium materials are present as 1/4-in.diam pellets of metal oxides in an 1100 aluminum matrix. The 20-in. active target length requires 35 individual pellets. The target pellets are sheathed in an extruded 3/8-in.-diam partially finned 8001 aluminum tube with welded end fittings.

The fins position the target tube within a 5/8-in.-diam 8001 aluminum cover can that has a short hexagonal section for positioning the target element in the target assembly. Development activities for fabricating the target elements centered around the blending and dispensing techniques of the aluminum and transuranium oxide powders used in cold pressing the target pellets and welding the end closures.

Other developments included a nondestructive eddy current inspection technique for determining the sheath-tocan spacing and forming and machining techniques for preparing the finned target tubes and target cans with the hexagonal positioning area. Because of the extremely high background irradiation levels $\left(>10^{4} \mathrm{rad} / \mathrm{h}\right)$ that would be encountered in fabricating target elements with reprocessed transplutonium materials, specialized processes and equipment were developed for remotely fabricating the targets.

Because of concern for contaminating the outside surfaces of the target elements during fabrication, all HFIR targets have been fabricated by the technique proposed by Sloan Bomar and A. L. (Pete) Lotts for pressing the tranuranium-aluminum powder mixture in a section of an aluminum tube with pure aluminum powder ends.

The blending and dispensing of the very dense and relative coarse

transuranium oxide powders with aluminum powder was a significant 
problem in the fabrication of targets for irradiation testing and early targets. The transuranium oxide must be dispersed uniformly within the 35 pellets of the active target zone because of the high heat generation and burnup the targets must withstand during their 18-month residence in HFIR.

The blending and dispensing technique developed by John Sease uses a miniature double cone blending vessel with a vibratory feeder for dispensing. It has been very effective making very uniform HFIR targets pellets. The dispensing hopper must be isolated from the vibratory feeding mechanism.

The end-closure fusion weld developed by Joe Eve and John Sease for the HFIR targets uses a unique integral filler metal joint design. The major problem in welding development was porosity in the final closure caused by expansion of the helium gas contained in the closed aluminum target tube.

This problem was solved by reducing the pressure inside the target tube below atmospheric and welding at atmospheric pressure. The weld joint design allows the establishment of a mechanical seal before welding. Because of the success of the final closure weld, both end fitting welds have been made with decreased internal pressure.

After some 25 years HFIR targets are still' being made by essentially the same equipment and processes developed in the mid sixties. The development of the remotely operated equipment was a major effort by Central Engineering and $M \& C$, and the fact that much of this equipment is still functioning in an extremely hostile environment is a testament to the design effort headed by Ken Preston with support of the $\mathrm{K}-25$ engineering group. Over the last 25 years several hundred targets have been fabricated remotely in Building 7920 hot cells at ORNL. Many M\&C personnel have been responsible for the successful fabrication of the HFIR targets, including John Van Cleve, L. C. Williams, and Edward Cagle. 


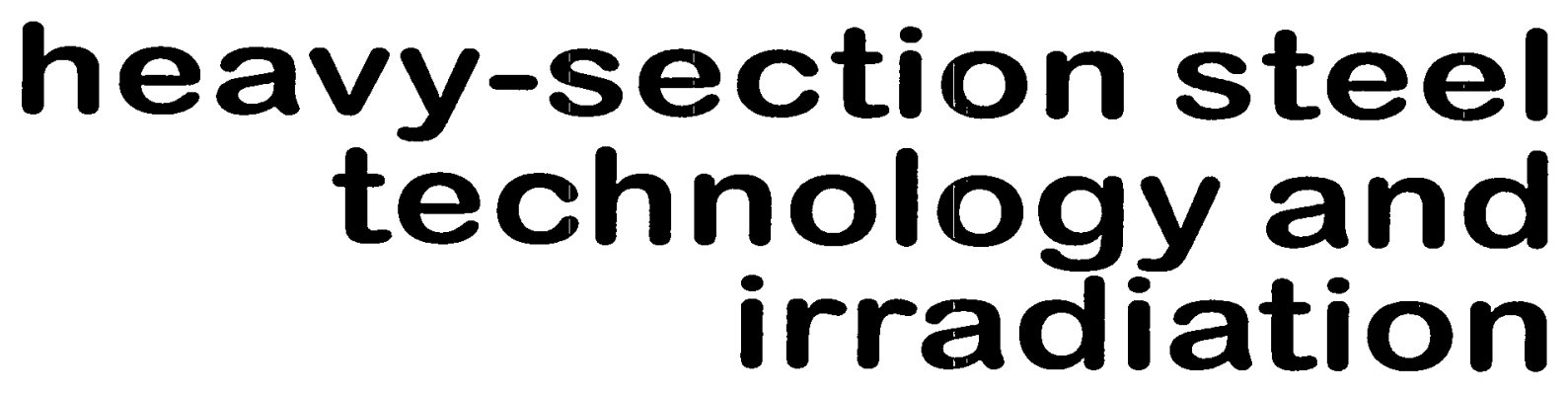

The reactor pressure vessel in pressurized-water and boiling-water reactors provides the primary line of defense in the event of an accident. In the 1950 s and 1960s, increased recognition of the importance of small flaws, which exist in all engineering structures, to fracture resistance led to major interest and advances in the new field of fracture mechanics. Because the reactor vessel is subjected to degradation by neutron irradiation and potential rapid cooling in certain kinds of accidents, and because it serves such a critical function, the application of fracture mechanics to those vessels assumed paramount importance.

The Heavy-Section Steel Technology (HSST) Program is probably the longest running research and development program at ORNL and is certainly the oldest program funded by what is now the Nuclear Regulatory Commission. The HSST Program was formally conceived in a November 24, 1965, letter from the Advisory Committee on Reactor Safeguards (ACRS) to the U.S.

Atomic Energy Commission (AEC). The pertinent passage in that letter, which was signed by William Manly, a former Metals and Ceramics Division member, was as follows: "...To reduce further the already small probability of pressure vessel failure, the committee suggests that the industry and the USAEC give still further attention to methods and details of stress analysis, to the development and implementation of improved methods of inspection during fabrication and vessel service life,-and to the improvement of means for evaluation and factors that may affect the nil ductility transition temperature and the propagation of flaws during vessel life. ... incorporating in many reactors the design approaches whose development is recommended above..."

The Pressure Vessel Research Committee (PVRC) of the Welding Research Council prepared a research program that responded to the recommendation of the ACRS letter. In June 1966, the PVRC presented its program to the AEC staff and suggested that ORNL might be a satisfactory organization to administer the program. Testimony to the AEC interest in the concept of a HSST program was provided in May 1966 when it authorized ORNL to procure test material for groups participating in planned fracture-mechanics programs. The PVRC Program Plan was modified by AEC to include irradiation effects and elastic-plastic analysis, and, on March 17, 1967, the HSST Program was officially authorized for $\$ 8.3 \mathrm{mil}$ lion and for a term of 6 years.

Management of the HSST Program, with Joel Witt as Program Director, was established in the Reactor Division (now Engineering Technology Division) with the Metals and Ceramics Division responsible for metallurgical studies, laboratory mechanical property experiments, and irradiation effects. The program was to be carried out in close cooperation with the material suppliers, pressure vessel fabricators, and design segments of the nuclear 
power industry. The HSST Program Staff at inception included Domenic Canonico, and Ray Berggren, in the materials characterization task.

The first project of the program was the preparation of a white paper, ORNL-NSIC-21, on Technology of Steel Pressure Vessels For Water-Cooled Nuclear Reactors, A Review of Current Practice in Design, Analysis, Materials, Fabrication, Inspection, and Test, which was published in December 1967 and served as a state-of-the-art report on the technology of steel reactor pressure vessels.

From inception of the program until 1974 the M\&C activities concentrated on procurement and characterization of large plates prototypic of nuclear reactor vessels under design [a press release of October 10, 1966, announced production of THE WORLD'S HEAVIEST PLATE, more than 45,000 kg $(100,000 \mathrm{lb})$ by Lukens Steel Co. for ORNL], fabrication and characterization of prototypic submerged-arc weldments, development of fracture mechanics experimental techniques and data, irradiation effects, and intermediate vessel tests.

From 1967 to 1974 , the plates and fabricated weldments were used to extensively characterize mechanical properties and fracture mechanics behavior, including variability through the thickness and throughout the plates. Some of the HSST specimens tested by the Naval Research Labora- tory weighed as much as $2080 \mathrm{~kg}$ (4580 lb).

Results from these studies showed that, even in such thick sections, these steels exhibit a ductile-brittle transition well below the operating temperature of reactor pressure vessels, so that vessel safety was assured through ductile material behavior. They also provided the basis for the development of Appendix G, Section III of the ASME Boiler and Pressure Vessel Code.

By 1974 , it became apparent that the HSST Program was going to be extended beyond its planned 6-year life. To provide for a more efficient and focused response to program needs, the Steel Technology Group (now the Fracture Mechanics Group) was organized within the Engineering Materials Section on March 8, 1974, led by Canonico. Until that time, all the fracture toughness testing for the HSST Program was subcontracted to outside companies. With added personnel the group procured equipment and developed in-house capabilities for fracture toughness testing and in December 1979 began to develop capabilities in crack-arrest toughness testing.

One of the hallmarks of the HSST Program was the experimental and analytical studies using intermediatesized pressure vessels designed and fabricated according to ASME Code rules from prototypic nuclear vessel materials. These vessels were fabricated with $1 \mathrm{~m}$ (39 in.) outer diameter, 
$0.15 \mathrm{~m}$ (6 in.) thick, by $1.37 \mathrm{~m}$ (54 in.) long cylindrical test sections. From 1972 to 1982 , twelve tests were performed on nine intermediate vessels with varying flaw sizes.

This series of experiments provided definitive confirmation of the large margin of safety inherent in Code designed and fabricated nuclear vessels in the as-fabricated condition. The group provided considerable input to both the material property data base required for experimental design and the posttest evaluations, while Robert McClung and his group developed nondestructive evaluation techniques.

Shafik Iskander of the Computing and Telecommunications Division (now of the Metals and Ceramics Division) developed the first major fracture mechanics computer code for analyses of the vessel tests. Another major aspect of importance for all the large structural experiments was the development of an electron-beam hydrogeninduced cracking technique for producing sharp flaws in specimens.

From 1975 to 1983 , a number of landmark vessel experiments were conducted to investigate the behavior of vessels, with varying flaw sizes, when subjected to a "thermal shock" resulting from injection of cold water by the emergency core cooling system during a loss-of-coolant accident.

Canonico and coworkers developed a heat treatment schedule to simulate the elevated tensile strength and degraded fracture toughness of irradiation-embrittled steels. Extensive fracture toughness experiments characterized the fracture behavior of the vessel materials and provided the basis for experiment design.

These experiments revealed that fracture toughness tests with small specimens in the transition temperature region exhibit substantially larger scatter than had been realized, and the use of statistical analyses was subsequently investigated. Iskander (C\&TD) developed a suite of codes that became known as the OCA (overcooling accident) Code used for analyses of vessels subjected to thermal shock and, later, pressurized thermal shock.

Extensive posttest fractographic examinations correlated the observations from the instrumented experiment with various fracture events; Randy Nanstad showed that the arrest of a cleavage crack is not preceded by a mode conversion to ductile tearing.

Important results from these experiments included the observations that short, shallow surface flaws could be made to grow long and deep by a series of multiple initiation-arrest events, which could be predicted from the fracture toughness and crack-arrest data obtained with small laboratory specimens.

From 1984 to 1987 , two technically challenging and significant pressurized 
thermal-shock (PTS) experiments were conducted with flawed intermediate sized vessels to investigate the combined effects of thermal and pressure loadings, and wide plate crack-arrest experiments were conducted by the HSST Program at the National Bureau of Standards. Nanstad and coworkers conducted fracture toughness and crack-arrest toughness characterization and heat treatment studies similarly to the thermal shock experiments.

In this case, however, Nanstad and others incorporated the single-specimen compliance and dc-potential drop techniques for computer control to produce $\mathrm{J}$-integral resistance (J-R) curves. Bill Corwin and coworkers incorporated the use of duplex specimens to increase the temperature range over which small specimens could provide crack-arrest data and developed techniques for conducting crack-arrest tests with precracked and warm-prestressed specimens to control initiation conditions at low temperatures.

The PTS and wide-plate experiments demonstrated that reactor pressure vessel steels, even those with very low tearing resistance, can exhibit arrest toughness values higher than the limit suggested in the ASME Code, and the arrest values obtained from the small laboratory specimens compared very well with those from the large tests.

To examine the role of stainless steel cladding, if any, in the behavior of surface flaws in reactor vessels, plates with weld overlay stainless steel cladding were tested in two experimental phases from 1984 to 1989 . The series of experiments showed that, with the materials used, the cladding had a limited capacity to arrest a running flaw on the surface. Another important aspect was the demonstration of a ductile-brittle transition that results in the cladding from brittle fracture of the small volume fraction of delta-ferrite as the temperature decreases.

The task involving the largest contribution from the Metals and Ceramics Division is that of irradiation effects; the program has irradiated a larger volume of material than any known program in the world. Because of the degrading effects of neutron irradiation, the overcooling accidents are significant to vessel integrity.

From 1968 to 1972, a series of experiments was conducted under subcontract. They emphasized the need for irradiation of large fracture mechanics specimens. Berggren and Walt

Stelzman found that the largest practical specimen for such experiments was a compact specimen of $101.6 \mathrm{~mm}$ (4 in.) thickness, which weighs about $45 \mathrm{~kg}$ (100 lb).

From 1972 to the present, seven series of experiments have been completed and three are currently under way. In the course of those irradiations, 34 of the largest specimens have been irradiated and remotely tested. These experiments have produced valuable 
information regarding the effects of irradiation on the fracture toughness and crack-arrest toughness of plates, welds, and stainless steel cladding, with significance to the integrity analyses of reactor vessels.

The early experiments and Series 1 demonstrated that crack initiation fracture toughness can attain high values under dynamic loading, even after irradiation. The Second and Third Series showed that irradiation can markedly reduce resistance to ductile tearing, even for welds with unirradiated low tearing resistance.

A plate and four current-practice welds tested in the Fourth Series validated the use of current welding practices as well as low copper and nickel contents to significantly reduce the irradiated fracture toughness degradation. The Fifth Series irradiated and tested 110 specimens (including 16 of the largest specimens) of two high-copper welds and showed that the irradiation-induced fracture toughness shift can be greater than that from Charpy impact specimens and that the fracture toughness curve may change shape.

Crack-arrest tests of the same welds in the Sixth Series more than doubled the world's database for irradiated crackarrest tests. The Seventh Series demonstrated that the fracture toughness of stainless steel weld overlay cladding is degraded by irradiation; and currently a high-copper, low-upper-shelf weld is being tested and irradiated in the Tenth
Series. In 1990, the irradiation task was split from the HSST Program and organized as the Heavy-Section Steel Irradiation (HSSI) Program, with Corwin as program manager.

Other examples of research not directly connected with the large structural test projects are (1) investigations of size effects in linear-elastic and elasticplastic fracture mechanics with accompanying statistical analyses for eventual development of an ASTM standard on fracture toughness testing in the transition temperature region; (2) the effects of thermal aging on the base metals and stainless steel cladding used for reactor vessels; (3) irradiation effects on vessel support materials; and (4) evaluation of the Yankee Reactor vessel embrittlement.

In summary, the HSST and HSSI programs comprise three broad areas of investigation involving materials, analysis, and experimental validation, with efforts closely coordinated to result in a unique program in solid mechanics research and development concerned with reactor pressure vessel safety. The programs have earned broad support from industry and government and have been given the opportunity to produce results vital to the safe operation of nuclear power systems. The people of the Metals and Ceramics Division have played a significant role in that effort over its more than 30-year history. 


\section{liquid-metal fast breeder reactor}

In the late 1960s and early 1970s, the U.S. Atomic Energy Commission (AEC) and Energy Research and Development Administration (ERDA) made the development of a Liquid Metal Fast Breeder Reactor (LMFBR) a focal point for resolution of the emerging energy crisis associated with continuing U.S. industrial growth.

Light water reactors (LWRs) of the pressurized and boiling water varieties were being ordered by U.S. utilities in preference to fossil-fired plants, and it was projected that as many as seventeen 100-MW(e) nuclear plants would be brought on line each year, totaling about 300 by the year 2000 . At this rate, rapid depletion of the U.S. (and the world's) ${ }^{235} \mathrm{U}$ supply was inevitable, even with recycling of ${ }^{239} \mathrm{Pu}$ from the LWR plants.

Although the United States had pioneered sodium-cooled reactor technology, i.e., the 20-MW(e) EBR-II in 1963, the rest of the industrial world had moved ahead to the demonstration plant stage. In 1976, the Clinch River Breeder Reactor Project (CRBRP) was finally authorized with Westinghouse, General Electric, and Rockwell International corporations playing key roles.

Oak Ridge National Laboratory was selected as a very important partner on the LMFBR team because of special talents in nuclear safety, physics, instrumentation and controls, hightemperature structural design, and, most importantly for the Metals and Ceramics (M\&C) Division, fuels and materials.

When Oak Ridge, Tennessee, was selected as the site for the CRBR, it became apparent that significant interactions among the staff of the industrial contractors and $\mathrm{M} \& \mathrm{C}$ Division principal investigators would be needed to optimize technology transfer. At times, as many as 30 person-years per year of Division effort were involved. However, by the late 1970 s, earlier government predictions of a "uranium gap" evaporated, and the urgency of breeding plutonium also vanished, resulting in the cancellation of the CRBR project in 1983.

Since LMFBRs would operate under conditions where creep and thermal transient loading effects could be significant, the Mechanical Properties Group, directed by Chuck Brinkman, was responsible for satisfying the data requirements for implementing advances in high-temperature inelastic design methods. Thus, servo-controlled testing machines and high-resolution extensometry were developed to gain more information on the essential behavior of high-temperature alloys.

High-temperature pressure vessel and structural materials that received the most attention included types 304 and 316 stainless steel, 2-1/4 Cr-1 Mo steel, alloy $800 \mathrm{H}$, alloy 718 , and modified $9 \mathrm{Cr}-1$ Mo (T-91) steel. As a result 
of data developed on cyclic hardening, primary creep, complex creep-plasticity interactions, creep-rupture, high- and low-cycle fatigue, creep-fatigue, and crack growth, the American Society of Mechanical Engineers (ASME) Boiler and Pressure Vessel Code cases were approved allowing use of types 304 and 316 stainless steels, $2-1 / 4 \mathrm{Cr}-1 \mathrm{Mo}$ steel, and alloy $800 \mathrm{H}$ in high-temperature nuclear applications for the first time.

One of the major accomplishments of the LMFBR Program was the development of an improved steel for steam generator and other applications. In 1974, the Department of Energy (DOE) authorized a task force to evaluate the deficiencies in types 304 and 316 stainless steels for liquid metal reactor (LMR) applications.

This group selected candidate alloys with the potential for improved performance and developed a plan to acquire the data base needed for use of each alloy in a future LMR economy in the late $1980 \mathrm{~s}$. The task force recommended that an improved ferritic steel be developed by modification of a $9 \mathrm{Cr}$ 1 Mo steel composition.

Vinod Sikka was designated task leader, and criteria that the alloy would have to meet were established. Subsequently, American Society for Testing and Materials (ASTM) specifications were established for most product forms, and the alloy is now advertised as available from Babcock $\&$ Wilcox (B\&W) Tubular Products Group, Nippon Kokan K.K., Sumitomo Metals Industries in Japan, and Valourec in France.

ASME Code cases have been approved, and Rockwell International Corporation has requested an inquiry for revisions to other cases Sect. III to permit nuclear applications of modified $9 \mathrm{Cr}-1$ Mo steel. After ten years of development, modified $9 \mathrm{Cr}-1$ Mo steel is a commercially available material that may be specified for use in an advanced $L M R$ and is being used worldwide in fossil plants and other applications, an outstanding example of technology transfer to the credit of DOE and M\&C Division staff.

Nondestructive testing (NDT) was essential to ensure the integrity of the separation boundaries between water and sodium in the steam generator for the LMFBR, and radiography was one of the NDT techniques required for evaluation of the tube-to-tubesheet weld joints. The basic approach developed by Bill Foster of the NDT Group involved placement of a very small gamma-ray source on the central axis of the tube in the plane of the weld joint, surrounding the joint with radiographic film, and making a $360^{\circ}$ panoramic exposure of the joint on a single radiograph.

Miniaturized wire- and hole-type penetrameters were fabricated and 
used to assess image quality of the radiographs. Through cooperation with the Isotopes Division at ORNL, these initial studies led to the development of techniques for fabrication of nearly spherical sources of iridium, ytterbium, and thulium with diameters as small as 0.01 in. $(0.25 \mathrm{~mm})$.

These fabrication techniques were subsequently transferred to private industry, and the studies led to the development of a microfocus rod-anode $\mathrm{x}$-ray unit at Technisch Physische Dienst in Delft, The Netherlands.

Ultimately, the high-sensitivity, highresolution radiographic technique using the rod-anode $x$-ray unit was selected and successfully used to test the tubeto-tubesheet welds for porosity, cracks, and other minute flaws. To date, no leaks have been found in the tube-totubesheet welds evaluated with this boreside technique, even after many thousands of hours of operational testing.

The potential danger of a tube leak from steam to sodium was also recognized as an important reliability and safety factor in the LMFBR steam generator. A method of eddy-current inspection was used for the pressurized-water reactor (PWR) plants mainly for its high speed.

However, the tubes in the breeder steam generators were made of a thick, ferromagnetic material rather than the austenitic material used in a PWR plant. Both the thickness and ferromagnetism made this inspection very difficult with eddy currents. Caius Dodd of the NDT Group determined that magnetic saturation was needed to overcome these factors. He found that a power of about 0.5 MW furnished enough field to saturate the tube.

However, that much power caused overheating, and the probe could not be pulled through the tube with the magnetic field energized. The solution was to use a pulsed field that saturated the tube for microseconds before being turned back off. This technique gave about the same inspection sensitivity for ferromagnetic tubing as the multiple frequency test for the austenitic steam generator tubing.

Later designs of the pulsed system reduced the saturation power to about $200 \mathrm{~kW}$ and allowed faster inspection. The technique has since been used to inspect the steam generators of the Yankee Rowe plant, where magnetite deposits on the inside of the tubing had previously hindered inspection attempts.

Other research and development accomplishments in support of the CRBRP and follow-on commercial plants included:

1. development of cladding and duct alloys to achieve $150 \mathrm{MWd} / \mathrm{kg}$ burnup and a 15-year doubling time. 
2. evaluation of europium sesquioxide $\left(\mathrm{Eu}_{2} \mathrm{O}_{3}\right)$ as an advanced absorber material, including fast-neutron irradiations in the EBR-I.

3. novel fabrication techniques for high-temperature boron nitride (BN) electrical insulators for simulated fuel element behavior studies.

4. equipment development for conveying, dispensing, and blending to achieve high-density "sphere-pac" loading.

5. evaluation of the compatibility of candidate steam generator materials with contaminated superheated steam under a high heat flux.
6. determination of the weldability of and development of optimized welding procedures for structural materials for primary, secondary, and steam generator circuits, including transition joints.

7. working with the Japanese to further develop mechanical properties and constitutive equations for modified $9 \mathrm{Cr}-1$ Mo steel (19891992).

8. working with the Japanese to develop mechanical properties data on an improved grade of stainless steel (316 FR) in support of fast breeder reactor development in Japan (1993-2000). 
$1975-1996$

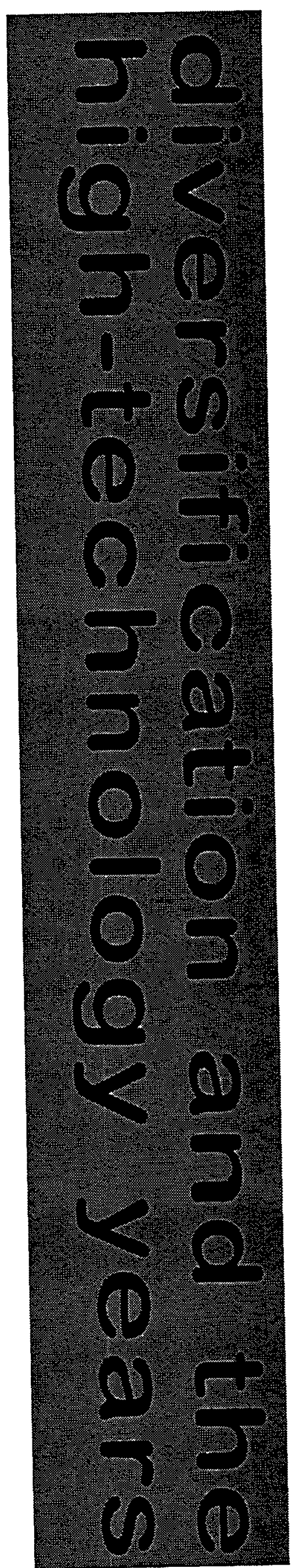




\section{structure and properties of surfaces}

Bob Clausing began the study of the structure and composition of surfaces and grain boundaries in 1969 to find the cause of embrittlement of the nickel-based Hastelloy $N$ (previously described as INOR-8 in the ANP section) used as the container for the Molten Salt Reactor. A home-built . Auger electron spectrometer system showed unambiguously that tellurium in the grain boundaries caused the embrittlement.
Auger electron spectroscopy and other surface analytical techniques have remained the key technologies in this laboratory ever since. Dewey Easton, Lee Heatherly, Scott Halstead, and Doc Emerson soon joined the surface analysis laboratory to build customized equipment for work in the Molten Salt Reactor and other projects, including the studies of the friction and outgassing of fuel elements for the nuclear rocket (for NASA), the embrittlement of grain boundaries in metals by neutron irradiation, and the plasma-material

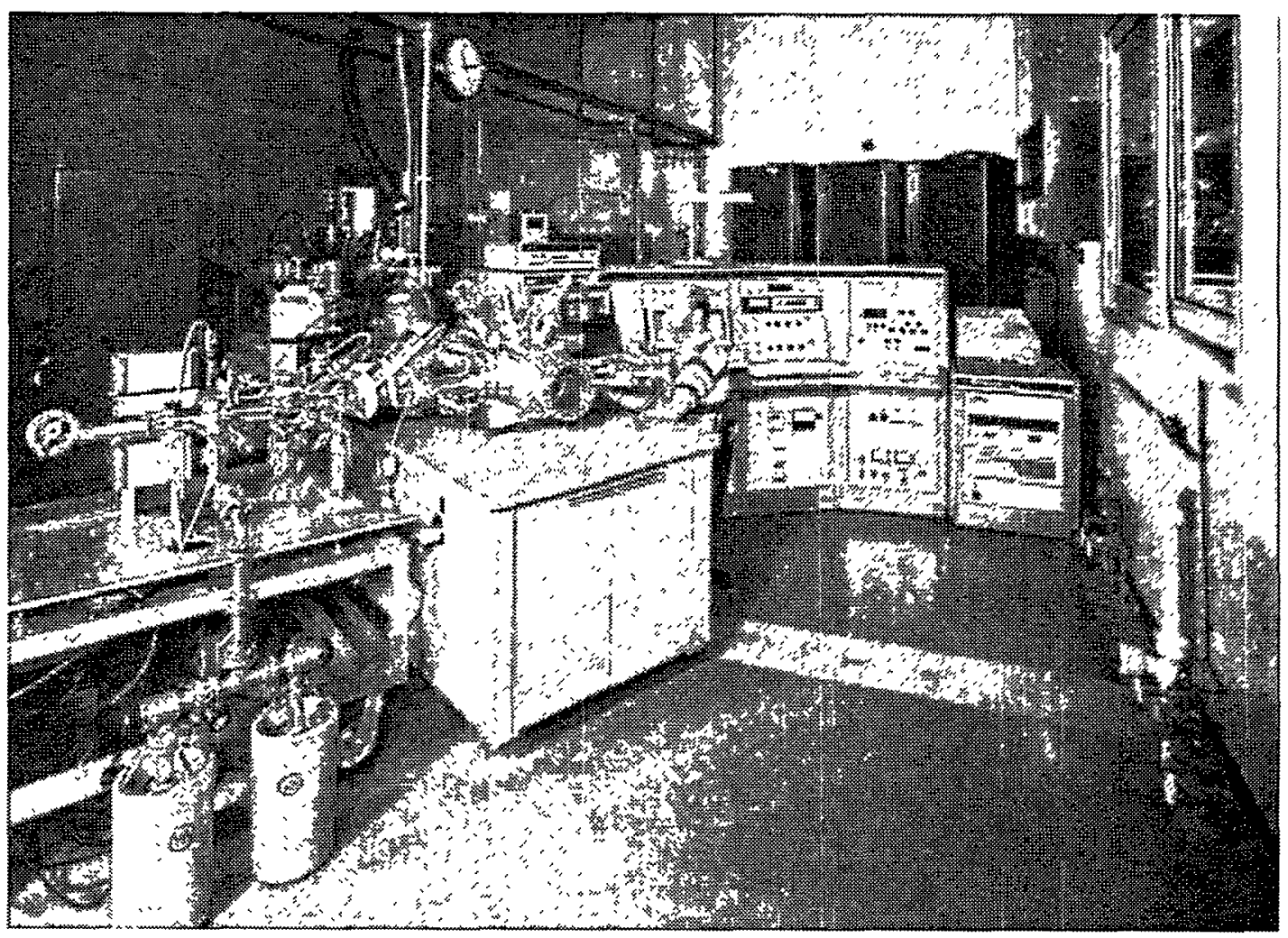

Fig. 12. Ray Padgett at the console of the Physical Electronics Model 590 scanning Auger microprobe, which has been modified to permit tensile, bending, or impact fracture of irradiated materials at cryogenic or elevated temperatures. The grain boundaries exposed by the fracture can be analyzed to study radiation-induced or other segregation. 


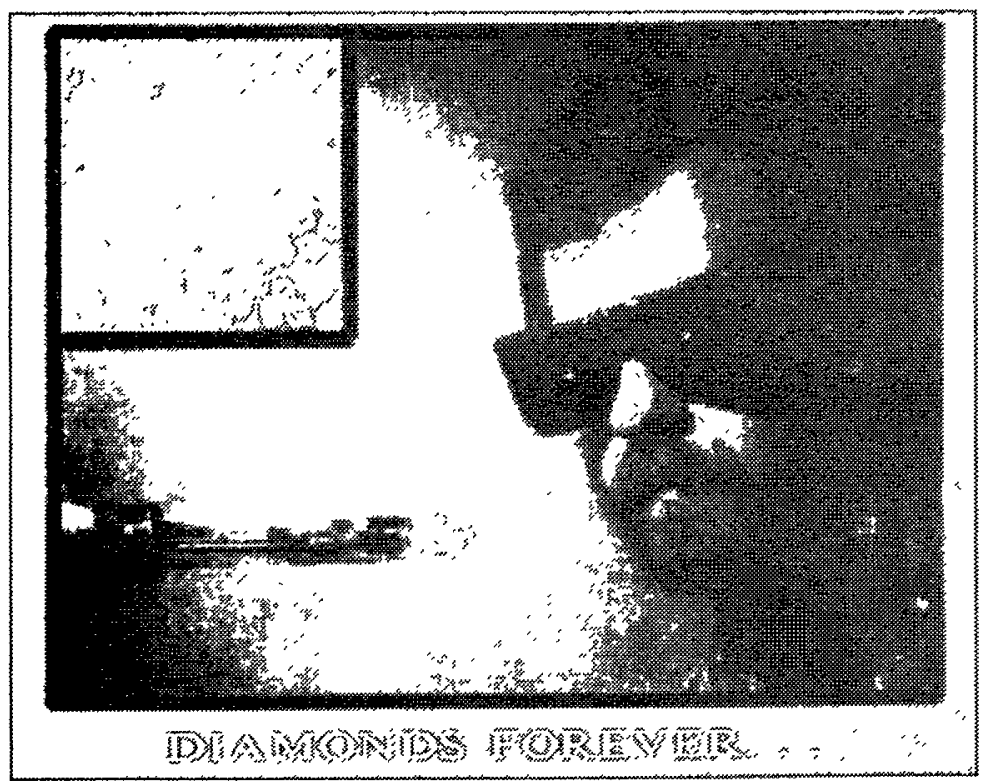

Fig. 13. Lee Heatherly and Diamonds Are Forever. He is checking on the growth of a diamond film by hot-filamentassisted chemical vapor deposition. The insert shows individual diamond crystals and a polycrystalline film formed by their coalescence.

interaction studies which continued for many years in support of fusion energy.

The plasma-material interaction studies included "field" work and Auger electron spectroscopy (Fig. 12) using ORNL designed and built equipment on fusion energy experiments not only in Oak Ridge but also in San Diego, Russia, Germany, and England. Cal White and Ray Padgett joined the group to study segregation to metal and intermetallic grain boundaries. Auger electron spectroscopy established that thorium in grain boundaries of iridium improves its high-temperature impact ductility. Auger electron spectroscopy also showed how boron segregation to grain boundaries in $\mathrm{Ni}_{3} \mathrm{Al}$ improved its ductility. This work continues under Easo George and graduate students.

In 1988, a seed money proposal and some support from the U.S. Army provided the beginning for a series of studies to link the growth and structure to the properties of diamond. This was an outgrowth of the plasma-materials interaction studies. Several hotfilament-assisted chemical deposition chambers are now in use to grow diamond films (Fig. 13) and freestanding sheet, while optical and electron microscopy as well as surface techniques are used to study the structure and composition of diamond surfaces and diamond-substrate interfaces. Current studies include exploring the growth of diamond single-crystal films on nondiamond substrates. 


\section{fossil energy program}

The Atomic Energy Commission (AEC) was replaced by the Energy Research and Development Administration (ERDA) in 1975, and the Office of Coal Research (OCR) was moved from the Bureau of Mines to ERDA. Recognizing the opportunity for coal-related research for OCR, ORNL initiated "The Coal Program," under the guidance of Jere Nichols of the Chemical Technology Division. Since many of the technologies for burning coal or for converting it to liquid or gaseous fuels required materials that could be used at high temperature and/or high pressure in very erosive or corrosive environments, materials research and development (R\&D) was needed to support OCR's coal technology programs.

Bill Martin, then Head of the Engineering Materials Section, along with Gerald Slaughter and Roy King, were soon on the road, getting to know the people at OCR Headquarters and at the Energy Research Centers at Pittsburgh (PERC) and Morgantown (MERC). Roy King began a project to provide failure analyses for components from coal combustion and coal conversion pilot plants.

Domenic Canonico and coworkers of the Steel Technology Group (now Fracture Mechanics) assessed R\&D needs for coal conversion pressure vessels. Gordon Godfrey went on assignment to PERC to learn about OCR activities and to provide an interface between PERC and ORNL.
On his initial visits to fluidized-bed combustion (FBC) plants (e.g., the Rivesville FBC plant) and coal liquefaction pilot plants (e.g., those at Fort Lewis, Washington, and Wilsonville, Alabama), Roy King encountered a great deal of skepticism. How could this metallurgist from a nuclear research center possibly help them with their problems in running their coal combustion or coal liquefaction plant? Roy recounts some of his early experiences:

"During the plant tour I would often see a scrap heap with several failed components on it. When I asked about these components, I would be told, 'Oh, that's just a pipe (or pump, or valve, or vessel) that failed last week. We replaced it and started up the plant again.' I would ask if I could take the failed component back to the Laboratory to see if we could determine the cause of failure. After we had successfully identified the cause of failure and had made recommendations to prevent recurrence on a few occasions, the people at the pilot plants began calling us when they had a failure."

These early efforts by King, Godfrey, and Canonico were the genesis of the Fossil Energy Materials Program in the Metals and Ceramics Division.

By 1978 ERDA had become the Department of Energy (DOE), and OCR had become DOE's Office of Fossil Energy. Following the runup in energy prices 
resulting from disruptions in the Mideast oil supply in 1973 and 1976, President Jimmy Carter declared "the moral equivalent of war." He set a national goal to double the use of coal and to provide a significant portion of the nation's liquid fuel needs by converting coal to gasoline and fuel oil.

Federal funding for coal R\&D was expanding, and DOE Fossil Energy was initiating several demonstration projects with industry on coal liquefaction, coal gasification, and fluidized-bed combustion. In that climate in 1978 DOE asked ORNL to devote significant resources to fossil energy research; in essence, to become a "lead lab" for fossil energy.

The task of building a significant fossil energy research program at ORNL was given to L. E. (Gene) McNeese, who by then was Director of the Laboratory's Fossil Energy Program.

One of the first national programs for which ORNL was asked to take the lead role was the Fossil Energy Materials Program, managed by Ron Bradley. The task during the first year was to transfer research projects from Headquarters to DOE-OR/ORNL and to begin research to address the materials needs of the coal liquefaction, coal gasification, and fluidized-bed combustion pilot plants.

Rod Judkins and Paul Carlson and later Nancy Cole assisted in the management of this National program. In the meantime, the failure analyses task had expanded to include in situ materials testing at several liquefaction plants, and James Keiser and Vivian Baylor were making regular trips to Fort Lewis, Washington, and Wilsonville, Alabama. They brought considerable credit to the Laboratory when they recognized that fractionation column corrosion was common to all the pilot plants and that it was related to the chlorine content of the coal.

With the insight derived from the results of in situ testing at the pilot plants, careful laboratory experiments, and some help from Rod Judkins' chemical engineering background, a good understanding of this corrosion process was developed and methods of preventing it identified.

About 1980 DOE-OR was given responsibility for the H-COAL coal liquefaction pilot plant being built at Ashland Oil Co.'s refinery in Catlettsburg, Kentucky. A team of Metals and Ceramics Division staff members including James Keiser, Rod Judkins, Arnold Olsen, Jack DeVan, and Ron Bradley reviewed the materials of construction and worked with the industrial participants in the project (Ashland Oil and Amoco) to develop a materials test plan.

Bob Swindeman led a project to perform a cyclic stress analysis on the $\mathrm{H}$ COAL reactor pressure vessel, and through this effort became the Fossil Energy Materials Program's resident expert on the requirements for coal 
conversion pressure vessel materials. By the time the H-COAL plant was started up, ORNL had established an excellent working relationship with the engineering and operations staff at the plant. On one occasion, an $\mathrm{H}-\mathrm{COAL}$ executive attending a meeting at DOEOR received word that a component failure had shut down the plant. $\mathrm{He}$ requested assistance from ORNL in identifying the cause of the failure, and within hours Bob Gray was on Ashland Oil Company's corporate jet, headed for Catlettsburg, Kentucky.

Also in the early ' 80 s, ORNL and TVA began a cooperative effort on fluidizedbed combustion technology, and Roy Cooper became the M\&C Division's personal envoy to Chattanooga.

This led to considerable research in the Division by Pete Ficalora on the effect of a pulsating oxidizing-reducing atmosphere on corrosion processes, by Jim Keiser on erosion mechanisms of solid particles impacting the surface of an alloy, and by Jack DeVan on the effect of calcium sulfate scales on the corrosion of fluidized-bed combustor in-bed heat exchanger tubes.

As time passed and the "energy crisis," eased, the long gasoline lines of the mid-seventies were forgotten and the need to develop coal liquefaction and coal gasification technologies diminished on the national agenda. President Reagan closed down the large pilot plants and canceled plans for the large demonstration plants. Activities on the
Fossil Energy Materials Program shifted to long range research to provide new materials and processes for future coal conversion or coal combustion processes.

Phil Maziasz and Bob Swindeman used the insight gained during several years of microstructural analysis of alloys on the Fusion Materials Program and knowledge of the requirements of alloys for fossil energy applications to develop advanced austenitics for use in coalfired steam generators.

C. T. Liu began research on nickel-iron aluminide to determine how much iron could be substituted for nickel in ductile Ni3Al. This work contributed significantly to the development of the nickel aluminide alloys later licensed by ORNL to industry and led to the later development of iron aluminides by Claudette McKamey, C. T. Liu, and

Vinod Sikka.

Jack Lackey and later Ted Besmann and David Stinton conducted work on the fabrication of continuous fiber reinforced ceramic composites by chemical vapor infiltration (CVI), which eventually established ORNL as a world leader in forced-flow CVI. This led to considerable other research on CVI funded by the Air Force and by the Conservation Advanced Industrial Concepts Materials (née ECUT, Energy Conversion and Utilization Technologies) and Continuous Fiber Ceramic Composites Programs. 


\section{synchrotron radiation beamline}

The Metals and Ceramics Division is a key player in the development of synchrotron radiation as a probe for materials science. In the middle 1970s members of the Metals and Ceramics Division's X-Ray Group began using an early synchrotron $x$-ray source at Stanford University. Based on their experience, they developed an $x$-ray fluorescence microprobe in 1976 with unprecedented sensitivity to test the reported existence of superheavy elements. The microprobe was the first application of crystal focusing optics to hard $x$ rays at a synchrotron. It conclusively demonstrated that the proposed superheavy elements did not exist in the samples at the concentrations reported.

Though $\mathrm{x}$-ray diffraction has been the major tool for solving the long-range and periodic arrangements of atoms in matter, intense electron microprobes and microscopes partly replaced the weak $\mathrm{x}$ ray sources for general purpose sample characterization beginning in the late 1960 s. Both the crystal structure and the disruptions from this long-range periodicity are useful to the understanding of changes in materials properties.

Since the diffraction effects from these disruptions of the perfect order are weak, in- tense synchrotron sources with $10^{3}$ to $10^{6}$ times the brightness of conventional $x$-ray sources have brought new opportunities to study defects in bulk materials.

The Department of Energy funded the construction of a synchrotron radiation facility (National Synchrotron Light Source, NSLS) at Brookhaven National Laboratory on Long Island, New York, for completion in 1984. The X-Ray Diffraction Group of the Metals and Ceramics Division took the lead with $\mathrm{X}$ Ray Groups of the Solid State and Chemistry Divisions to fund ( $\$ 900 \mathrm{~K})$ and to construct an $\mathrm{x}$-ray diffraction

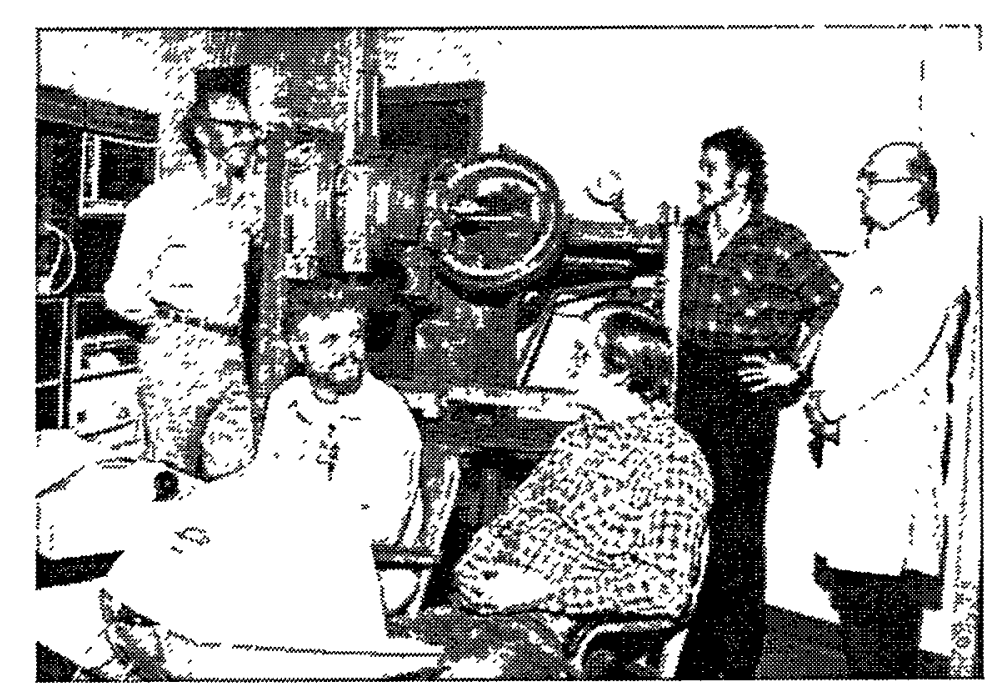

Fig. 14. Members of the construction team that built an $x$-ray diffraction facility at the newly proposed National Synchrotron Light Source are shown in 1981 with their recent purchase of a 4circle goniometer to orient samples in the $x$-ray beam. Software for computer control of motor drives was an interdivisional effort. From left are Cullie Sparks (M\&C), David McMillan (I\&C), Tony Habenschuss (ORAU Research Associate), Gene Ice, and Harry Yakel (M\&C). 
beamline at this new synchrotron facility. Construction began in earnest in 1981 with the team shown in Fig. 14 gathered around our first large purchase (a crystal diffractometer used to orient the sample in the synchrotron $x$ ray beam). New $x$-ray optics were invented and patented to focus synchrotron radiation. This invention in $\mathrm{x}$-ray optics won an IR 100 award and has become the standard for focusing hard $x$ rays from synchrotron sources. The facility was assembled on the ground floor of Building 4508 of the Metals and Ceramics Division. In 1984, the equipment was loaded on a large van, as shown in Fig. 15, and moved to the NSLS. Workers at Brookhaven were amazed when the beamline suddenly appeared intact on the NSLS floor.

This synchrotron beamline has resulted in many collaborative research projects within the Metals and Ceramics Division, with other ORNL scientists, and with hundreds of scientists from dozens of universities, industries, and other government laboratories. Collaboration is open to scientists in research areas of importance to DOE programs. This high intensity $x$-ray facility has helped uncover new information about the structure of metal alloys, intermetallics, interfaces, thin films, ceramic surfaces, quasicrystals, heavy fermion systems, and superconductors, among others. This new information is leading to a better understanding of the relationship between the structure and properties of materials. A newer facility is under construction for the Advanced Photon Source at Argonne National Laboratory, which will provide a thousandfold gain in brightness when completed in 1996.

Fig. 15. After completion of the $x$-ray beamline construction at ORNL, riggers operate a forklift to load the equipment onto a van for transportation to the National Synchrotron Light Source on Long Island. 


\section{shared research equipment program: collaborative research at ornl}

Since its inception in 1979, the Shared Research Equipment (SHaRE) Program at Oak Ridge National Laboratory has permitted collaborative research projects by the staff of the Metals and Ceramics (M\&C) Division and scientists from universities, industries, and other national laboratories. These projects take advantage of the facilities within the M\&C Division that often define state-of-the-art and are a major national resource. Thus, SHaRE enables research projects that are valuable to both outside investigators and ORNL scientists.

The SHaRE program is designated a User Facility by the U.S. Department of Energy (DOE). However, unlike many other User Facilities, the SHaRE program requires that projects are collaborative. The program has been funded by the DOE, Office of Basic Energy Sciences (BES), Division of Materials Sciences. In the past 18 years, SHaRErelated research has resulted in over 280 publications, a similar number of presentations at national and international meetings, and 53 completed M.S. and Ph.D. theses.

Whereas access to many of the research facilities within the M\&C Division is possible to SHaRE participants, the strongest interest has been in the transmission electron microscopy (TEM), analytical electron microscopy (AEM), atom probe field ion microscopy (APFIM), and mechanical properties microprobe (MPM) facilities. The ben- efits derived from SHaRE providing access for outside investigators to the world class AEM/APFIM/MPM facilities at ORNL are manyfold. Few universities or industries can afford state-of-the-art facilities in all relevant areas. The national laboratories provide an immense resource of such facilities.

The current facilities covered under SHaRE include three AEMs, an APFIM (Fig. 16), and two MPMs. Currently under development are a high-temperature MPM and two APFIMs, including the mapping atom probe (MAP), all of which will be available under SHaRE when fully functional and user ready. Both an advanced 200-kV field emission gun AEM and an analytical scanning electron microscope was added during CY 1994. The M\&C Division's Microscopy and Microanalytical Sciences (M\&Ms) Group is responsible for maintaining and developing the AEM, APFIM, and MPM facilities and provides a core of expertise and talents upon which the SHaRE projects draw. In addition, other M\&C Division staff collaborate on such projects. These scientists have demonstrated expertise in the application of AEM, APFIM, and MPM and are nationally and internationally recognized in their fields. The primary thrust area for the M\&C Division (and therefore most SHaRE projects) is structural materials and the correlation of processing, structure, and properties for a wide range of metallic, ceramic, and composite materials. Additional SHaRE projects have 


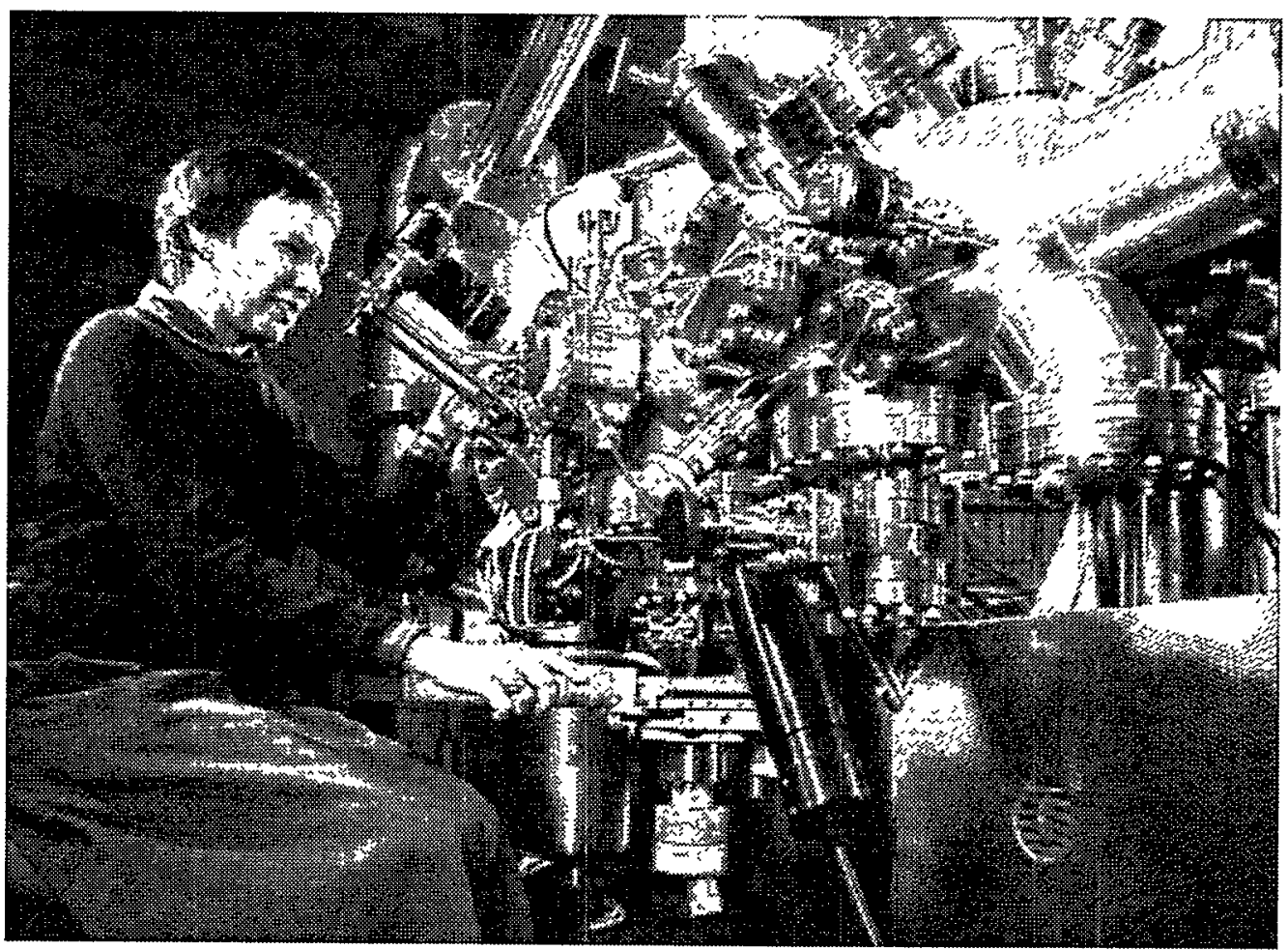

Fig. 16. A number of SHaRE projects have utilized the atom probe field ion microscope (APFIM) for high spatial resolution imaging and microanalysis that can approach near atomic level. The APFIM provides the combined capabilities of a field ion microscope, a time-offlight atom probe, and an imaging atom probe.

dealt with the application of microscopic techniques to magnetic materials, catalysts, and semiconducting device materials. Recent areas of research include high-Tc superconductors, surface-modified polymers, nano- structured materials, and embrittlement of metals. A conscious decision has focussed the efforts of the M\&Ms Group staff in its strength areas and has defined and obtained state-of-theart facilities for its studies. 


\section{electron beam welder}

The electron beam welder (Fig. 17) was obtained in 1984 by the Materials Joining Group to support both the welding research activities and specialized joining needs of several programs at ORNL and other laboratories. Applications for this equipment have included fabrication of electrodes for the production of iridium alloy, specimen joining for large heavysection steel fracture mechanics testing, refractory alloy test coupons and component joining for space nuclear power project, joining of precision components for the fusion energy pro- gram, and weldability evaluations for new alloys.

New applications are continually being found for this machine, which moves the components by computerized numerical control under a high-intensity beam of focused electrons. By utilizing the wide range of electron beam power available

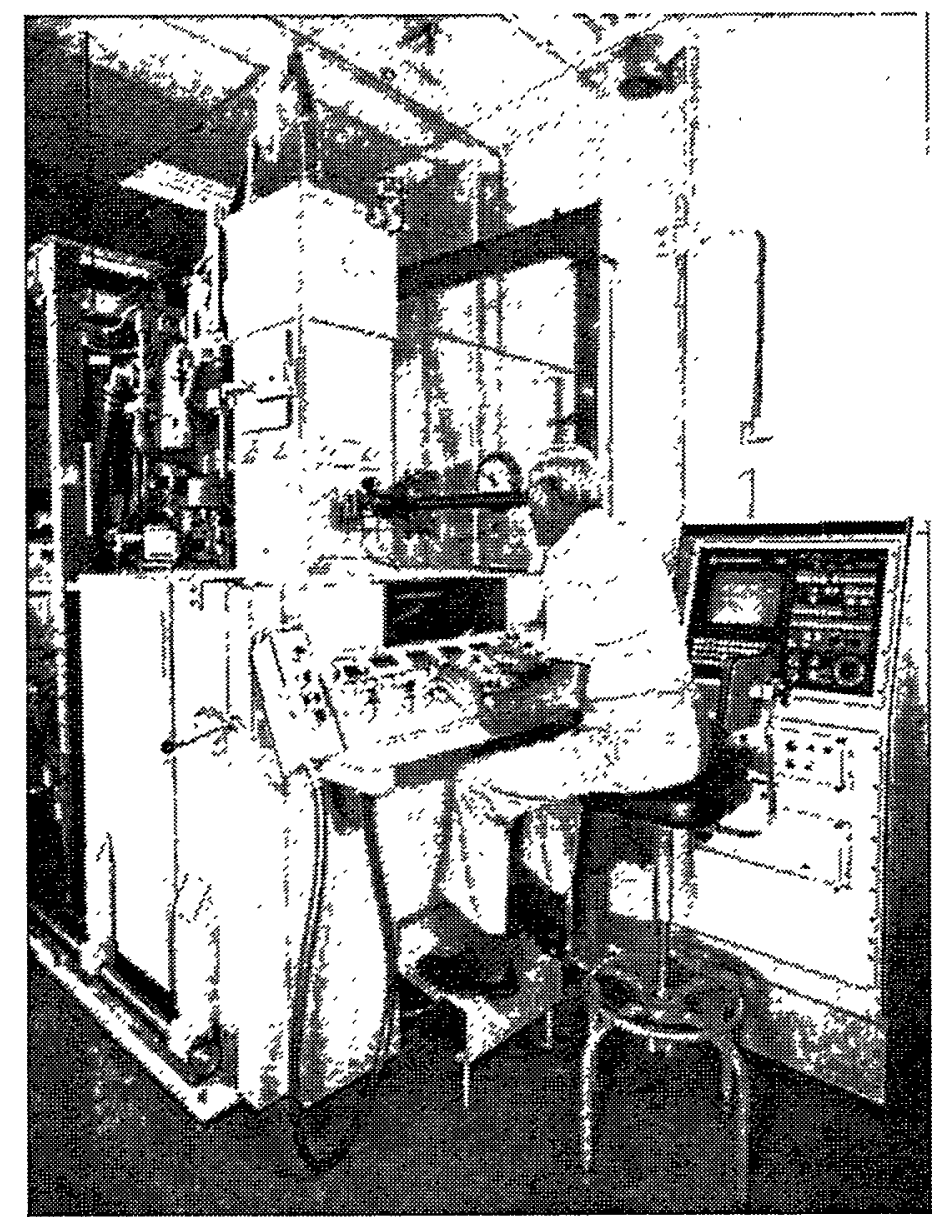

$(15 \mathrm{~kW}$ maximum) and beam manipulation features, one can weld materials ranging from thin metallic foils to 80mm-thick plate. Defocused and magnetically deflected beams can also be used for material heat treatment, surface treatments, and brazing.

Fig. 17. Leybold-Heraeus Electron Beam Welder, shown here with J. D. Hudson, can make precision microwelds and high depth-towidth ratio deep penetration welds in a range of materials. 


\section{the high temperature
materials laboratory}

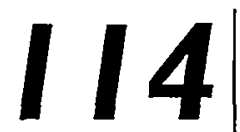

On April 18, 1989, the Coors Corporation announced its plan to build a new, advanced high-temperature ceramics production and research facility in Oak Ridge, Tennessee. This corporate decision to bring a new, high-technology industry to Oak Ridge is but one example, among many, of the very favorable response of the industrial and academic research communities to the Metals and Ceramics (M\&C) Division's new High Temperature Materials Laboratory (HTML).

The HTML is a research facility that not only contains an integrated staff devoted to research in the critically important new field of high-temperature materials but also offers to the staff and outside users access to the collection of advanced, modern research equipment needed to characterize, on an atomic scale, the structure of new materials. In addition, testing facilities are available to measure the physical and mechanical properties of newly developed materials.

The idea of a special laboratory devoted to the study and development of hightemperature materials originated in discussions among and between the research staffs of the $\mathrm{M} \& \mathrm{C}$ and the Solid State Divisions in the early seventies. The initial draft of a proposal to construct the HTML was prepared in August 1977 by Timothy Reiley of M\&C at the direction of Alex Zucker, ORNL Associate Laboratory Director in charge of the project. This version of the
HTML, was presented to the Basic Energy Sciences (BES) staff of the Department of Energy who authorized a formal conceptual design study. John Cathcart of the M\&C Division became involved in moving the project forward and remained so until construction was completed.

Almost everyone seemed to think that the concept of an HTML was a wonderful idea, hopes were high for quick congressional approval and an actual start on construction. No such luck! As Zucker likes to say, "the gestation time for a major construction project is 10 years," and in 1979, the project was ahead of that schedule. Not until the third Schedule 44, in September of 1982 , at the very end of the fiscal year, appropriation of $\$ 1$ million was accomplished. Success was triggered by two events: a director of the HTML, Victor Tennery, was appointed, and in Washington, sponsorship of the project was switched from BES to the Conservation and Renewable Energy area of DOE. A. Chesnes, the director of the Heat Engine Propulsion Division, assumed the responsibility for presenting the case to Congress. He arranged the million dollars and enough additional in subsequent years to make a total of $\$ 19.1$ million for the entire project.

That first million dollars set in motion the process the government uses in selecting an architect for a construction project. The Pittsburgh architectural firm Deeter Richey Sipple (DRS) won 
the design competition, and it along with A M. Kinney, Inc., to whom DRS subcontracted the engineering design work, began the actual design of the HTML. Within a year after architectural work started, we were able to obtain bids for the construction work. The low bidder was Blaine-Hays Construction Corp., of Knoxville, Tennessee, whose bid was just over $\$ 9$ million.

Construction began in the snow on January 20, 1985. It was too cold then for a proper ground-breaking ceremony, so an HTML Inauguration Celebration was held on May 27, 1985 in front of the just completed architectural bent. Department of Energy (DOE) Assistant Secretary for Conservation, Donna Fitzpatrick, was the featured speaker.

Another two years was required to complete construction. That was two years full of problem solving - handling the inevitable design changes, coping with late deliveries by vendors, dealing with special requests from future occupants of the laboratory.

The leadership of John Murray, the architect, and our building contractor, caused the HTML to be finished within budget and on schedule in time for the formal dedication ceremony on April 17,1987 , almost exactly 10 years after Tim Reiley's draft proposal! Donna Fitzpatrick again led the speakers in predicting a useful future for the HTML, and a special plaque was un- veiled in the HTML lobby acknowledging Al Chesnes' contributions to the success of the project.

The HTML is a two-story glass-andconcrete structure containing 64,500 sq. $\mathrm{ft}$ of floor space consisting of 49 laboratories with office space for a staff of about 75 . The final cost of the building itself was $\$ 9.8$ million. Another $\$ 6.3$ million was spent on the special research equipment for the User Centers, and $\$ 2.8$ million represented the cost of design and supervision. The building accommodates two groups involved in various aspects of research and development of high-temperature ceramic materials. It also provides space for six User Centers, which contain the sophisticated instrumentation needed for the characterization of advanced high-temperature materials, especially the new high-temperature ceramics that promise to be so important in the transportation industry. A new ceramic manufacturability center has been created recently and is also housed in the building.

The concept of the HTML as a user center existed early in its evolution. When the HTML national user program started, there were four user centers: materials analysis, physical properties, $\mathrm{X}$-ray diffraction, and mechanical properties. In 1992, due to industrial requests, two new centers were requested and approved by the DOE. In 1993, a new Ceramic Manufacturing Center was started as a partnership 
between Energy Conservation, Defense Programs, and Energy Research that focuses on new manufacturing processes for advanced structural ceramics. In 1994, a new Neutron Residual Stress Facility was approved for operation; this facility provides industry the capability, as users, to measure the stress field within complex components such as gears and turbine rotors.

Over the years, the educational potential of the HTML became more and more obvious, but there was no program which could directly fund graduate students or industrial researchers to come to the HTML for prolonged periods to conduct their dissertation or special research. Typical HTML user projects had lengths of about two or three weeks. There was a clear need for funds to support a researcher of a different type for a year of more. Solicitations for both industrial and university candidates in 1991 resulted in two university candidates and three industrial candidates being selected. This is called the HTML Fellowship Program and has continued to grow.

Several major research instrumentation and research achievements have been made during HTML operation largely due to needs identified with either users or prospective users.

Some of these include:

1. Creation of the world's largest ceramic tensile testing facility with 12 machines of a new class in place and ready for operation in July 1987 - this facility resulted in the U.S. ASTM standard method for performing ceramic tensile strength measurements.

2. Development of specimen shape and geometry requirements plus gripping systems for ceramic tensile specimens which are now ASTM standards.

3. Development of the specimen system gripping systems for ceramicceramic (CFCC) composite tensile specimens which are in the process now of becoming ASTM standards.

4. Development and implementation of the statistical method for Weibull analysis of fracture strengths in ceramic materials in the United States.

5. Development of software for computer control of diffraction spectrometers which was particularly user friendly.

6. Creation of the first residual stress spectrometer in the U.S. based upon neutron diffraction.

7. Implementation of ORNL's first laboratory complex using fully digital imaging from electron optical instruments - this has resulted in easier dissemination of data anywhere in the world on the World Wide Web and has greatly reduced chemical effluent production common to film developing. 
8. Creation and demonstration of the mathematics and instrumental requirements for successful electron holography.

9. The elucidation of the microchemistry and microstructure of a wide variety of silicon nitride, silicon carbide, and fiber reinforced ceramic matrix composites as a function of stress, temperature, and environmental exposure using the ultrahigh resolution transmission microscopes. This resulted in the first detailed understanding of cavitation processes in these structural ceramics at high temperatures.

10. Elucidating for the first time the ultimate microstructure of a variety of heterogeneous catalysts as a function of their exposure in engine combustion environments.

In closing, five people must be mentioned a last time, who were crucial to the creation of the HTML. First, was Albert A. Chesnes, the DOE sponsor of this laboratory. The remaining four include, Alex Zucker who provided resources and encouragement. Felicia Foust who was always ready to prepare documents, viewgraphs, or whatever was needed to stem the crisis of the moment; John Cathcart who based upon his long experiences was helpful in hundreds of ways during the creation and construction days; and Roger
Carlsmith, who was the Conservation Program Manager at ORNL during this entire time. In the latter years, Bill Appleton, Associate Director for Physical Sciences, was most supportive for the program.

Vic Tennery retired on December 31, 1994, and Arvid Pasto became the second Director of the HTML.

Since its completion, the HTML has gone a long way toward its initial promise. In 1988, it won High Honors in a nationwide laboratory design competition sponsored by Research and Development Magazine, and it is recognized as the architectural showpiece of the Oak Ridge National Laboratory. It provides a staff of 75 with comfortable and attractive working areas and surroundings. The research being done in the high-temperature ceramics area attracts international attention, and the access by industrial and university researchers to the research equipment in the User Centers is highly prized. Five and a half years after its completion, 175 user agreements have been signed, 79 with universities across the country and 96 with a variety of industrial concerns; in addition, there has been interaction with five other government laboratories. More than 26,000 user days have been logged. The HTML has, indeed, become a national resource for high-temperature materials research. 


\section{multiple ion irradiation: metals, ceramics, and polymers}

In the 1970s, the Metals and Ceramics Division acquired a $5.5-\mathrm{MV}$ " $\mathrm{CN}^{\circ}$ Van de Graaff accelerator (located in the 5500 building) for materials science, in particular, studies of radiation effects. The accelerator, designed and built by High Voltage Engineering Company, was first bought by ORNL in the 1950 s for nuclear physics research. Later in the decade, a second accelerator, a 0.4-MV Van de Graaff, was added to permit simultaneous dual-ion irradiations. The smaller machine was used primarily for helium injection and the larger machine for metallic self-ions of the specimen material.

The dual ion irradiation capability turned out to be crucial in understanding neutron radiation effects in fission and fusion reactor materials. In a fission or fusion reactor environment, displacement damage occurs while helium builds up through $(n, a)$ reactions. Helium profoundly influ- ences the radiation response of materiais.

In the $1980 \mathrm{~s}$, a third accelerator, a 2.5MV Van de Graaff was installed to permit simultaneous triple-ion irradiations (Fig. 18). The third machine also fulfilled needs for an intermediate size accelerator to be used for nuclear reaction and Rutherford backscattering analyses. The triple configuration allows a considerable generalization to be achieved in both radiation effects

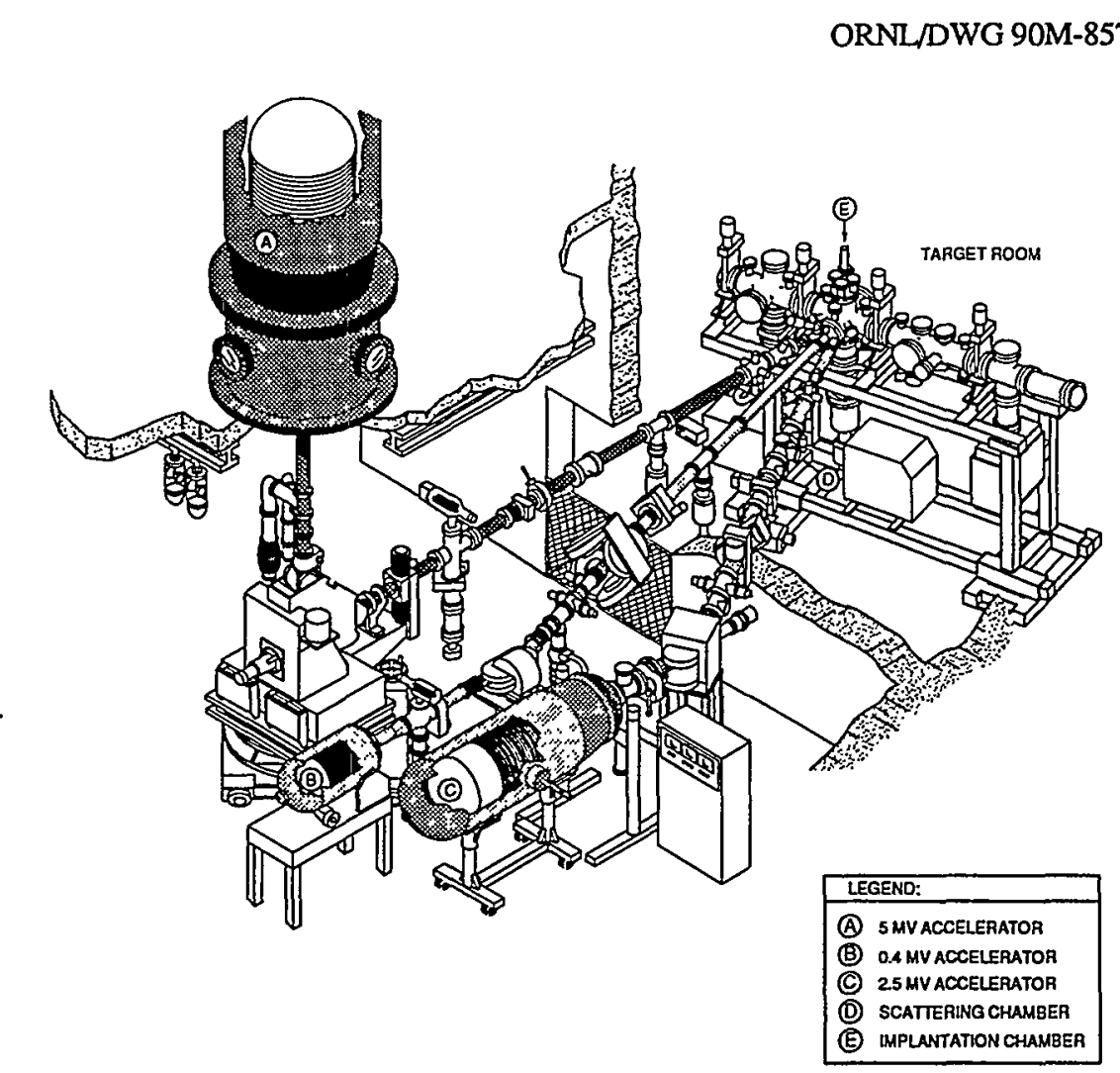

Fig. 18. Schematic of Triple Ion Irradiation Facility. 
and ion beam treatment research. It permits, for example, simultaneous anion-cation-helium bombardments for studies on the fundamentals of displacement damage and helium response in ceramics, while it allows independent control of defect behavior induced by departures from stoichiometry. This is particularly relevant for studies of fusion reactor insulator materials, for example. Simultaneous triple-beam capability is also a key to powerful ion beam treatment research.

The Triple Ion Irradiation Facility is shown schematically in Fig. 18. The primary implantation chamber $(E$ in the figure) is located at the intersection of the three accelerator beam lines. The target assembly has five individual target stations. The specimen temperatures can be regulated between -196 and $1000^{\circ} \mathrm{C}$. The three ion beams enter the chamber by separate ports approximately $15^{\circ}$ apart. In addition to the main implantation chamber, the facility includes a film deposition chamber and an ion-scattering chamber (D). Auxiliary equipment includes a computercontrolled goniometer, a residual gas analyzer, a $5-\mathrm{kV}$ sputter-gun, and a 20$\mathrm{kV}$ electron gun. Today the facility is used extensively for both basic radiation effects research and surface modification and analysis of metals, ceramics, and polymers. 


\section{conservation materials program}

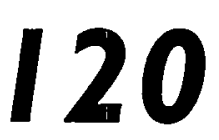

Several separate entrepreneurial efforts that later evolved into conservationrelated research and development (R\&D) were under way at ORNL. Roger Carlsmith's involvement in conservation began with the start of the National Science Foundation (NSF) Environmental Program in June 1970.

Carlsmith's effort on the NSF Program was associated with "Environmental Impacts of Electrical Energy Production," co-chaired with John H. Gibbons, who 20 years later became President Clinton's science advisor and director of the White House Office of Science and Technology Policy. The charter was to do a study of environmental impacts having to do with electricity. The first study identified energy conservation as the one strategy that would deal simultaneously with all of the environmental impacts of energy production. For about the first 2 years, funding came entirely from NSF, and the first 18 months were devoted to analysis and study with no experimental work. The group did a number of technical assessments and some economic analyses having to do with price elasticity of energy demand.

The whole energy situation changed in the fall of 1973 with the Arab oil embargo. President Nixon established the Federal Energy Office (FEO) to deal primarily with the impacts of the oil embargo, and the Laboratory began to get some funding from this office (later changed to the Federal Energy Admin- istration under the White House.) The FEO began to look at some more longrange projects and authorized some of the first experimental work on building insulation. The Laboratory got some funding from Maxine Savitz who was then head of the residential segment of the FEO.

When the Energy Research and Development Administration (ERDA) was created in 1975, the Laboratory lost its NSF funding. However, with the advent of ERDA, energy conservation was given prominence in the federal government, and the Laboratory started receiving funding from ERDA for research in this area.

The Metals and Ceramics Division's involvement in the Energy Conservation Program began with a phone call, in early August 1975, from Bob Anderson of ERDA to Vic Tennery inquiring about our capablilties for conducting research on high-temperature ceramic and metallic materials, such as refractories and high-nickel alloys. Bob had just joined ERDA and was reporting to Doug Harvey, who was in the process of defining and setting up a national energy conservation program including what are now the buildings and industrial energy conservation programs. Doug and Bob were then in the process of performing studies to identify industrial manufacturing sectors in which the most energy-saving impacts might be realized via improvements in industrial practices and/or the development 
of new materials. At the end of August the Division was asked by Headquarters to prepare our first energy conservation research proposal involving an assessment of the technical status of industrial thermal insulations. This funded project was the beginning of the Energy Conservation Program in the M\&C Division.

The industrial thermal insulation project was completed in about six months, including a national workshop held in Oak Ridge, and the results were reported in ORNL/TM-5283 for which many hundreds of copies were printed and distributed to over 300 companies that had provided information for the assessment project. The result of this work was a new national awareness of the important energy conservation potential for upgrading steam distribution systems in all types of industrial plants, and the many unknowns associated with high-temperature ceramic insulation systems and waste heat recovery systems. This was the first multi-divisional energy conservation project involving the $\mathrm{M} \& \mathrm{C}$ and Energy Divisions, and the work resulted in many new industrial contacts for the Division in later years, as this assessment was considered to be of high quality by industrial people of the time.

After completing the assessment on industrial thermal insulation, Tennery was asked to organize a proposal directed at questions associated with waste heat recovery from high-tempera- ture process flow streams, such as those in the primary metal (steel and aluminum) industries and the ceramic industries. This proposal resulted in a second piece of work in which a materials and equipment assessment was done for waste heat recovery devices, where heat exchangers (typically called recuperators in industrial parlance) could be used. This work was funded in late spring of 1976 and was conducted both in the Ceramic Technology and Thermophysical Properties Groups. This work helped M\&C make many contacts in the industrial sector in the areas of thermal insulations and waste heat recovery systems, and at the time, allowed the Division and ORNL to gain the acceptance of industrial managers and researchers as an organization truly interested in their problems and in helping them resolve important energy conservation issues.

The next opportunity that really offered the potential for substantial R\&D came in late 1976 when many companies were being denied access to their required natural gas supplies due to shortages from producers in the southwestern United States. These firms were then switching to residual fuel oil since highly refined fuel oil was too expensive--the impurities in these residual oils were quickly found to cause major corrosion problems in ceramic and metal processing furnaces.

We were asked to organize and rapidly initiate an effort to determine the origin 
of the corrosion and to recommend possible solutions. This work included George Wei and Gary Weber, plus a large number of technical support staff, and resulted in a set of technical reports that were widely distributed to industrial companies. The ERDA sponsors required that the results be published as quickly as possible in official ORNL technical reports. The first two reports, ORNL-5592 in 1976 and ORNL-5909 in 1977, established that the corrosive effects of these oil impurities were extensive and that analyzing specimens from industrial furnaces was very difficult due to highly variable industrial operating practices, making it extremely difficult to correlate specific oil impurities with refractory or insulation failures.

As the Energy Conservation and Utilization Technology Program was being initiated, the program in the Division expanded to include building insulation and other energy conservation systems such as walls and windows. The result was that the predecessor of the Buildings Conservation Program (a national effort) was started within the M\&C Division. Dave McElroy and his group, including Bob Williams and Peyton Moore, became major participants in the program characterizing a large number of building thermal insulations. This work has continued in some form to the present day.

During this time also, Ted Lundy, a group leader in the M\&C Division, was asked to manage various programs, one of which was Building Thermal Envelope Systems and Materials (BTESM), which Tom Kollie later took over and then Ken Wilkes. M\&C eventually turned the BTESM work over to the Energy Division on the recommendation of the Advisory Committee.

Around 1978, shortly after Tony Schaffhauser took over as Energy Conservation Program Manager, the Division was directed to develop an energy audit program for houses and apartments that the utilities companies could offer to their residential customers. There needed to be a good technical basis for doing this.

A lot of this effort involved recommendations on insulating materials. M\&C was asked to help primarily because of Dave McElroy's prior work on insulation standards. At that time, Dave had been working with the American Society for Testing and Materials (ASTM) and others on standard test methods. Dave had become involved in the standards work as an outgrowth of the industrial insulation program.

It was next proposed that a major experimental combustion exposure facility be constructed at ORNL in which thermal insulator and other types of refractories could be exposed to residual oil combustion products in a controlled manner. The first results from this work showed that residual oil impurities, such as nickel and iron, 
were very detrimental to the then newly developed refractory fibrous insulations being adopted rapidly by U.S. industry. During 1978, five additional sets of experiments were performed. Material exposures were conducted using multihundred-hour combustion exposures in the Refractory Test Facility (RTF) in addition to continued analyses of industrial refractory and insulation specimens. Finally, a special assessment of ceramic recuperator materials was conducted. This work resulted in considerable future work in the Solar Energy Program and later the Industrial Conservation Program.

In 1980 , most of the $R \& D$ was focused on experimental exposures in the RTF. The results showed the modes of corrosion and failure of a wide variety of ceramic refractories and alloys due to high-temperature exposure to a variety of combustion species. During this year Irv Federer and Vic Tennery also published a report on the degradation of refractory fibrous insulations due to corrosion from fuel impurities. These were the first such experiments done in the United States and resulted in widespread recognition of ORNL.

In 1981, the industrial conservation staff started a new national DOE effort to modify the RTF in order to conduct experiments on tubular ceramic specimens which could simulate components of tubular ceramic heat exchangers. These devices had become of major interest for industrial waste heat recov- ery. The first experiment was conducted during that summer and the first results showed the role of heavy metal fuel impurities in accelerating the high-temperature corrosion of silicon carbide and aluminum oxide ceramics at temperature to $1300^{\circ} \mathrm{C}$ for exposures of hundreds of hours. This work became the central focus of the Industrial Energy Conservation Program in the M\&C Division for the next several years.

The RTF was later modified and used for a four-year project sponsored by the Fossil Energy Materials Program in which coals of various chemistries were fired in a special burner for exposing structural ceramics to direct molten slag impingement.

Improving the thermal efficiency, and thereby conserving energy, may be accomplished by increasing the operating temperature of energy conversion devices or processes. The upper temperature limit for operation with conventional heat resisting alloys had been reached. An avenue for improving this situation was recognized by $\mathrm{C}$. T. Liu in the potential of intermetallic compounds to allow higher operating temperatures.

Emphasis on the intermetallic alloys in the 1980s. was on $\mathrm{Fe}_{3} \mathrm{Al}, \mathrm{FeAl}$, and $\mathrm{Ni}_{3} \mathrm{Al}$. The problem with the intermetallic compounds is that the ductility approaches zero at ambient temperature. C. T. Liu discovered that the iron 
aluminide $\left(\mathrm{Fe}_{3} \mathrm{Al}\right)$ could be made ductile with small chromium additions of about $2 \%$, and the nickel aluminide with the addition of about $200 \mathrm{ppm}$ of boron.

These inventions provided the basis for potential commercial uses, and incentive for development of alloys for specific applications. The inventions themselves were funded by ORNL seed money and the Basic Energy Sciences programs and the BES program continued funding basic aspects of the work. Development and commercialization efforts were funded mainly by the conservation and fossil energy programs, and this work was conducted by Vinod Sikka in the fabrication aspects and by Gene Goodwin and Mike Santella for welding. The total government investment in the development and commercialization of these alloys has been fifteen years and about \$35 million; the industrial investment is difficult to determine but is probably of the same magnitude. All three alloys are currently being produced commercially for various uses in the metals processing industry.

The efficiency of gas turbines had reached its upper limit in the sixties. A large effort was funded by the Department of Defense to develop a ceramic gas turbine using the existing ceramic technology. This effort was a total failure and was abandoned. The problem was that the silicon carbide ceramic fracture toughness was inadequate and inconsistent.

A joint program between the ceramics group at Wright Patterson Air Force Base funded by NASA and the DOD, and the M\&C Division funded by the DOE Division of Research and Conservation Programs, was begun in the mid seventies. This program was aimed at improving the properties of a broad range of ceramics for potential uses in gas turbine and reciprocating engines. The basic work on toughening mechanisms was done by Paul Becher.

A number of people made important contributions during the twenty years since the start of the program including George Wei, Gary Weber, Mark Janney, Terry Tiegs, David Stinton, and others in the Ceramic Processing and Ceramic Surface Systems Groups. The entire processing sequence from powder to consolidation to heat treatment to machining was improved. The properties and their consistance was improved in zirconia, alumina and silicon nitride. The fracture toughness of silicon nitride was improved by a factor of six, and is the ceramic of choice for gas turbine and other engine applications. 


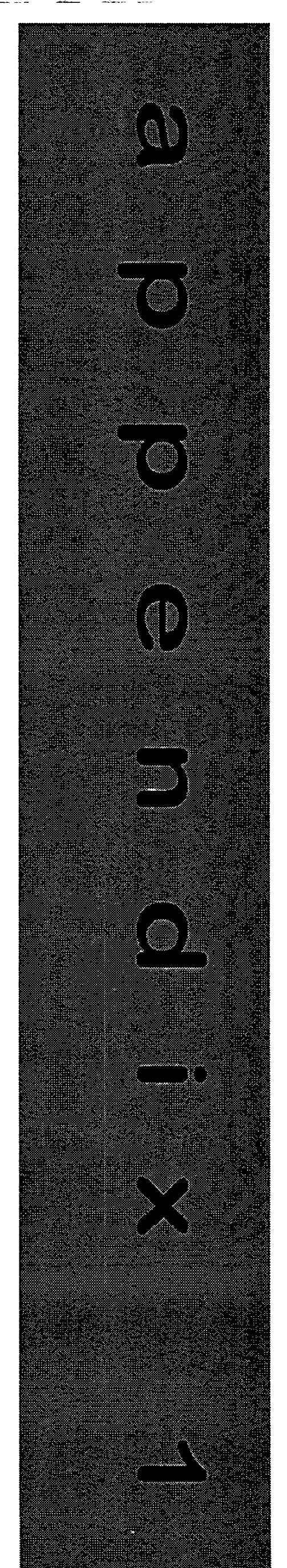




\section{introduction}

The chronology of Metals and Ceramics

Division Directors and Organization

Charts at the beginning of their tenure.

appendix 1 


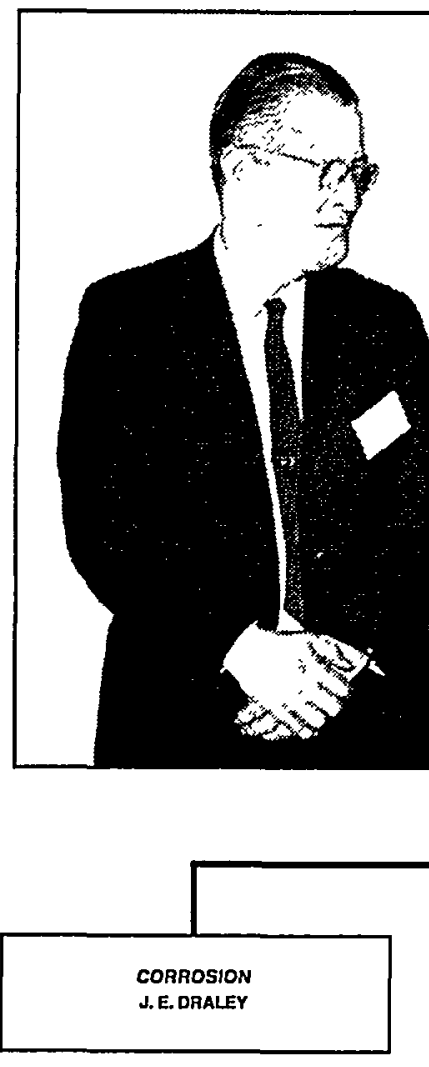

\section{W. A. Johnson} Director (1946-1949)
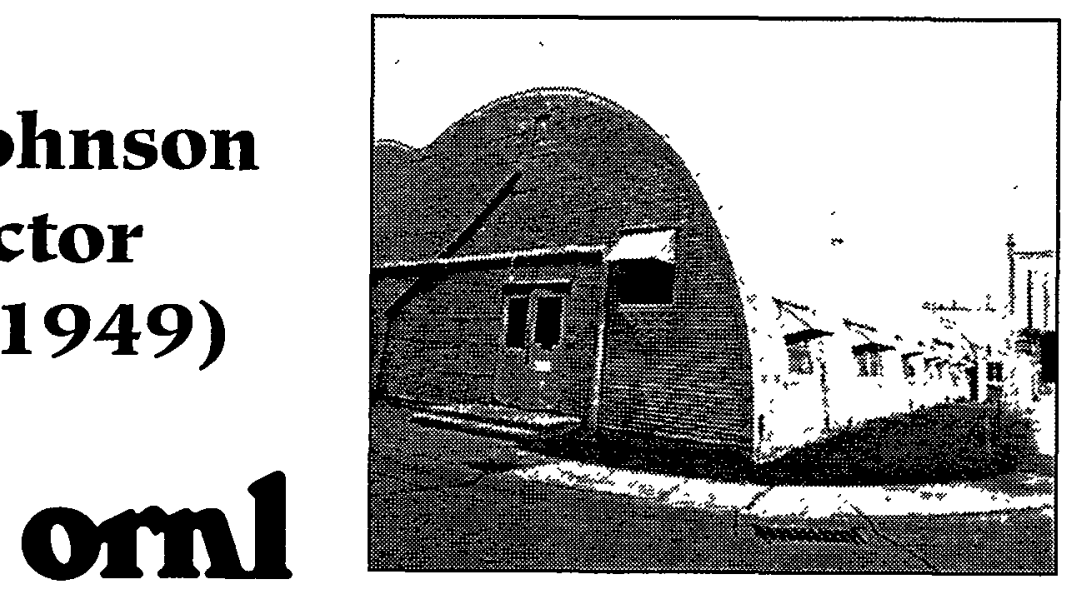

METALLURGY DIVISION W. A. JOHNSON DIRECTOR
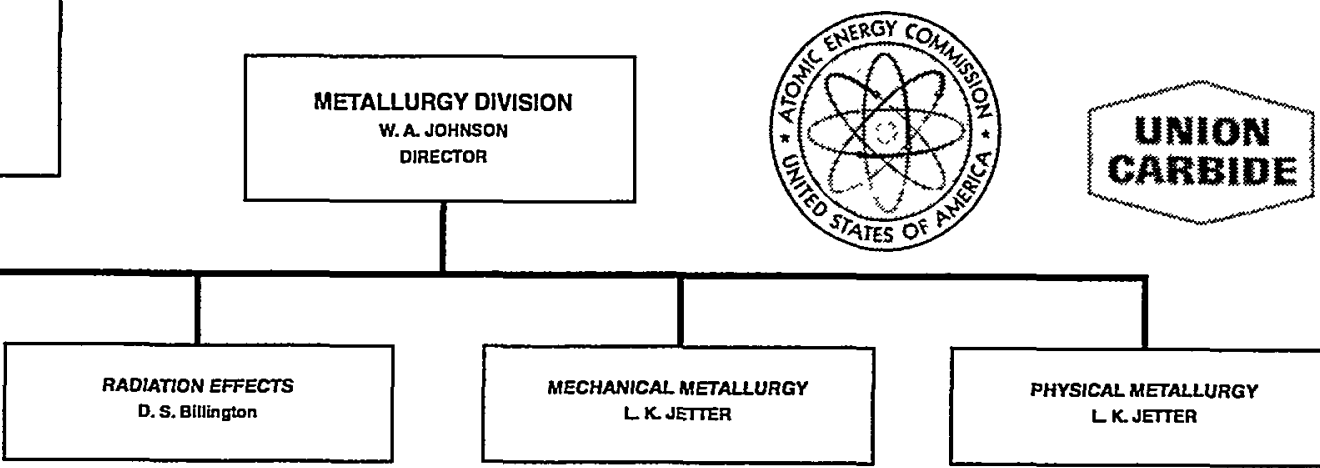

MECHANICAL METALLURGY LK. JETIER

PHYSICAL METALLURGY LK. JETTER

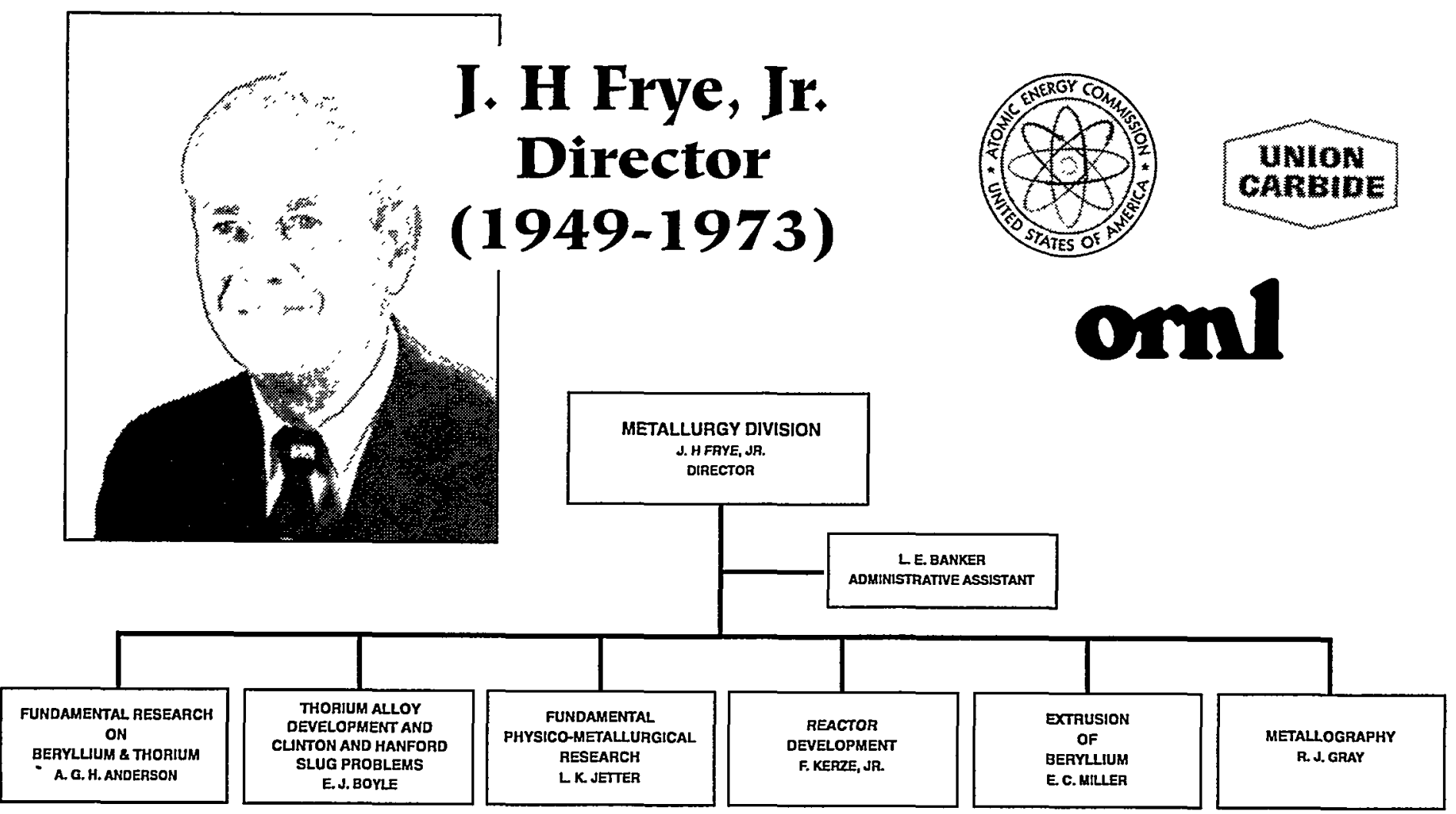



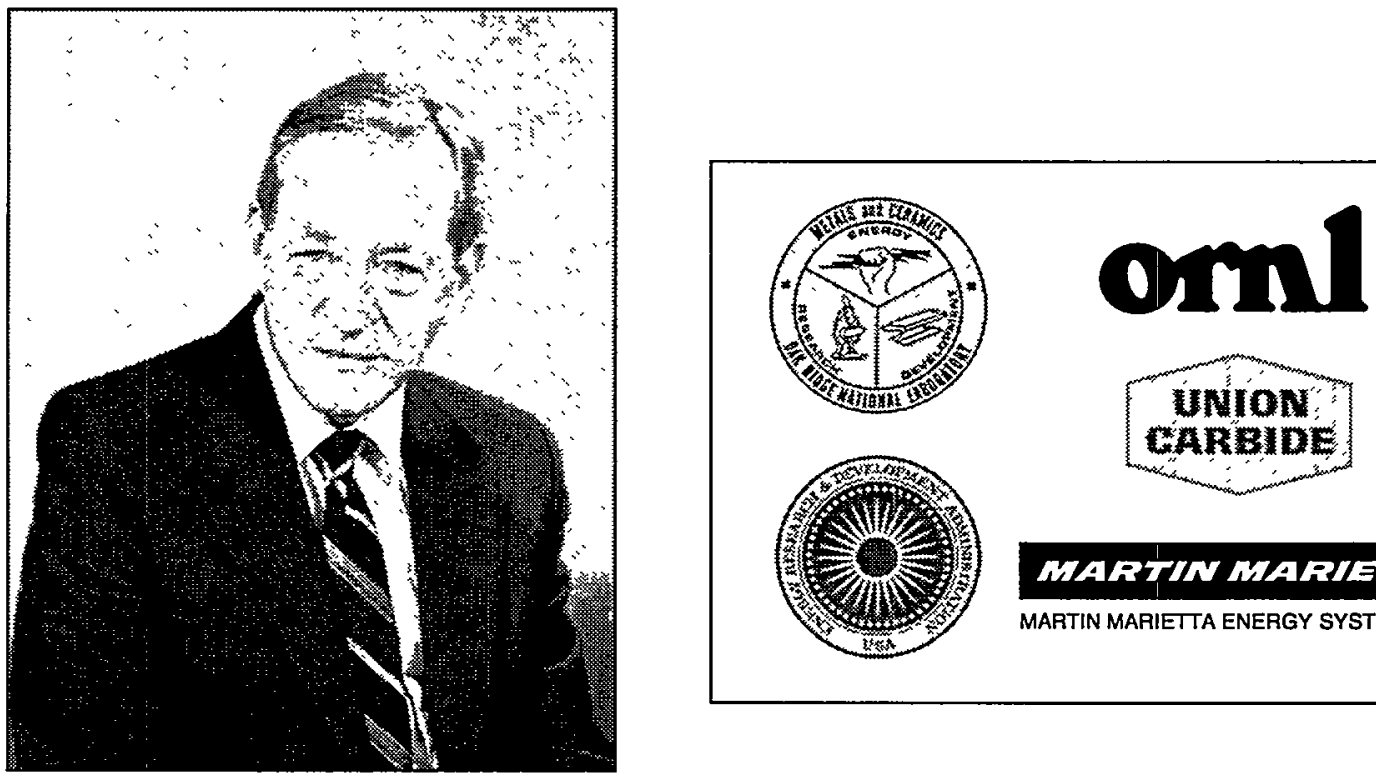

\section{MARTIN MARIETTA}

MARTIN MARIETTA ENERGY SYSTEMS, INC.
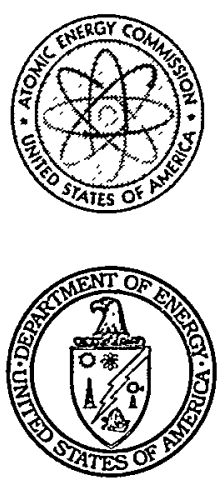

J. R. Weir, Jr.

Director

(1973-1984)
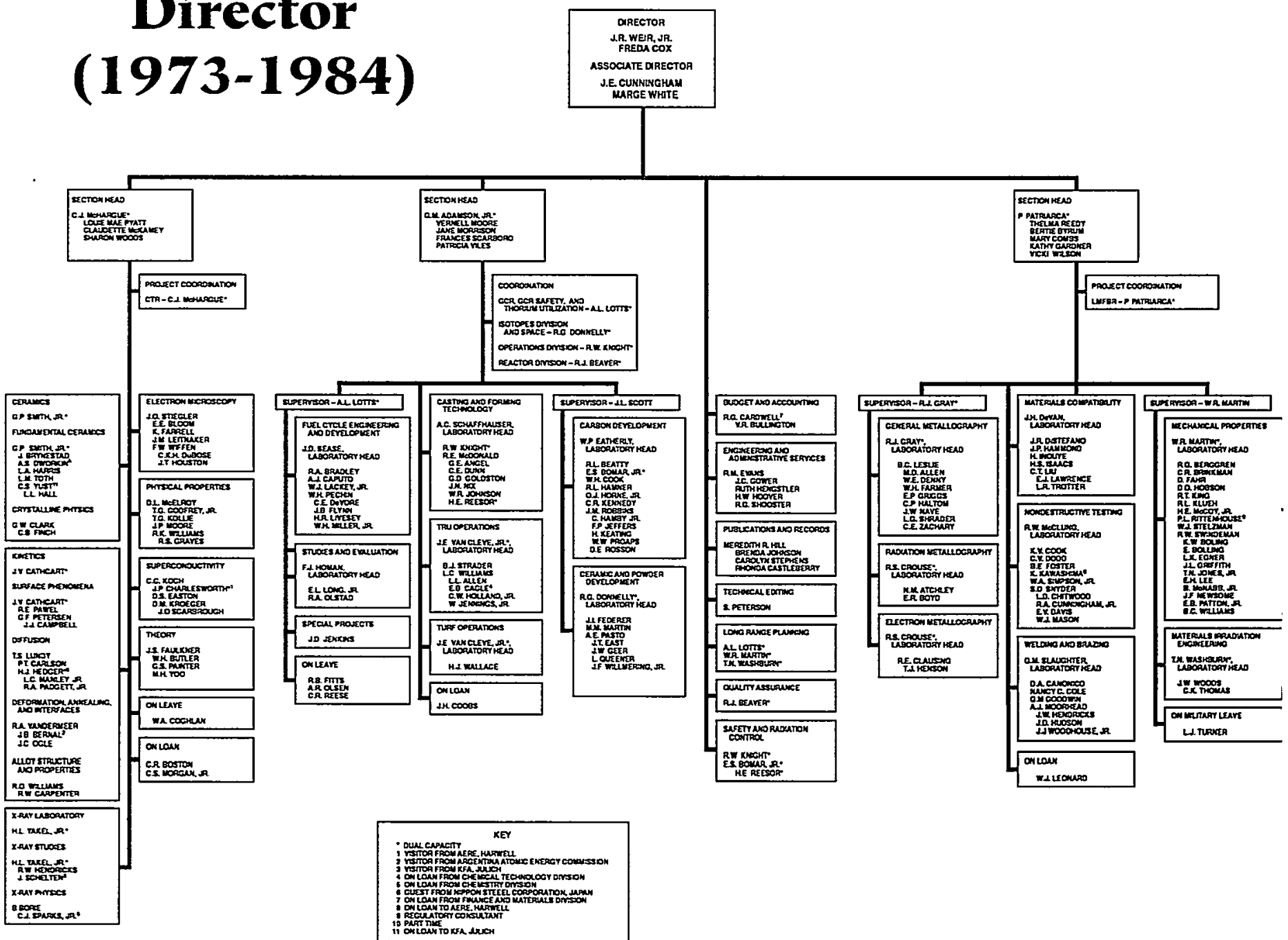

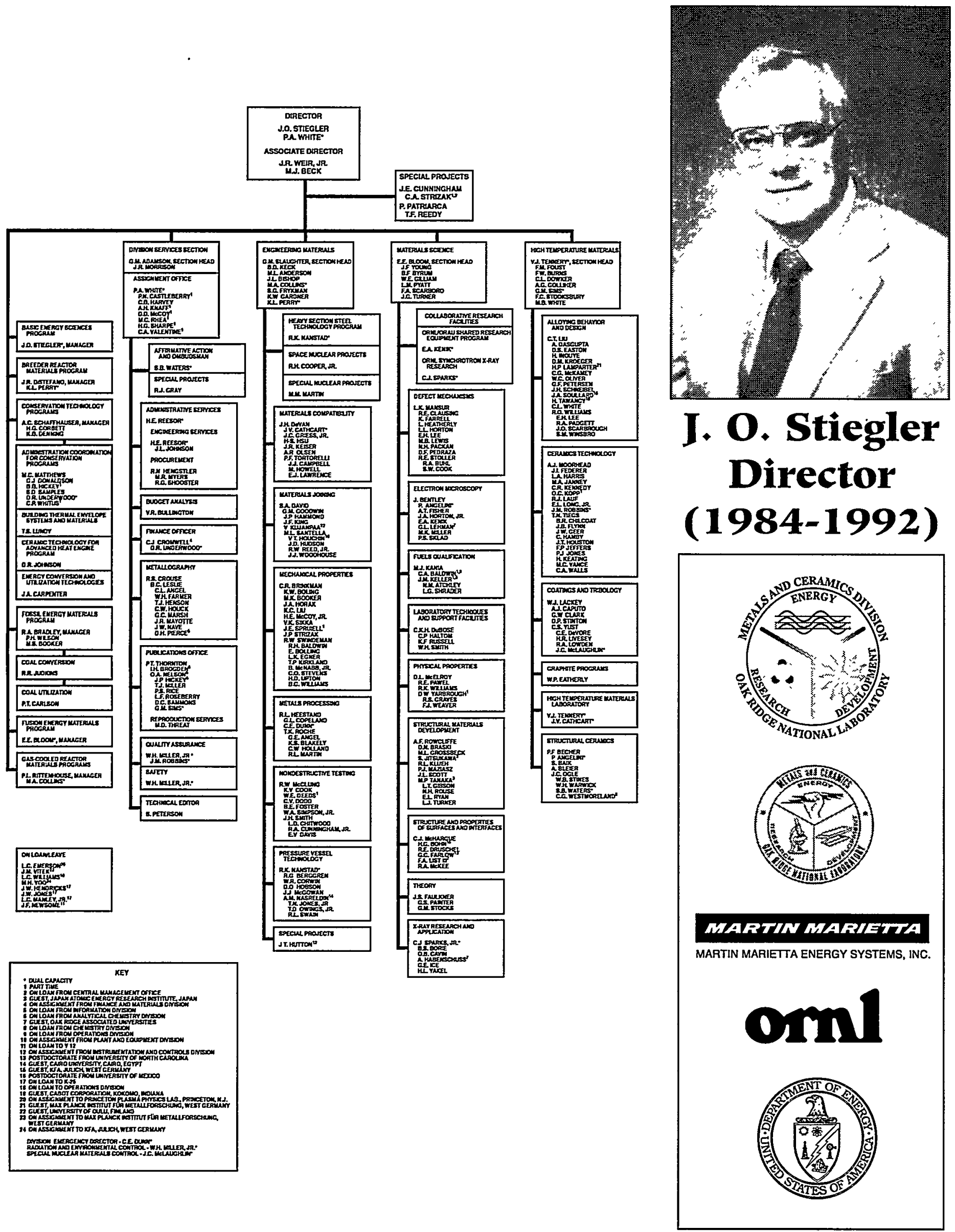


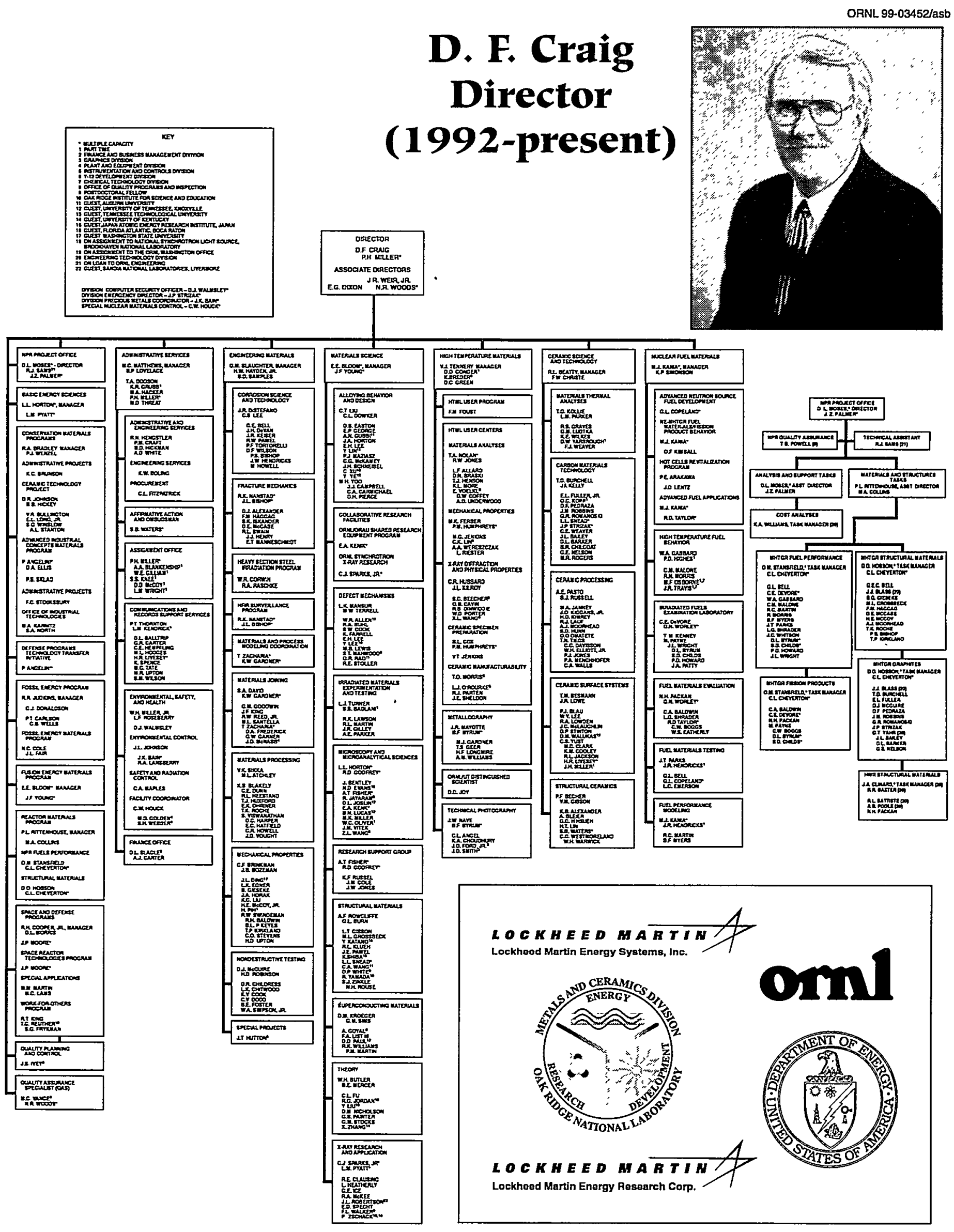





\section{introduction}

132

Photographs were selected for presentation in this appendix that represent samples of the administrative staff, the technical staff at some information meetings, and social events. An attempt was made to present photographs of as many of the staff over as wide a time frame as possible. Omissions were inevitable for which the compilers apologize. 


\section{division's secretarial staff (1960)}

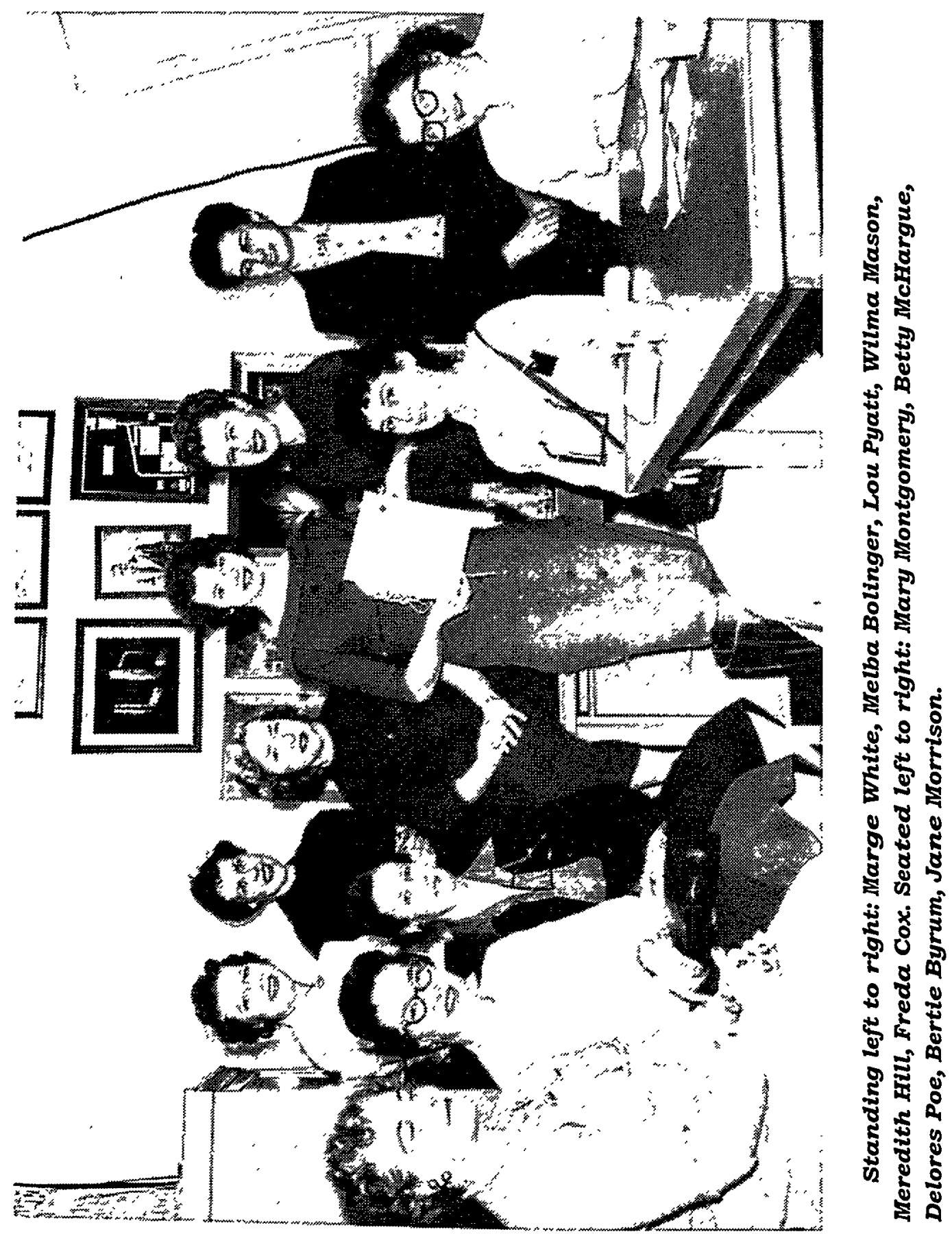

133 


\section{division's office staff (1968)}

I34

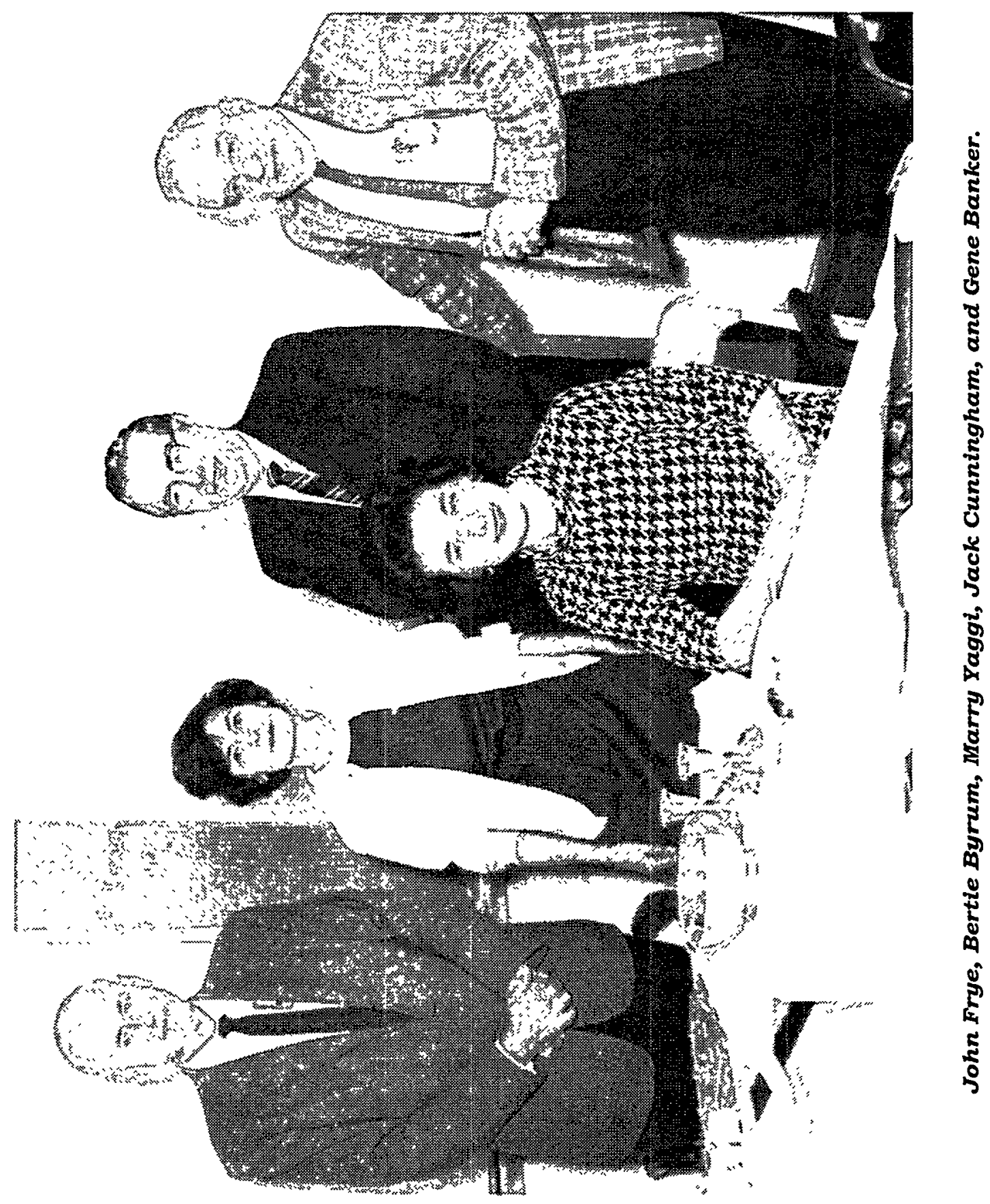




\section{division's \\ information meetings (1962)}

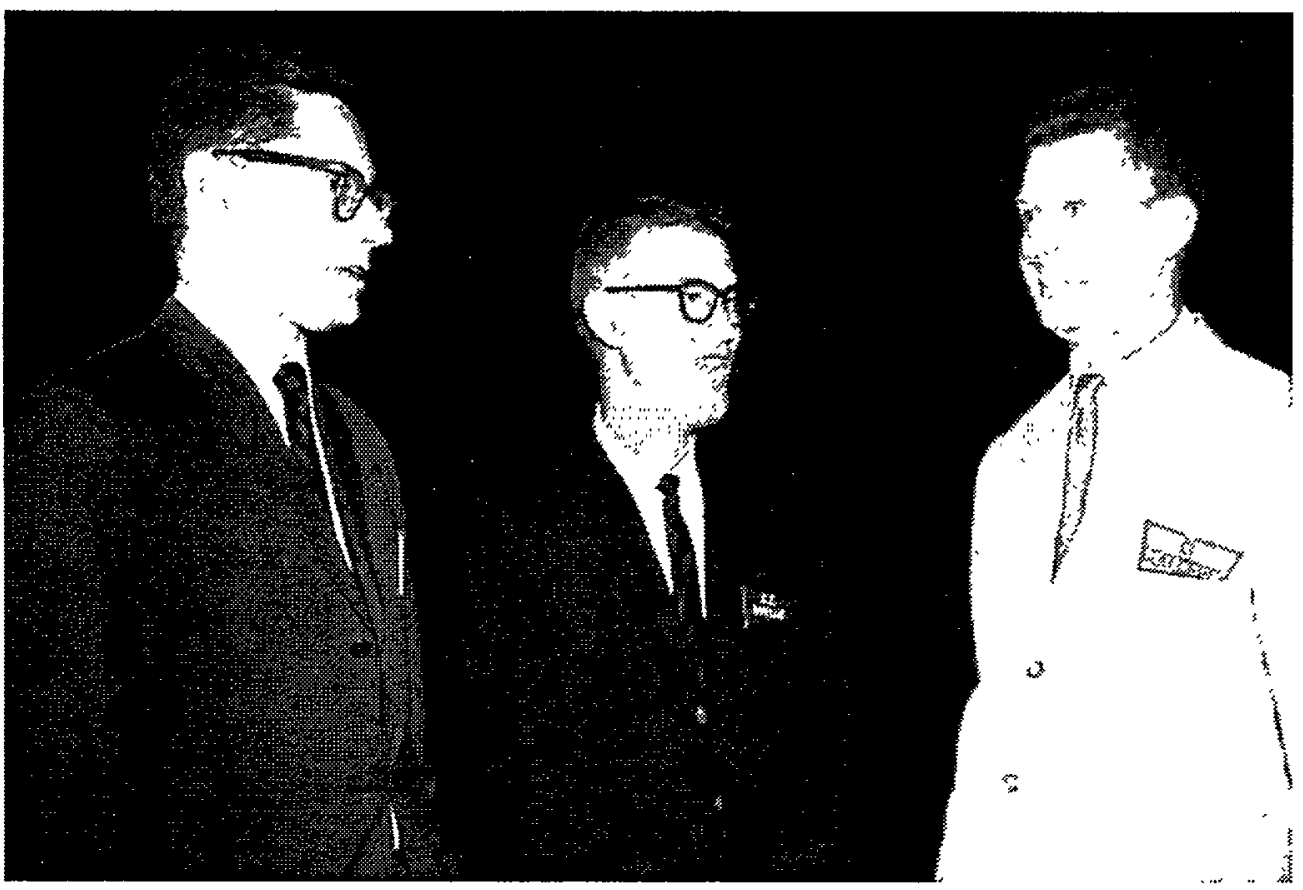

135

Charlie Yust, Chester Morgan, and Sig Peterson.

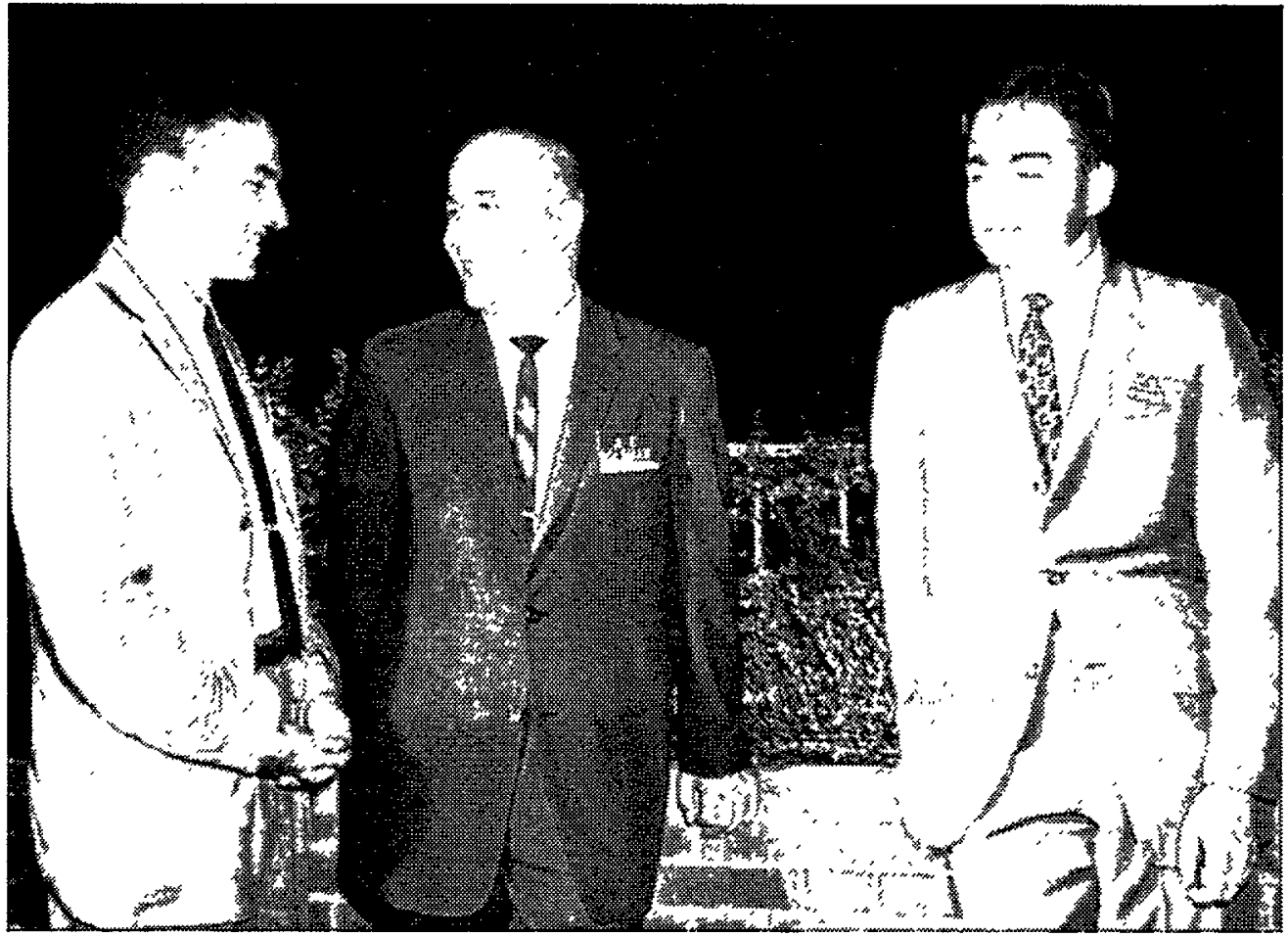

Al Taboada, Al Goldman, and Cabel Finch. 


\section{division's information meetings (1963)}

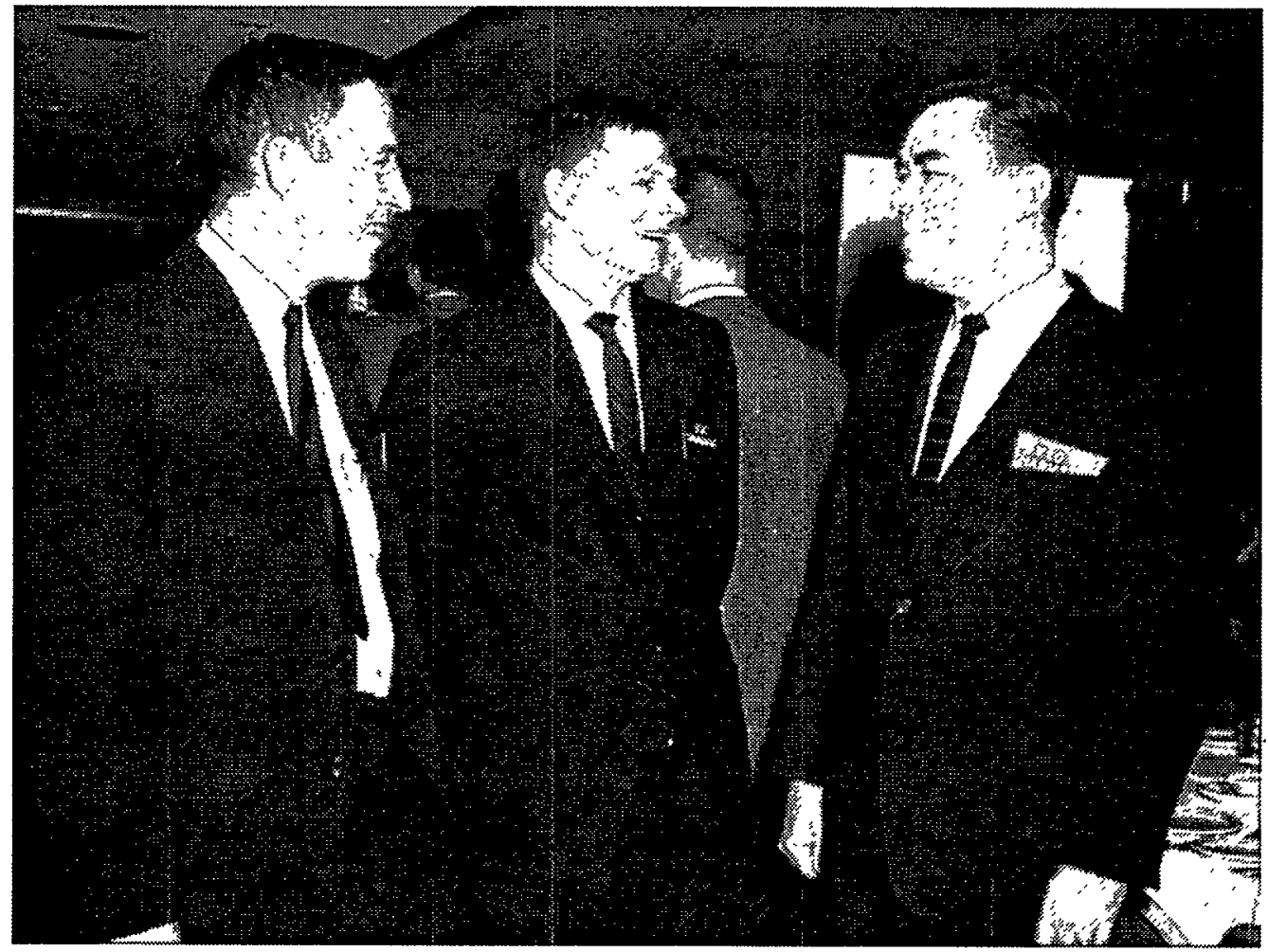

Jim Weir, Bob Swindeman, and Bill Harms.

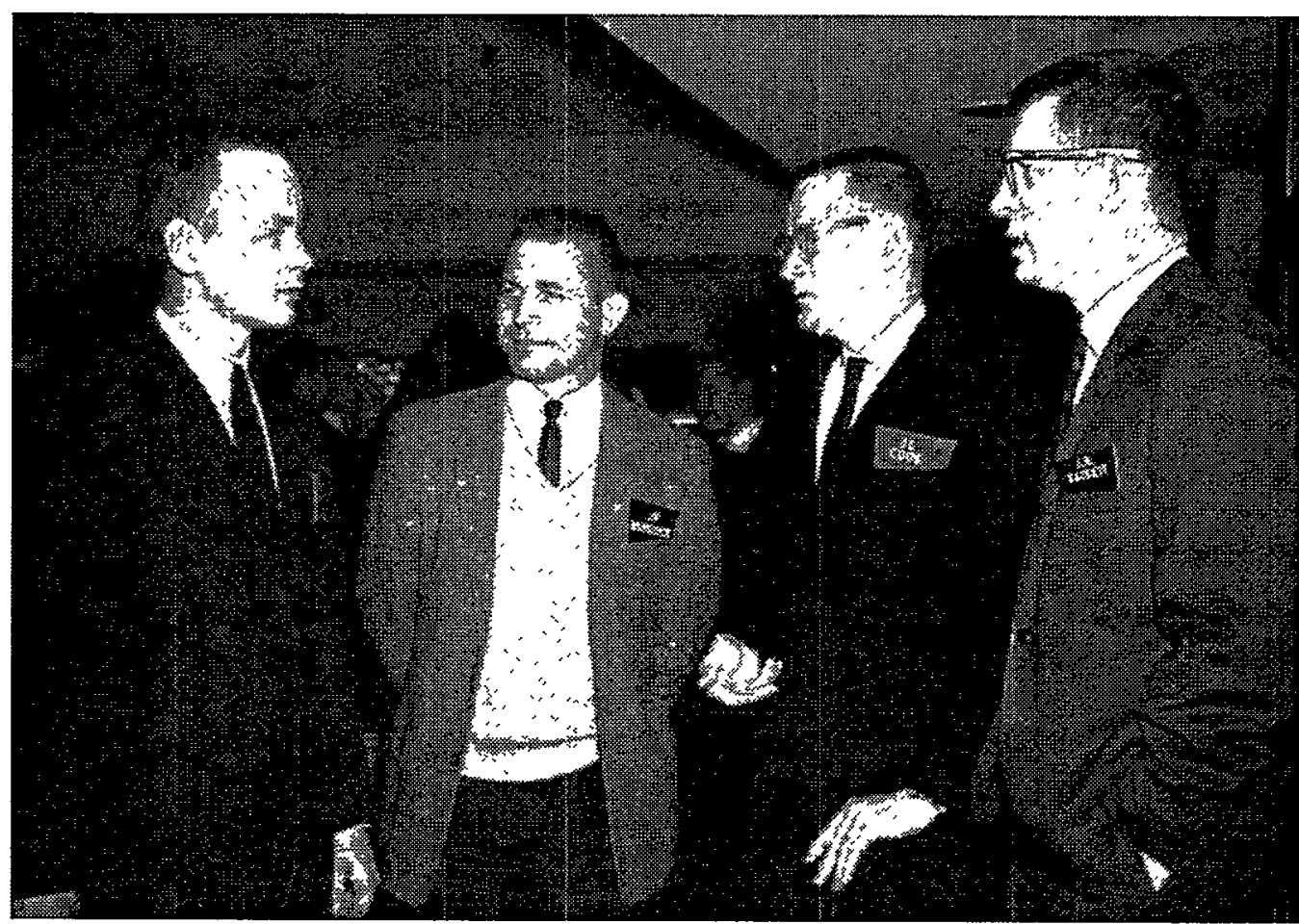

Charles Fox, Jim Murdock, Jack Cook, and Joe Tackett. 


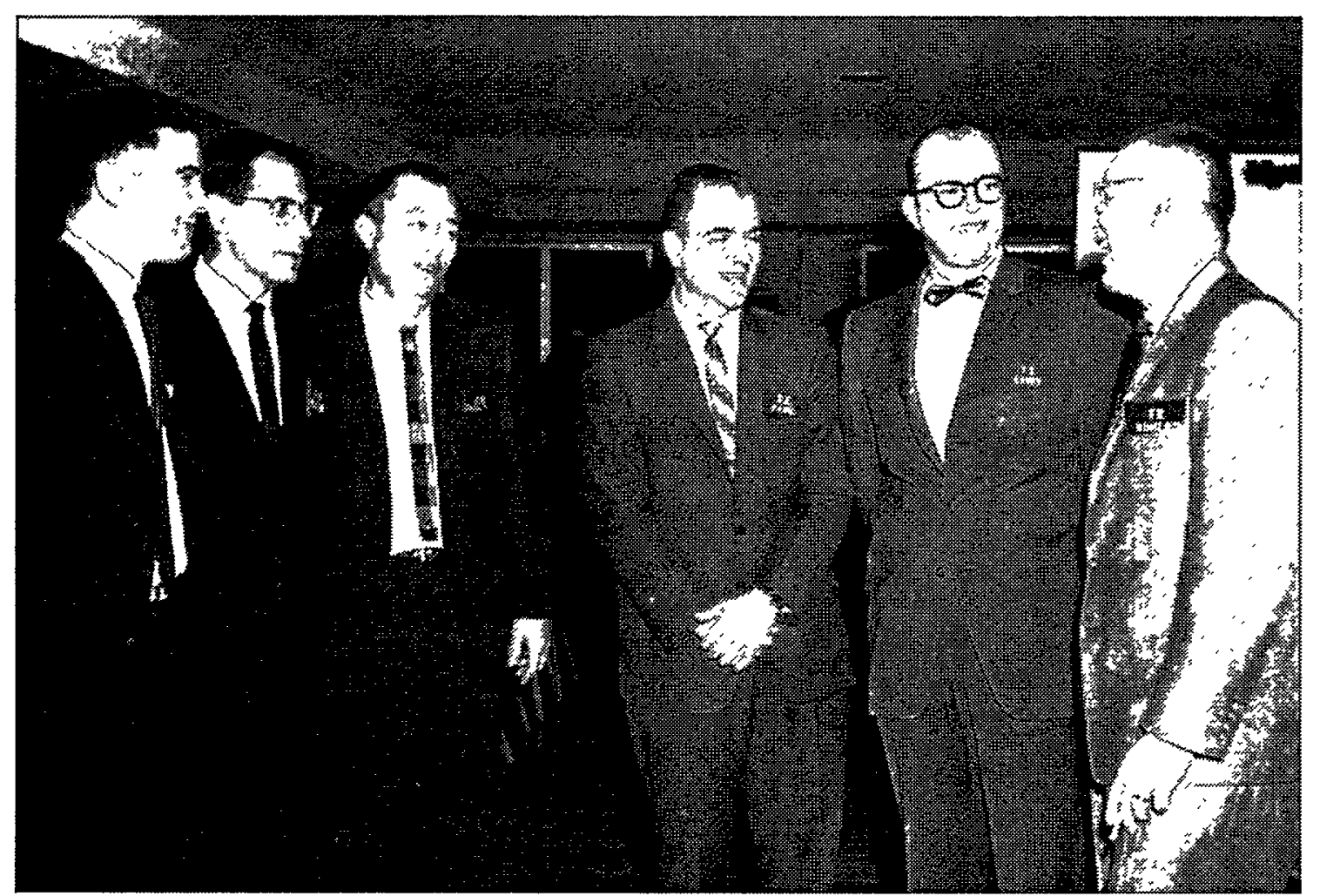

137

Unknown, Chuck Boston, John Cathcart, Dick Pawel, Ted Lundy, and Fitz Winslow. 


\section{division's information meetings (1971)}

\section{8}

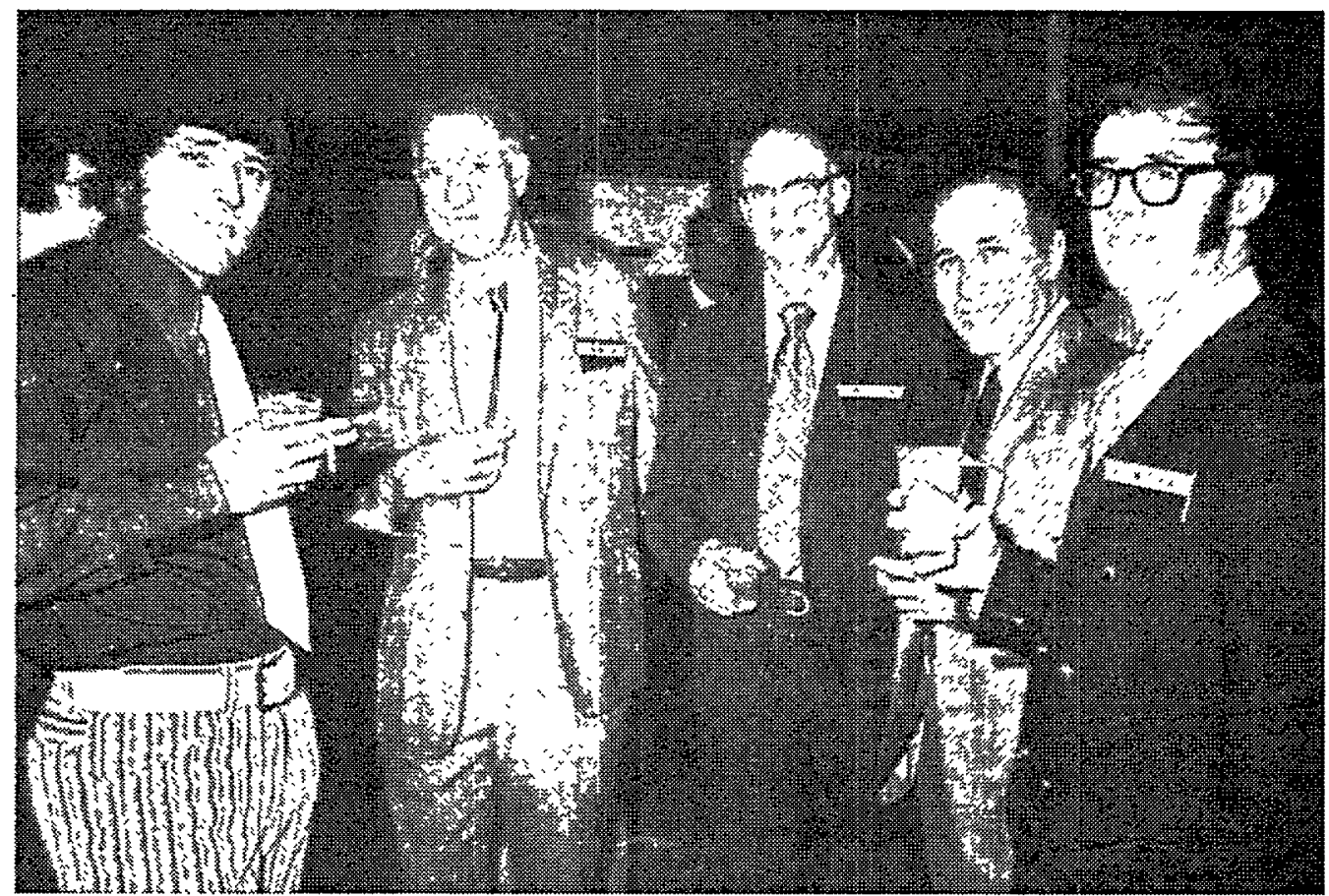

Gene Goodwin, Clarence Wodtke, Gerry Slaughter, Al Goldman, and Artie Moorhead.

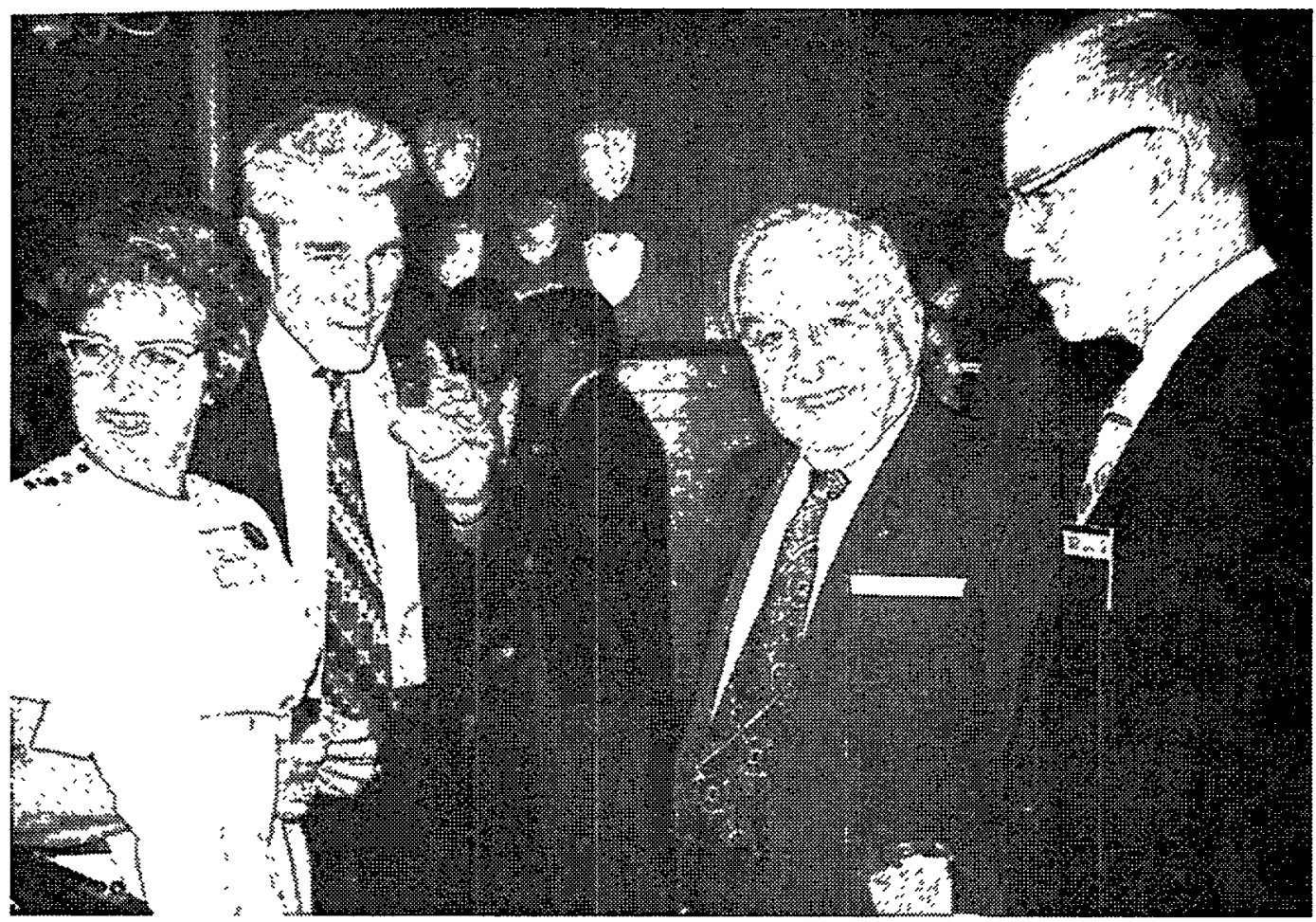

Marge White, Bob Adams, Gene Banker, and Gerry Slaughter. 


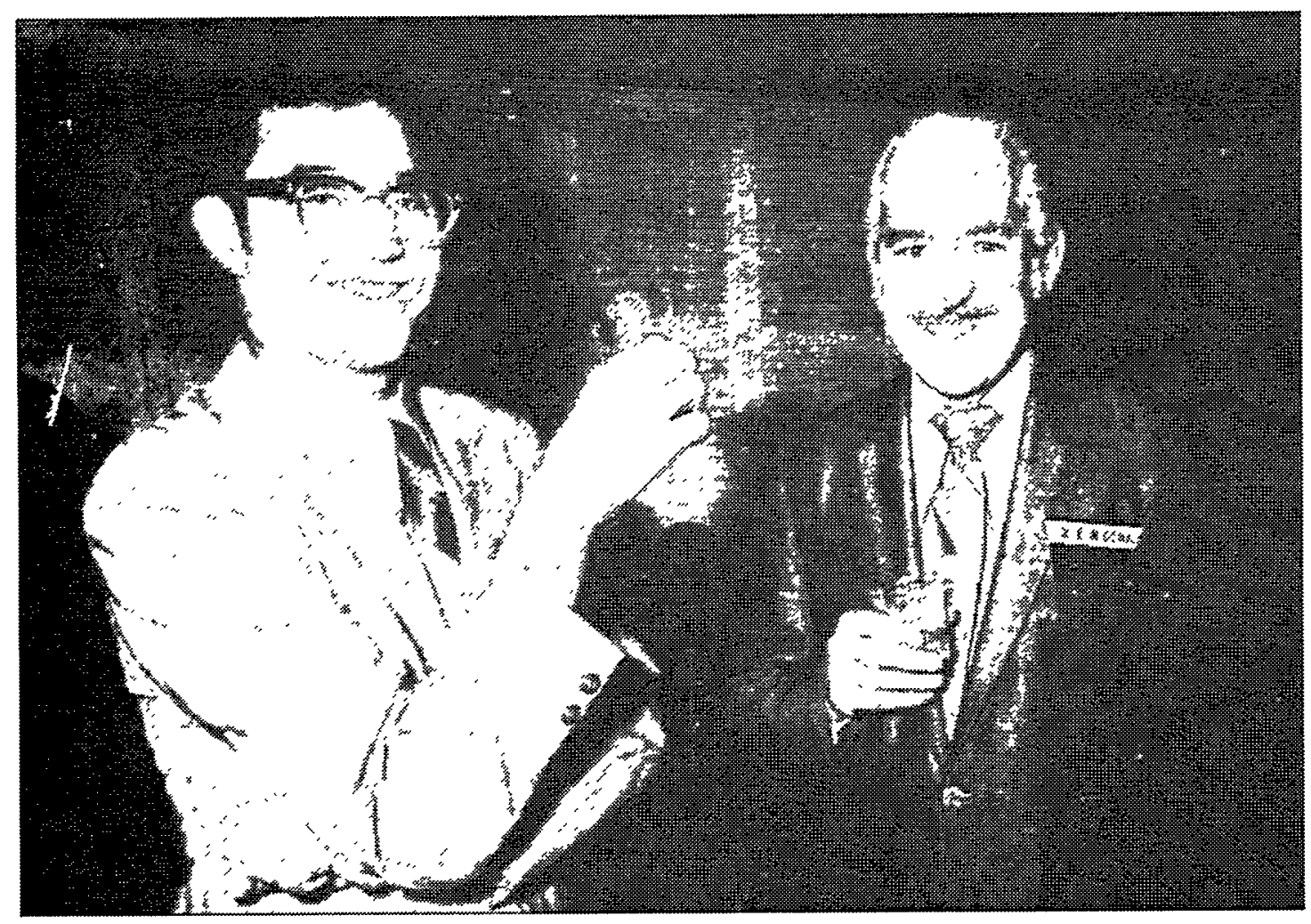

139

Jim DiStefano and Bob McDonald. 


\section{division's alumni reunion (1981)}

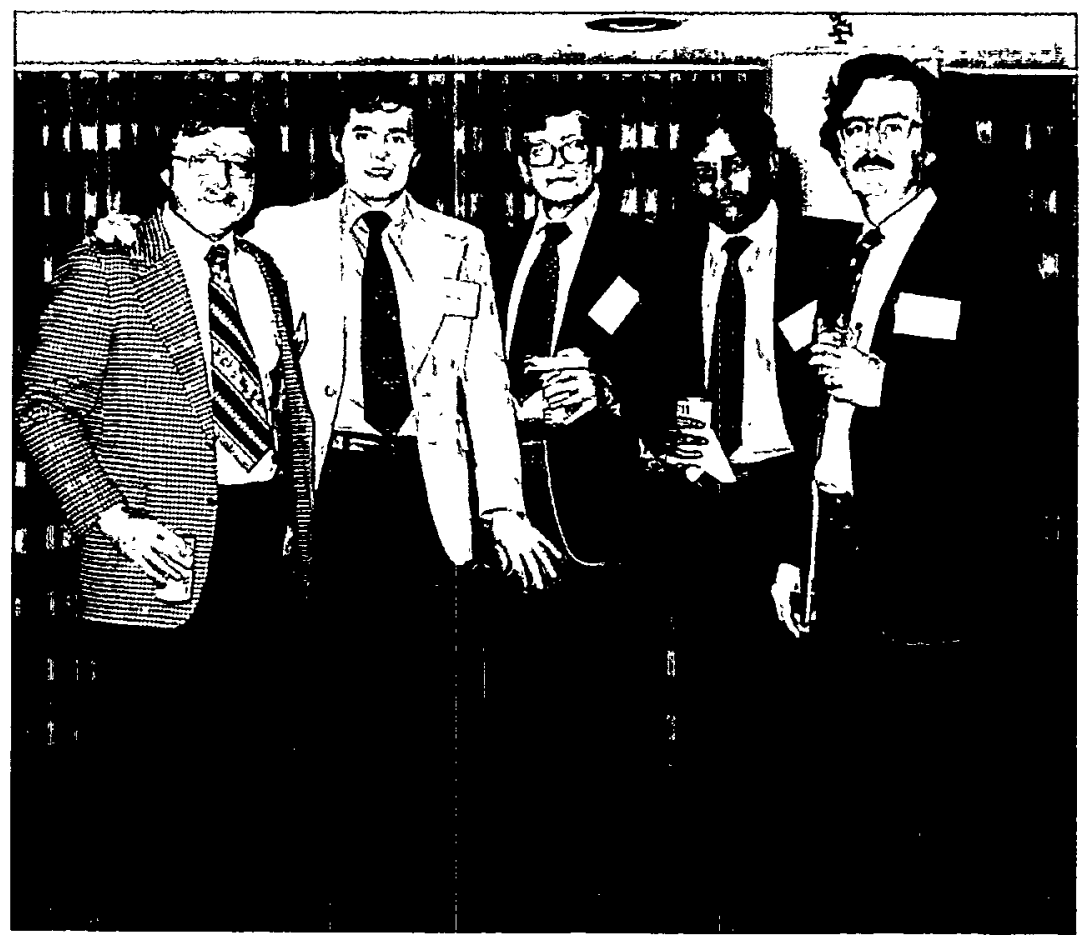

Jim King, Randy Nanstad, Dave Edmonds, Stan David, and Artie Moorhead.

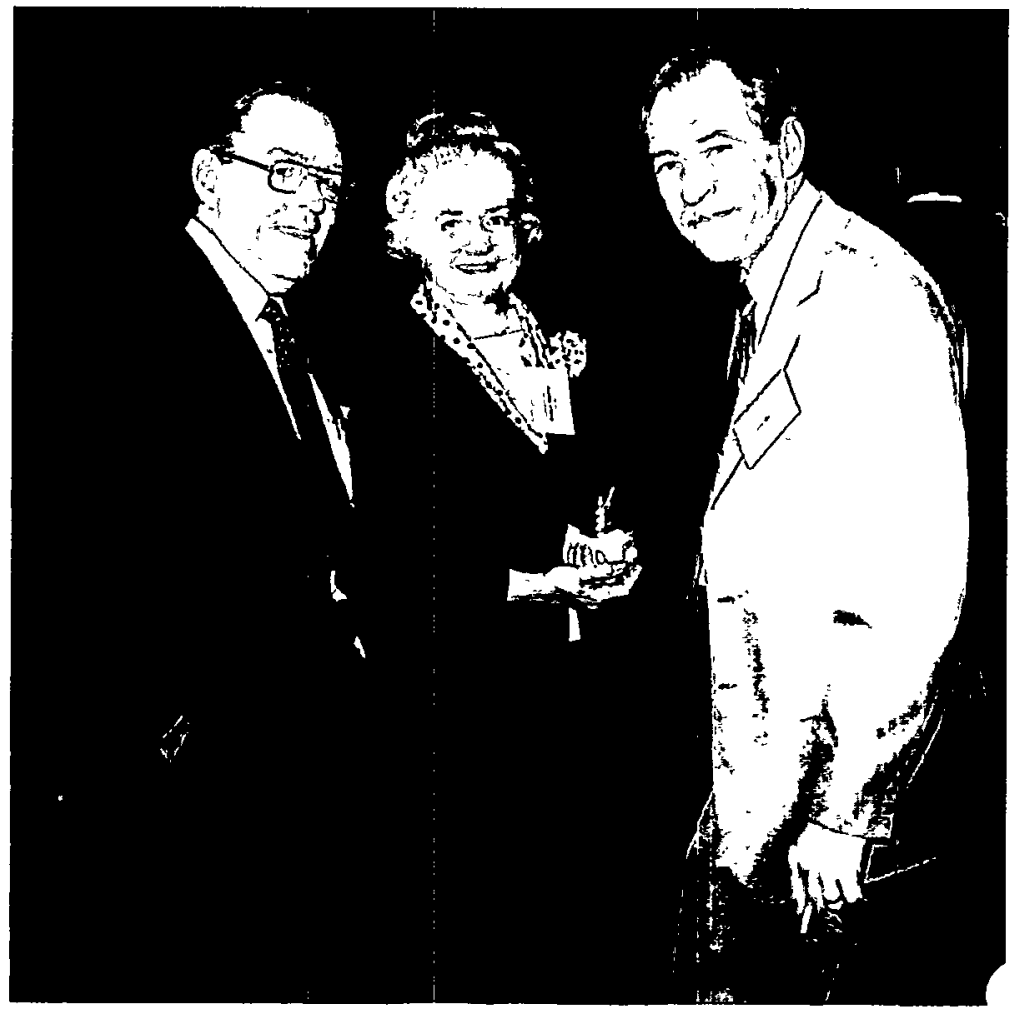

Bill Harms, Grace Harms, and Jim Weir. 


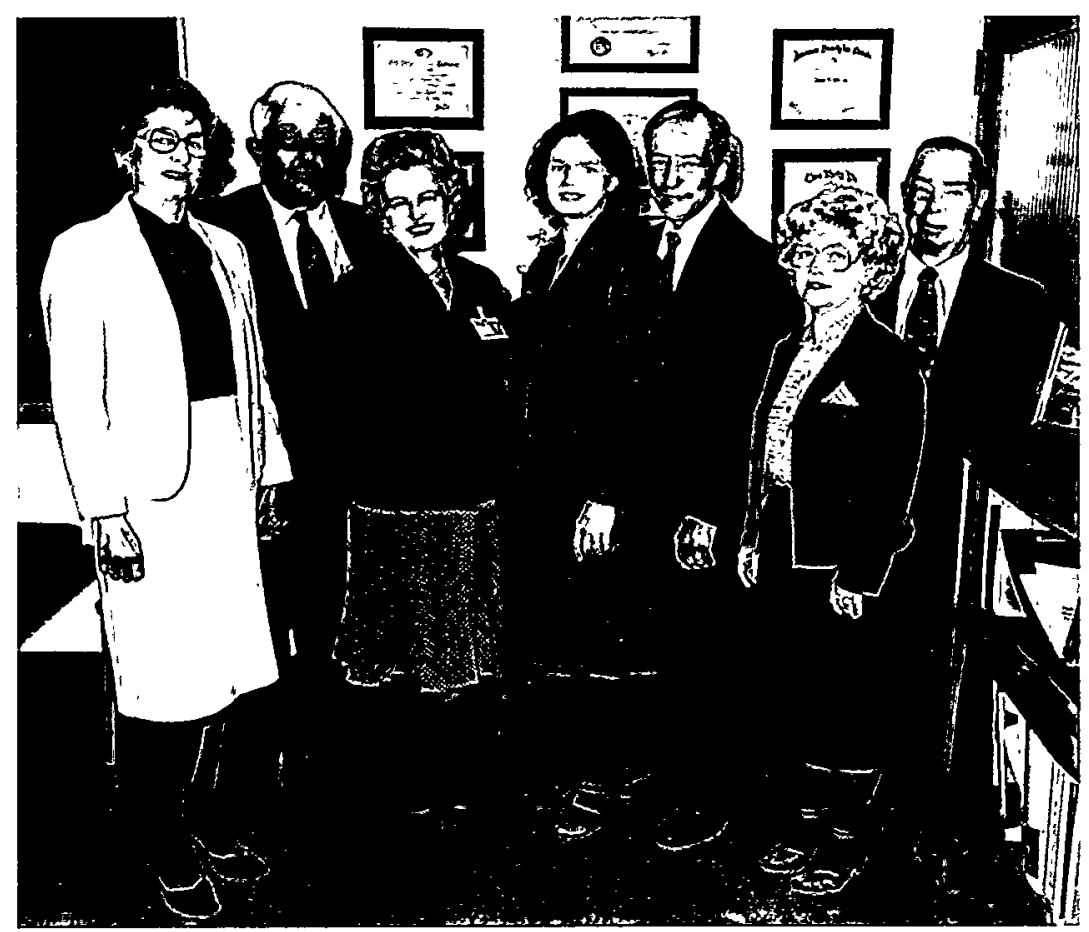

Freda Cox, Bill Manly, Meredith Hill, Wilma Mason, Jim Weir, Lou Pyatt, George Adamson.

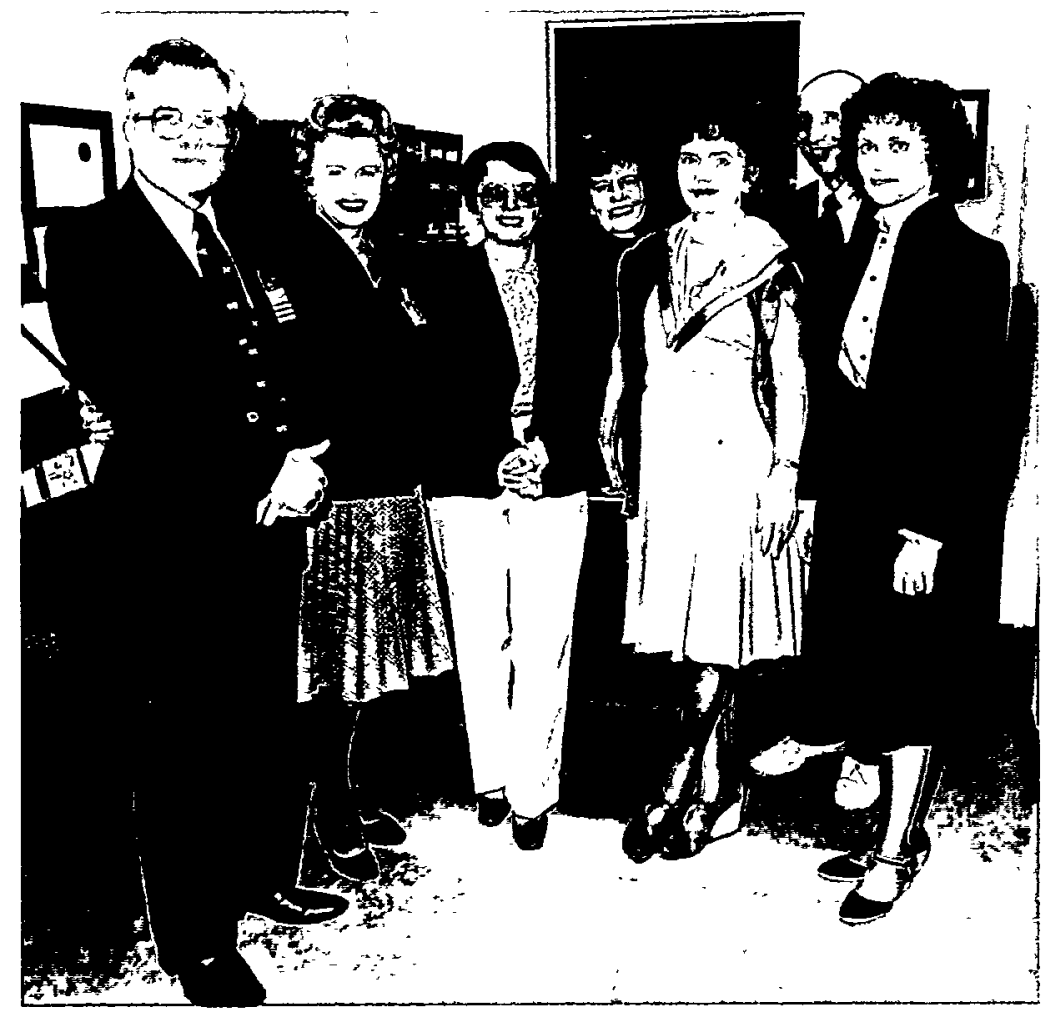

Bill Martin, Meredith Hill, Pat Row, Ted Reedy, Frances Scarbroro, Don Douglas, and Sharon Buhl. 


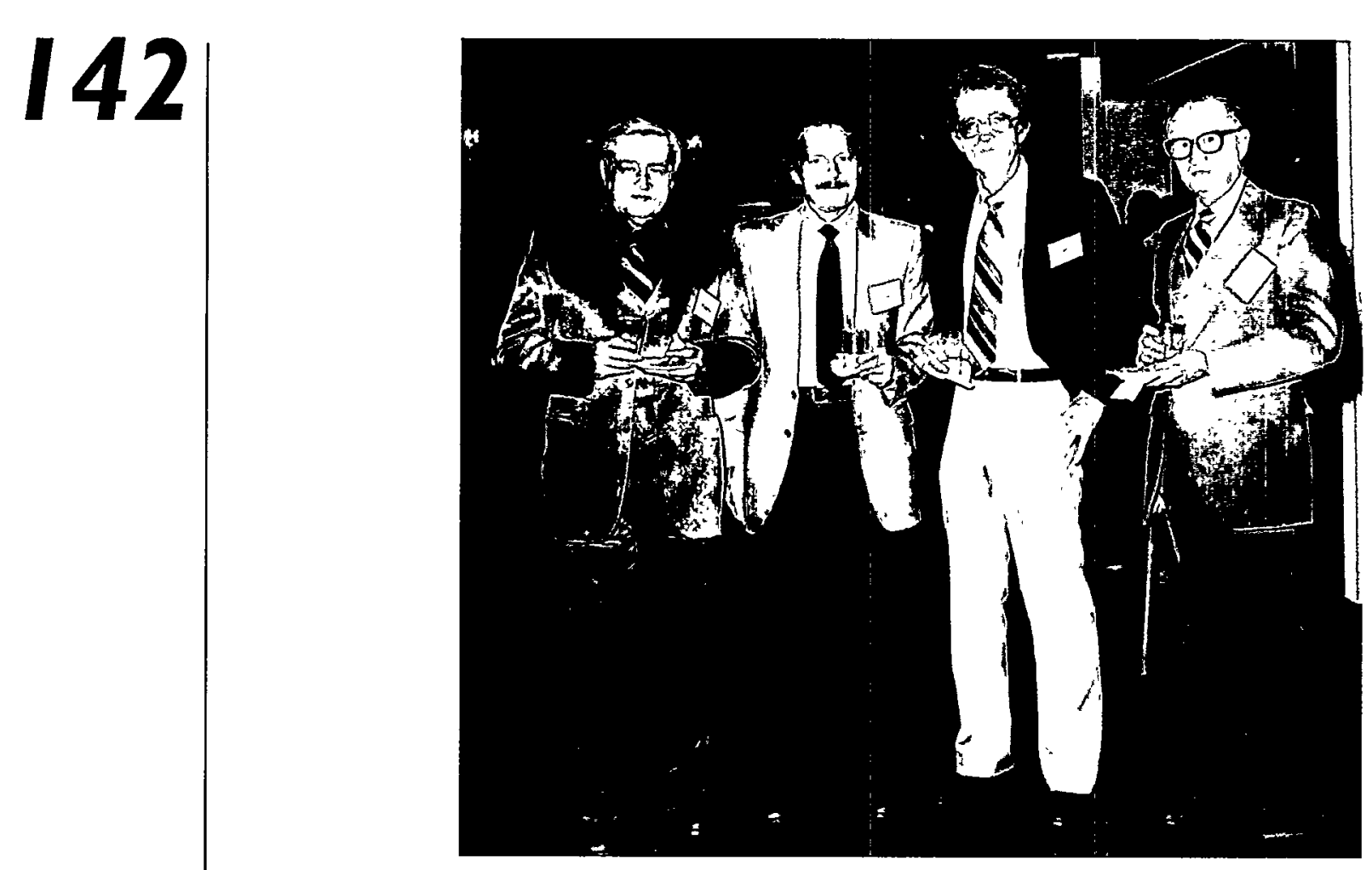

Pete Houck, Bill Leslie, Leonard Williams, and Bob Crouse.

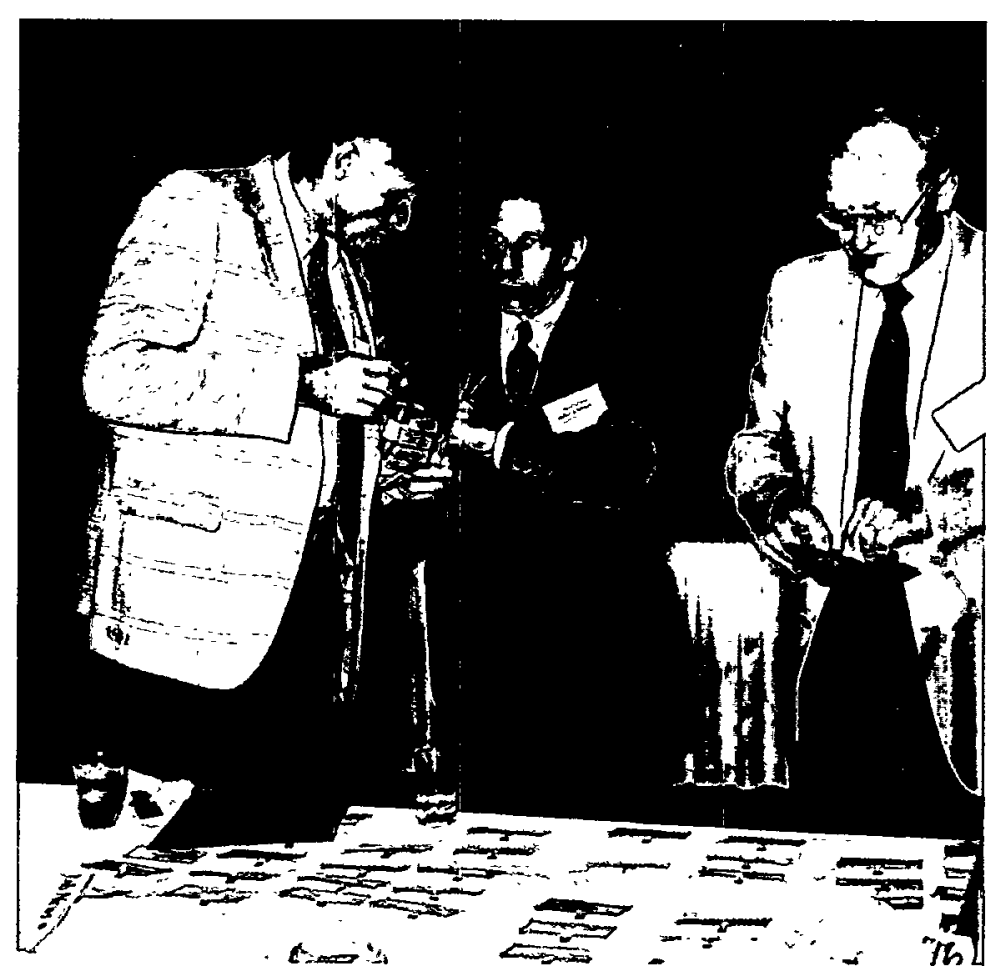

Roger Waugh, Al Goldman, and Dick Heestand 


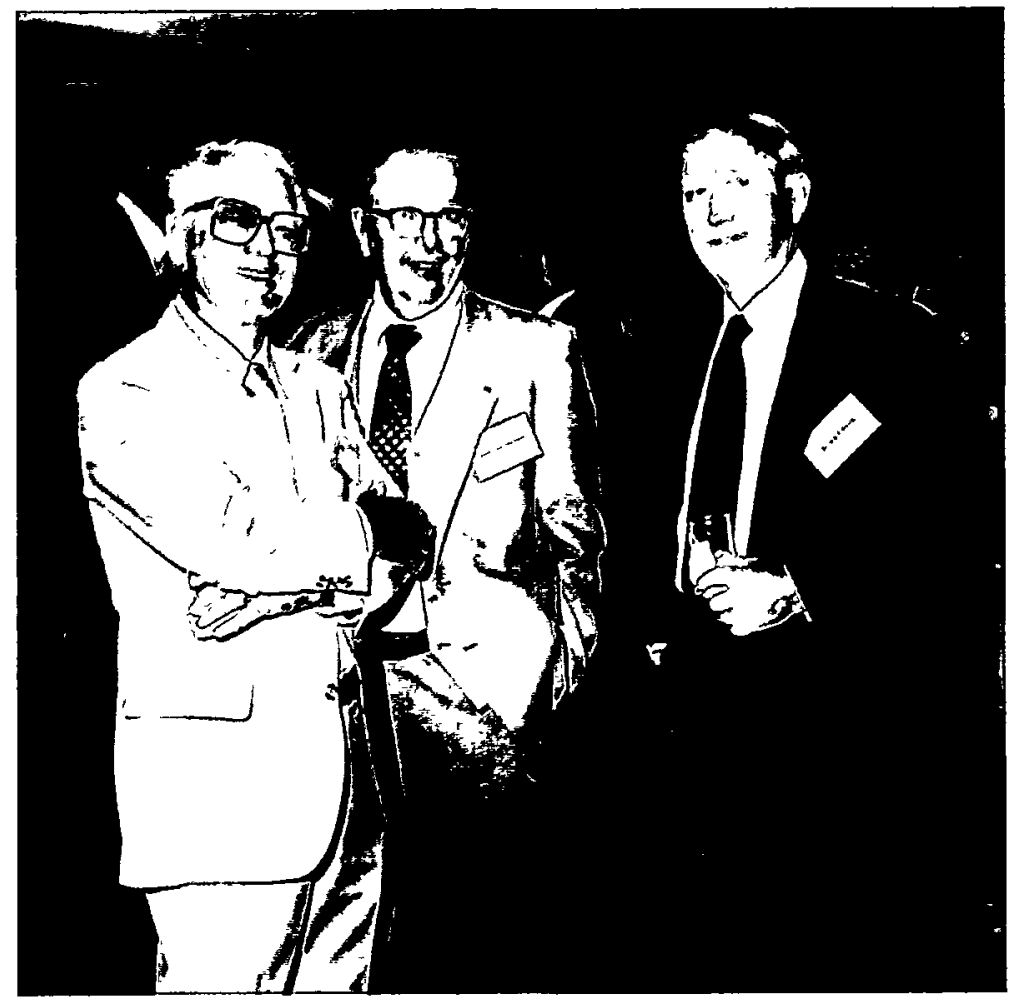

Dick Beaver, Jack Cunningham, and Durwood Hamby

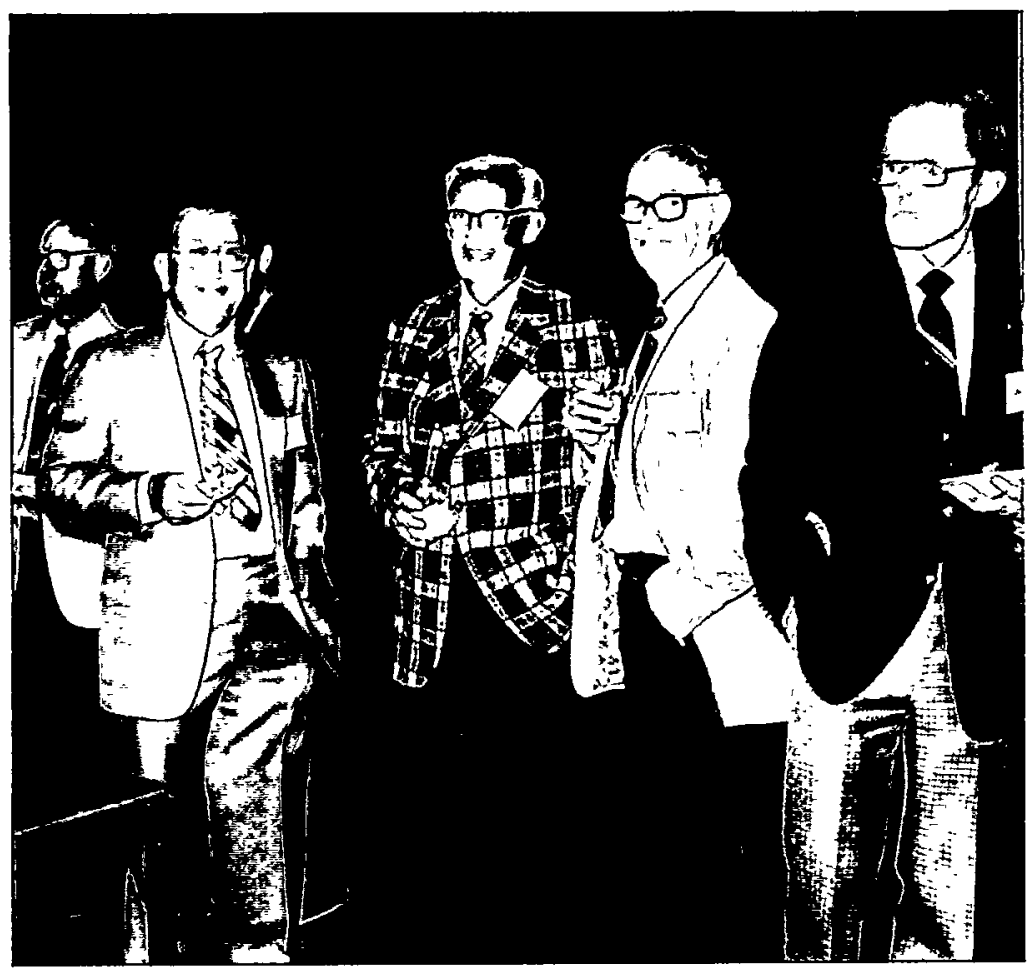

Gerry Slaughter, Bob Gray, Ed Boyle, sloan Bomar, and Bud Dubose 


\section{division's picnic (1988)}

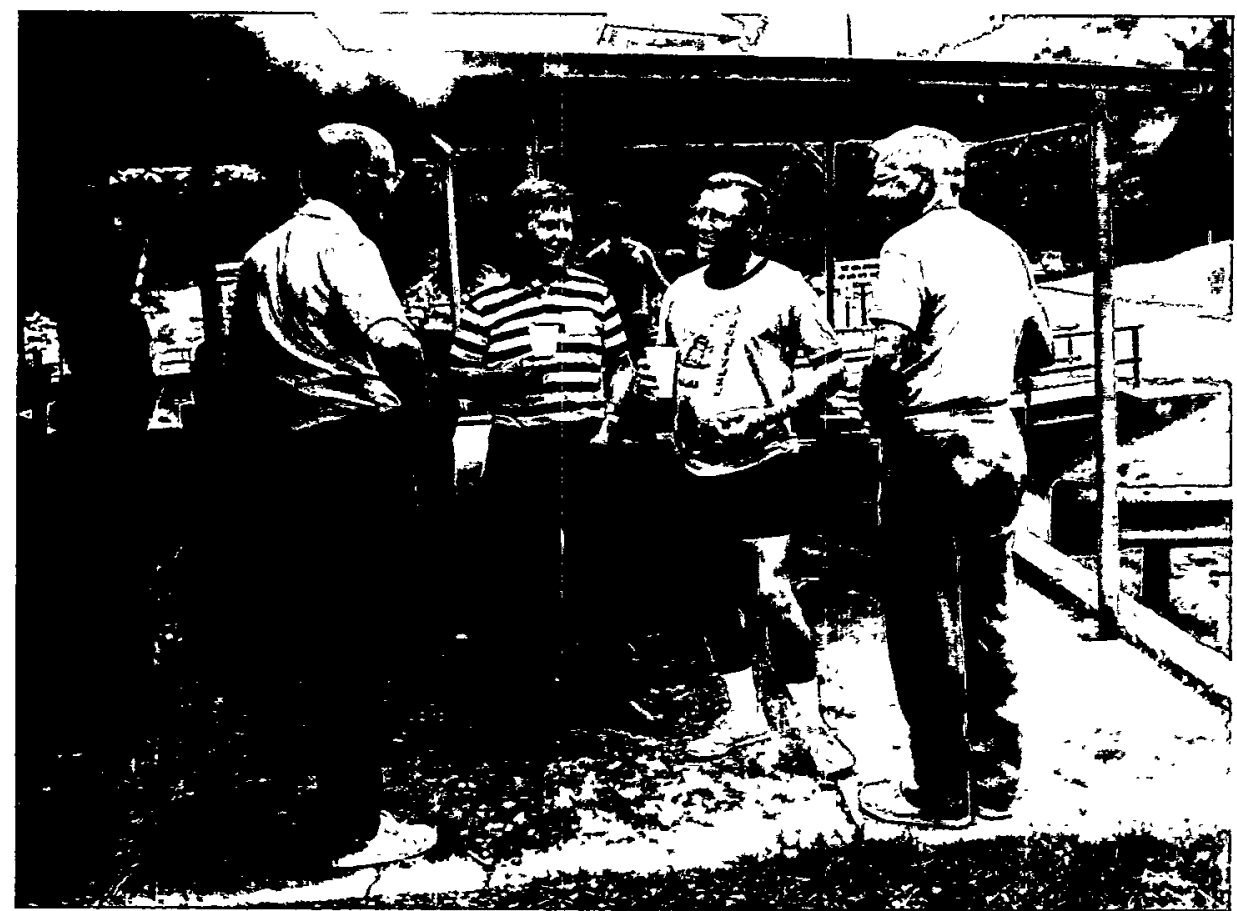

Greg Kern, Tony Schaffhauser, Everett Bloom, and Jim Stiegler

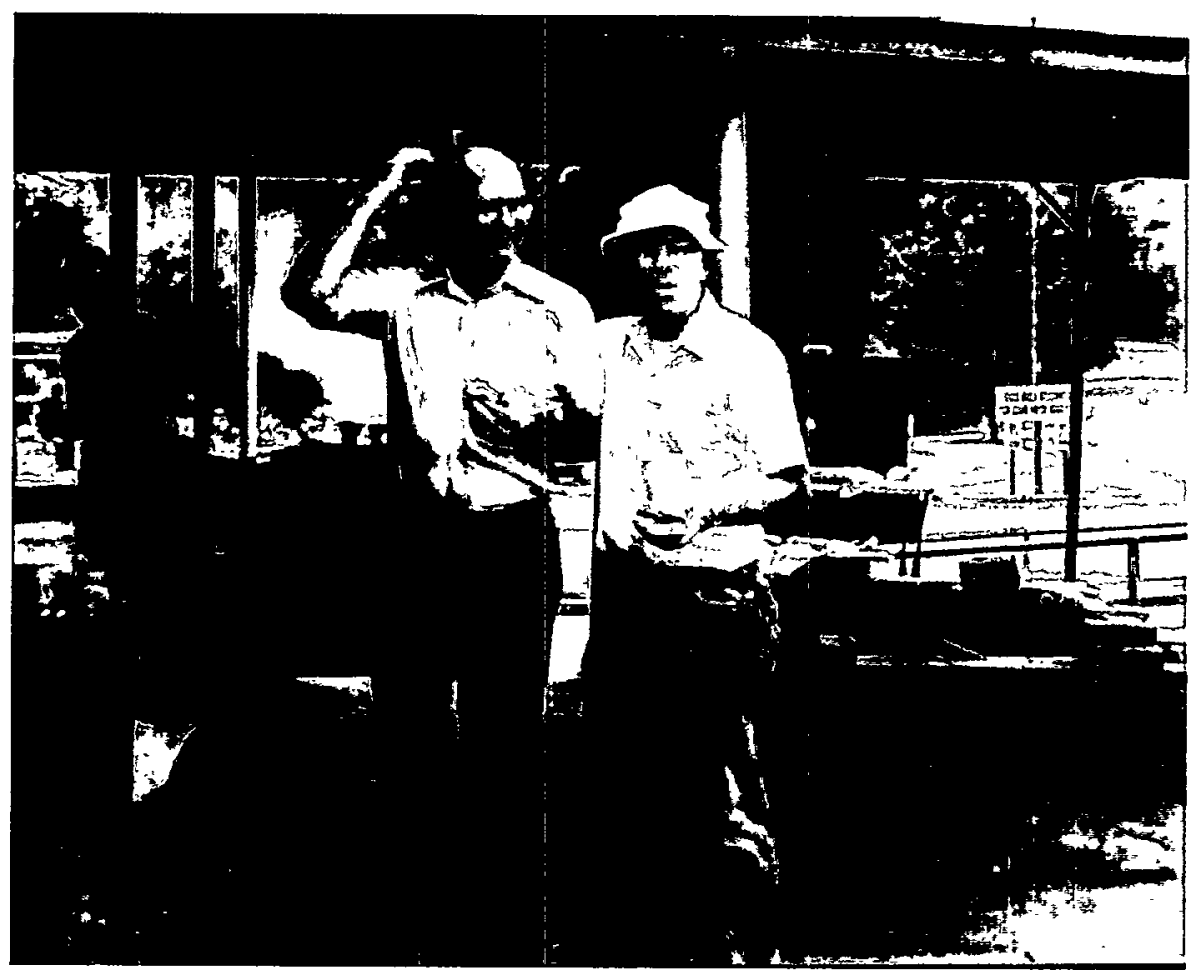

Greg Kern and Bill Miller 


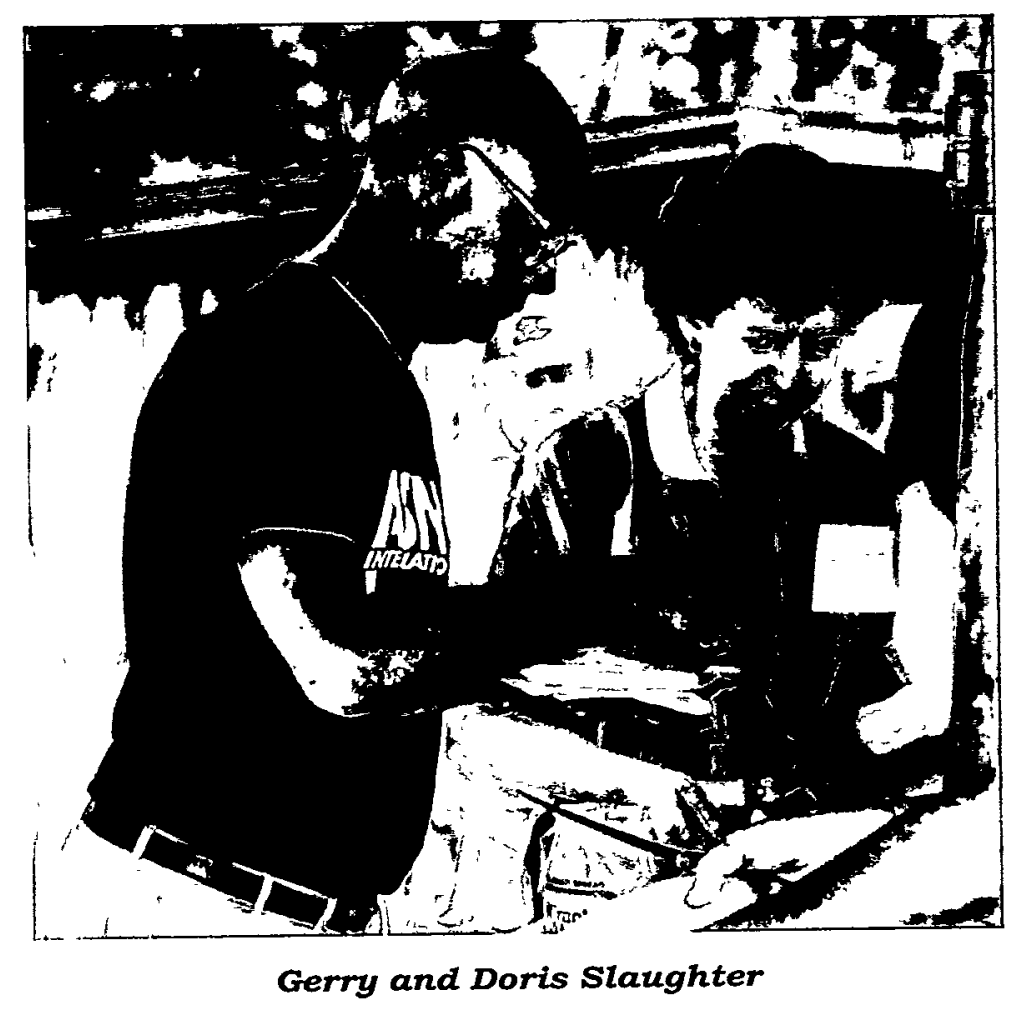

145

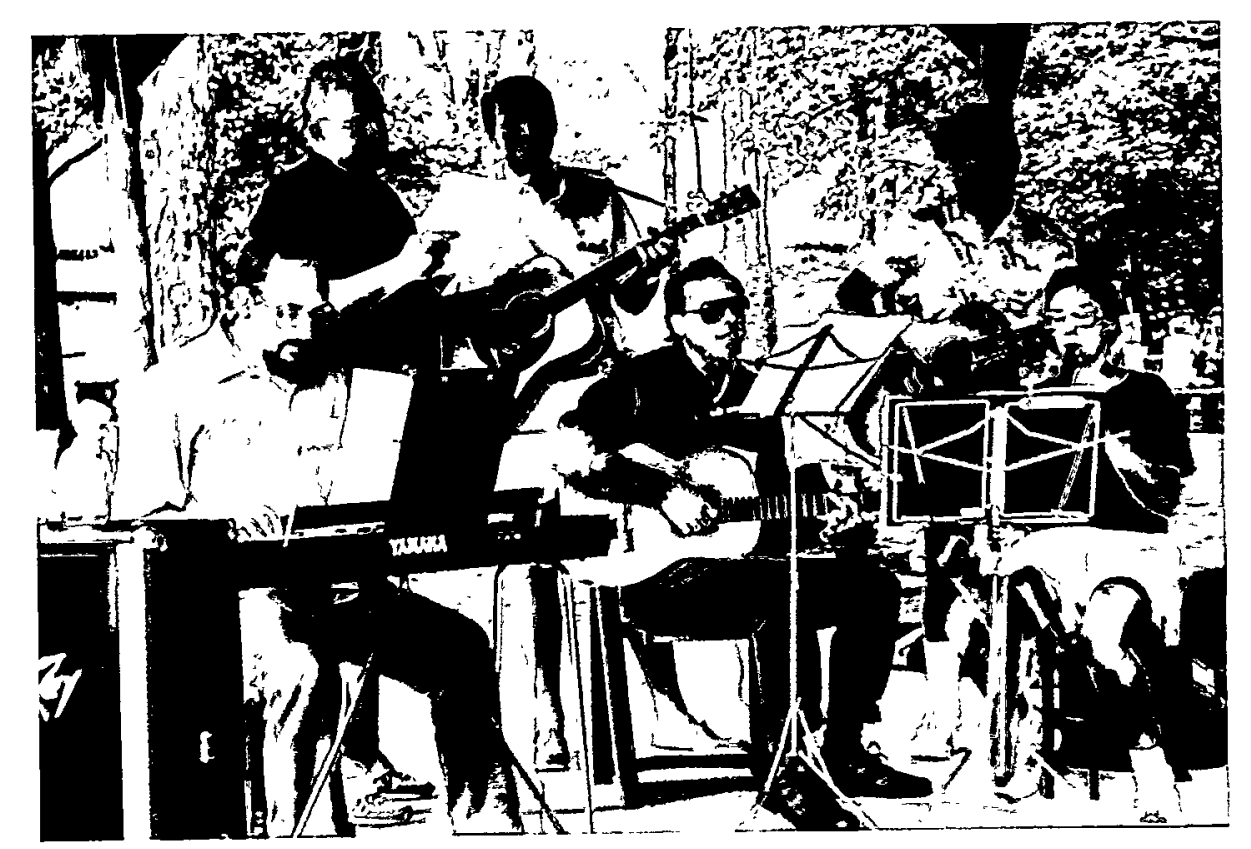

Standing: Orville Kimball, Charlie Devore, Terry Tiegs Seated: Peter Blau, Pete Angelini, and Laura Riester 


\section{6}

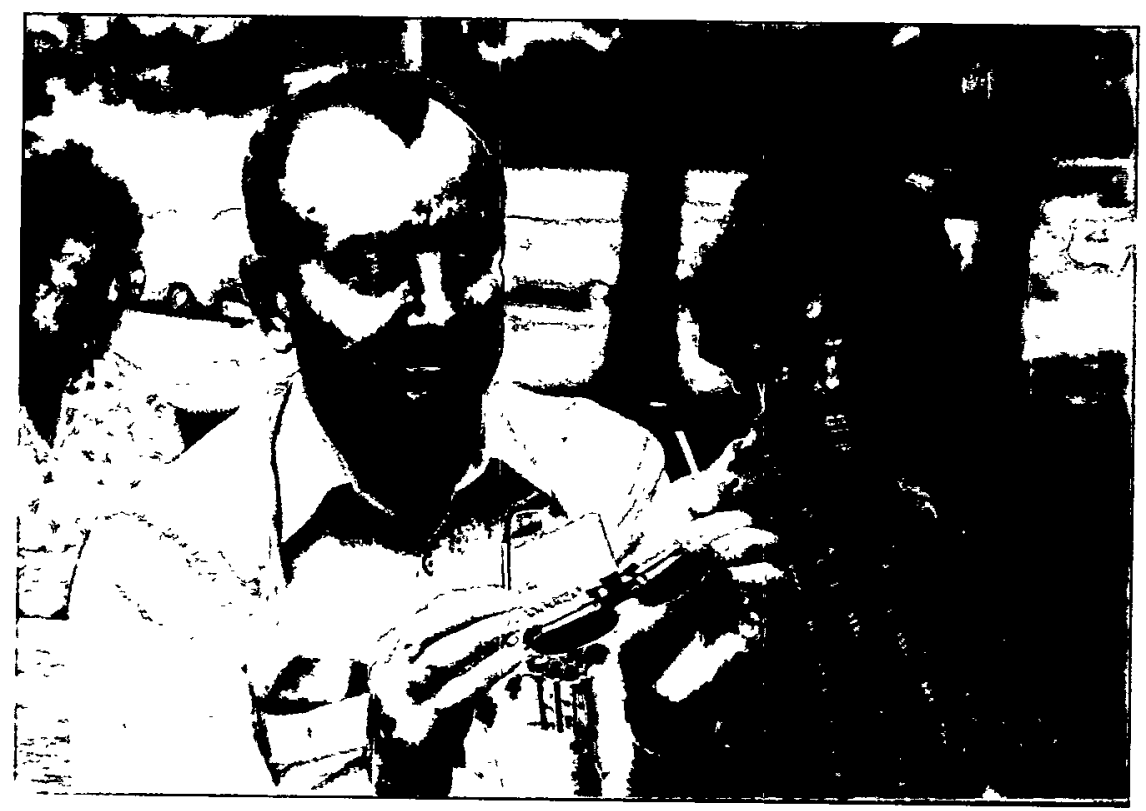

Vic and Joyce Tennery

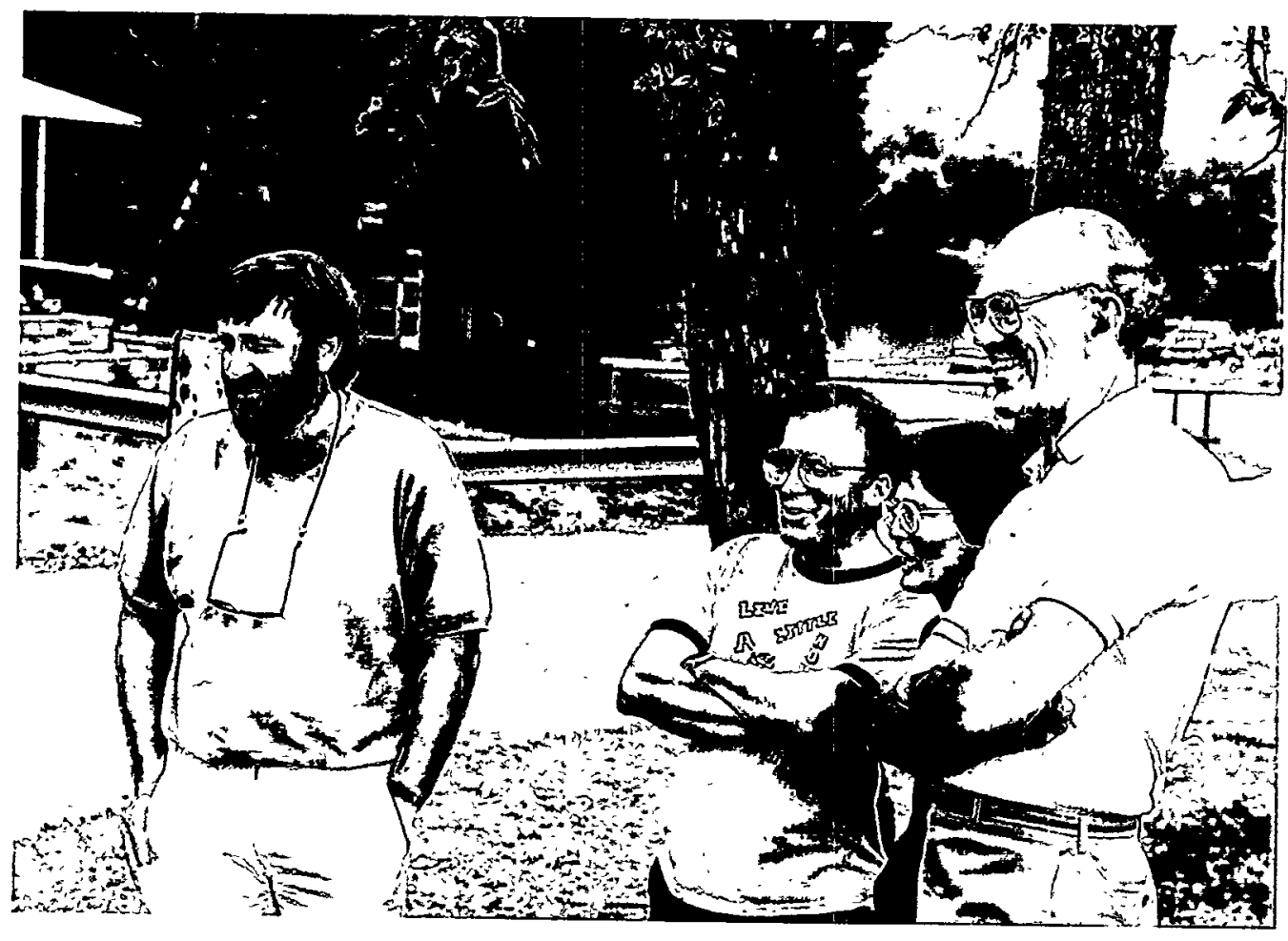

Malcolm Stocks, Everette Bloom, Claudette McKamey, and Cullie Sparks 


\section{christmas party skit}

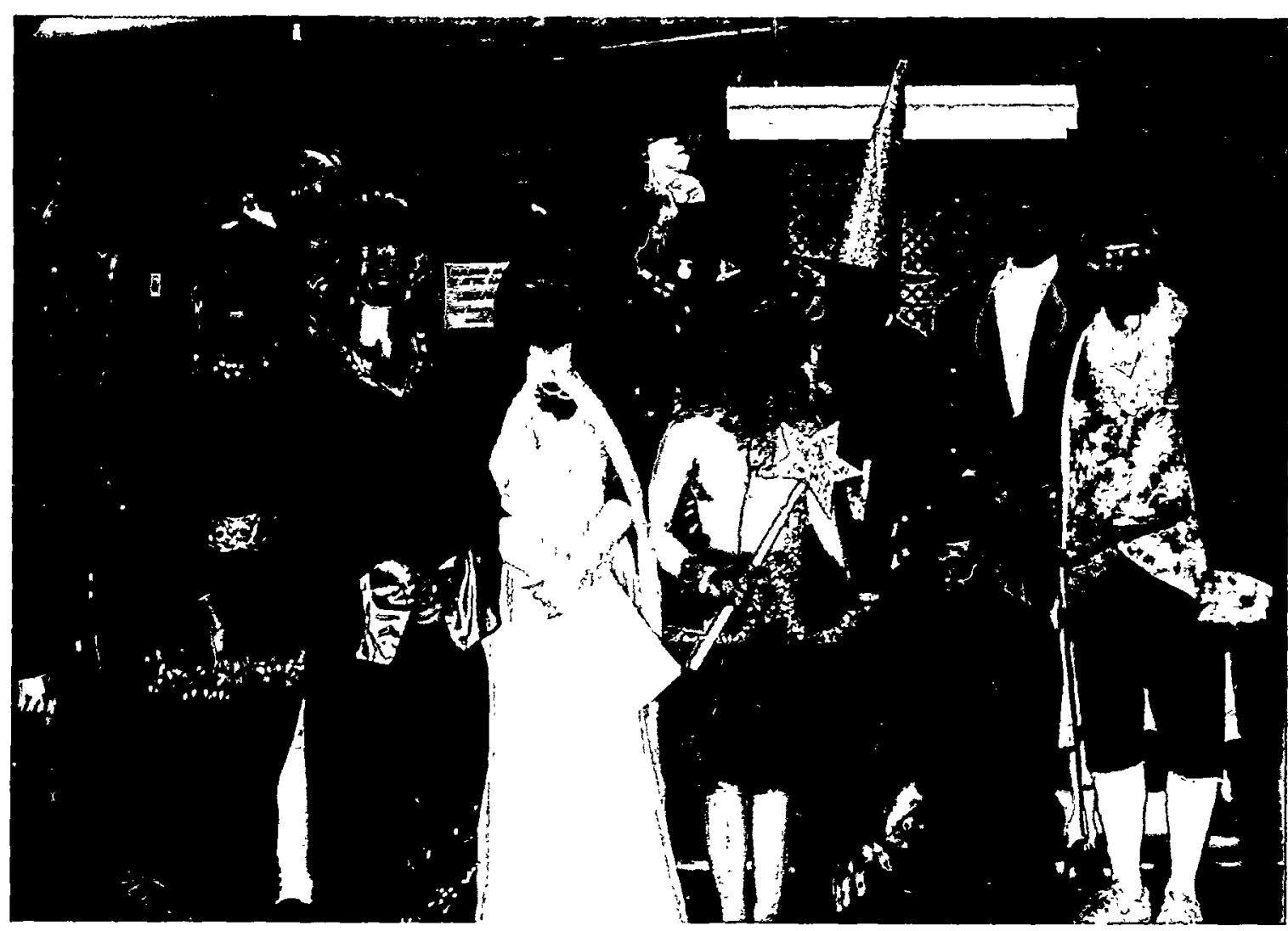

For two years the Division staff members wrote and produced a skit presented during the annual Christmas celebration. This skit "The Princedom and the Christmas Fairy" was presented in 1990 and was written by David 0 . Hobson. The cast left to right: Shirley Frykman (program manager), Holly Parkinson (page), David 0. Hobson (the Grinch), April McMillan (program manager), Mary Ann Collins (princess), Phil Rittenhouse (narrator), Cathy Cheverton (fairy), Jim Weir (Merlin), Bob

Swindeman (section head), Ron Swain (section head), and Jim Stiegler (the prince). 


\section{christmas party skit (1991)}

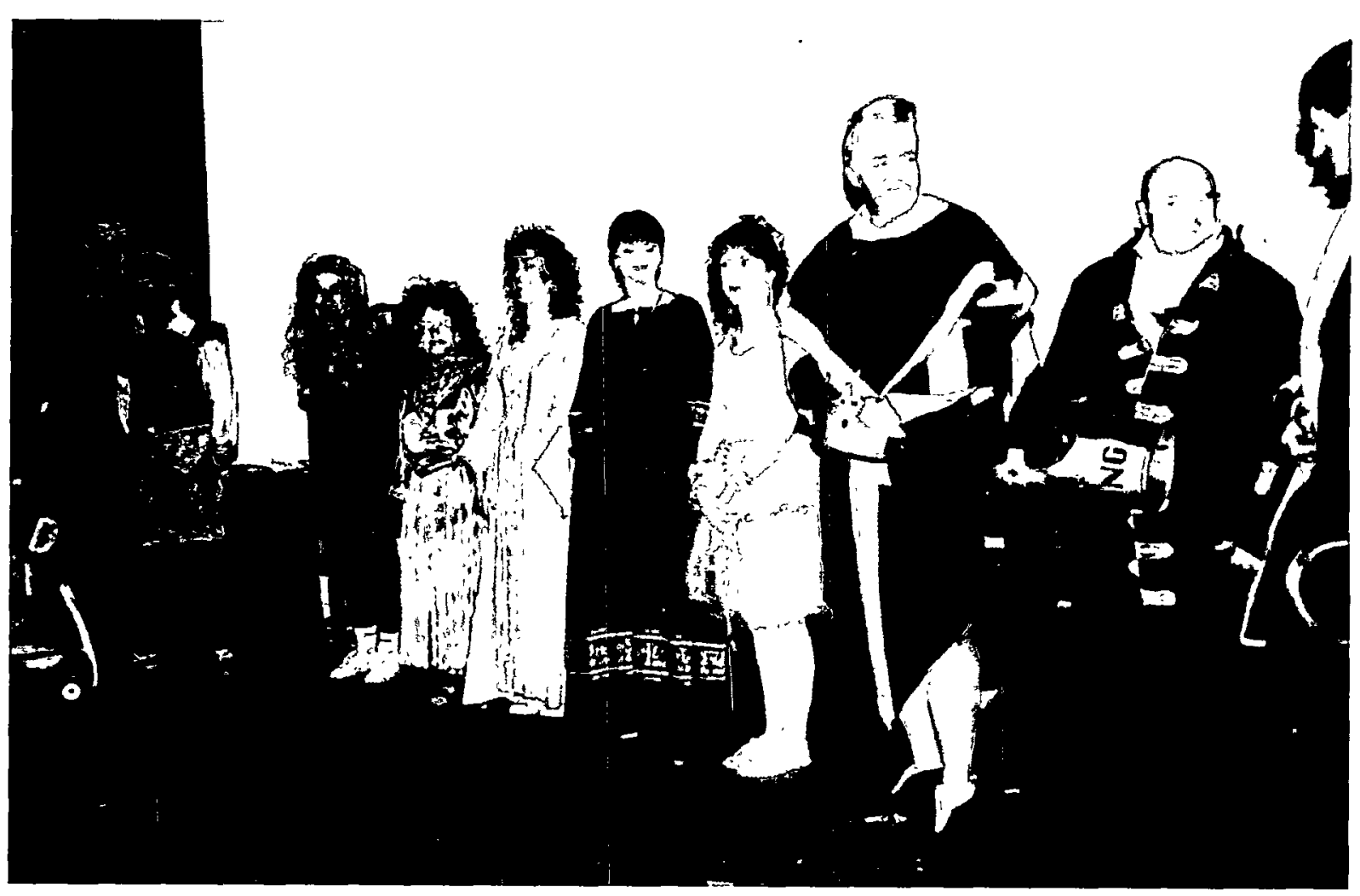

The second skit, aslo written by Dave Hobson, was presented in 1991. The cast left to right, Jim Weir (Merlin), Tim Burchell (Loyal subject 1), Cheryl Lee (xmas spirit past), Lou Pyatt (loyal subject 3), Holly Parkinson (loyal subject 2), April McMillan (xmas spirit present), Cathy Cheverton (xmas spirit future), Doug Craig (assistant king 2), Harry Livesey (king), and Ron Swain (assistant king 1). 